DIW BERLIN

Discussion

Papers

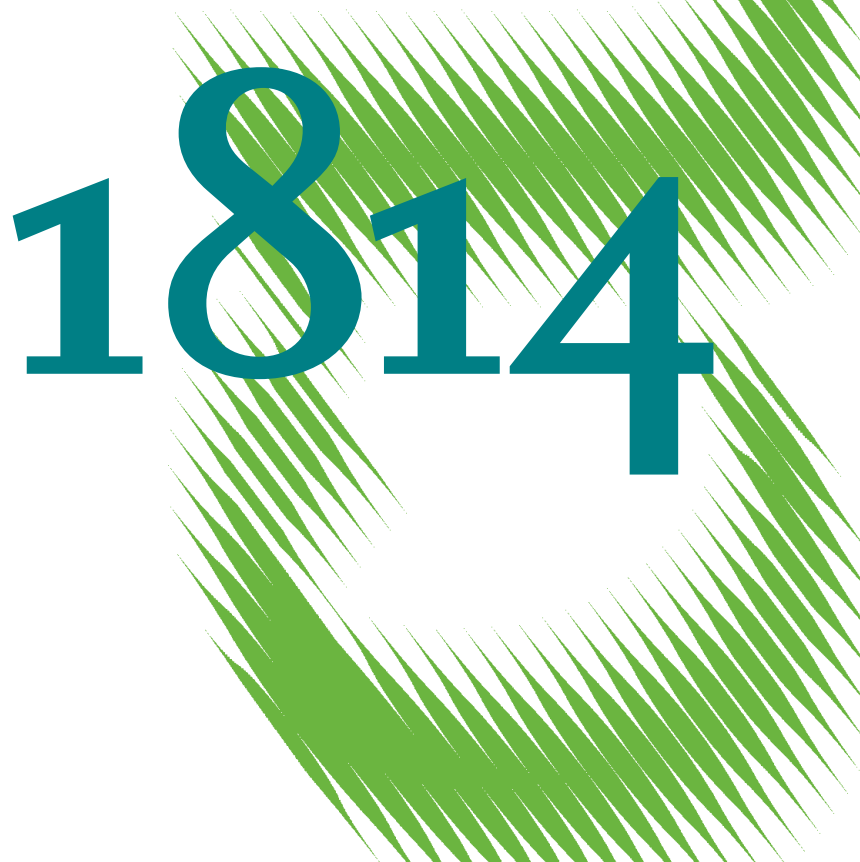

Macroprudential Regulation and Leakage to the Shadow Banking Sector 
Opinions expressed in this paper are those of the author(s) and do not necessarily reflect views of the institute.

IMPRESSUM

(C) DIW Berlin, 2019

DIW Berlin

German Institute for Economic Research

Mohrenstr. 58

10117 Berlin

Tel. +49 (30) $89789-0$

Fax +49 (30) $89789-200$

http://www.diw.de

ISSN electronic edition 1619-4535

Papers can be downloaded free of charge from the DIW Berlin website:

http://www.diw.de/discussionpapers

Discussion Papers of DIW Berlin are indexed in RePEc and SSRN:

http://ideas.repec.org/s/diw/diwwpp.html

http://www.ssrn.com/link/DIW-Berlin-German-Inst-Econ-Res.html 


\title{
Macroprudential Regulation and Leakage to the Shadow Banking Sector
}

\author{
Stefan Gebauer, Falk Mazelis ${ }^{\dagger}$
}

July 23, 2019

\begin{abstract}
Macroprudential policies for financial institutions have received increasing prominence since the global financial crisis. These policies are often aimed at the commercial banking sector, while a host of other non-bank financial institutions, or shadow banks, may not fall under their jurisdiction. We study the effects of tightening commercial bank regulation on the shadow banking sector. For this purpose, we develop a DSGE model that differentiates between regulated, monopolistically competitive commercial banks and a shadow banking system that relies on funding in a perfectly competitive market for investments. After estimating the model using euro area data from 1999 2014 including information on shadow banks, we find that tighter capital requirements on commercial banks increase shadow bank lending, which may have adverse financial stability effects. Coordinating the macroprudential tightening with monetary easing can limit this leakage mechanism, while still bringing about the desired reduction in aggregate lending. We discuss how regulators that either do or do not consider credit leakage to shadow banks set policy in response to macroeconomic shocks. Lastly, in a counterfactual analysis, we then compare how a macroprudential policy implemented before the crisis on all financial institutions, or just on commercial banks, would have dampened the leverage cycle.
\end{abstract}

JEL: E58, F45, G23, G28

Keywords: Macroprudential Regulation, Monetary Policy, Shadow Banking, Non-Bank Financial Institutions, Financial Frictions

${ }^{*}$ DIW Berlin, Freie Universität Berlin. E-mail address: sgebauer@diw.de.

${ }^{\dagger}$ European Central Bank. E-mail address: falk.mazelis@ecb.int.

The views in this paper are those of the authors and do not necessarily reflect the views of the European Central Bank or DIW Berlin.

We thank Mathias Trabandt, Marius Clemens, Marcel Fratzscher, Wouter den Haan, Peter Karadi and participants at the Third Research Conference of the CEPR Network on Macroeconomic Modelling and Model Comparison (MMCN), Frankfurt am Main, the 2019 ASSA Annual Meeting, Atlanta, the 24th Annual Conference on Computing in Economics and Finance (CEF), Milan, the 2018 Verein für Socialpolitik Annual Conference, Freiburg and the FU Berlin Empirical Macroeconomics Seminar for useful comments. 


\section{Introduction}

The global financial crisis of 2007/2008 triggered a substantial debate about the adequate design of financial regulation. As of today, a broad consensus has been reached among scholars and policy makers that sound financial market regulation requires a particular focus on macro developments in financial markets, in addition to supervising single financial institutions separately. ${ }^{1}$ Such a macroprudential approach towards financial regulation should focus on systemic developments in financial markets like swings in aggregate credit or financial market volatility, as well as on the role of financial cycles for business cycle movements. ${ }^{2}$

Regulatory authorities are currently undergoing a dramatic shift with respect to macroprudential supervision. In most advanced economies, new institutions responsible for macroprudential oversight and the design of adequate policy tools to counteract systemic financial risks have been installed. ${ }^{3}$ Furthermore, macroprudential policies depict core elements of recently implemented policy frameworks. For instance, the rules on banking regulation laid down in the latest round of Basel accords on banking regulation (Basel $I I I)$ strongly focus on supervisory and regulatory tools targeting macro developments in credit and risk-taking, such as rules on interbank lending, cyclical adjustments of capital requirements, and supervision on bank interconnectedness.

In this study, we discuss the implications of considering non-bank financial intermediaries, or shadow banks, in the conduct of macroprudential regulation of the commercial banking sector. Shadow banks, in our view, depict a set of diverse institutions conducting highly specialized tasks in the financial system. However, on an aggregate level, the shadow banking sector intermediates funds from savers to borrowers in a similar fashion to the traditional banking system. Given the diverse nature of financial firms involved in shadow bank credit intermediation, their regulation falls into the court of various regulatory authorities. This makes consistent and comprehensive regulation more difficult to attain. Since shadow banks might take up some of the lending that banks have been prohibited from extending due to macroprudential policies ${ }^{4}$, understanding the interaction between commercial bank regulation and non-bank financial institutions is crucial for the assessment of macroprudential policy.

\footnotetext{
${ }^{1}$ See Borio (2003), Kroszner (2010), or Allen and Gale (2000) for a review of the pre-crisis microprudential approach of guaranteeing financial stability by supervising single institutions alone.

${ }^{2}$ See Borio and Shim (2007), or Borio $(2009,2011)$ for a detailed description of the macroprudential approach.

${ }^{3}$ The European Systemic Risk Board (ESRB), the US Financial Stability Oversight Council (FSOC), and the Bank of England's Financial Policy Committee, as well as the internationally active Financial Stability Board (FSB) are prominent examples of newly-implemented institutions.

${ }^{4}$ See Cizel et al. (2016)
} 
We derive a dynamic stochastic general equilibrium (DSGE) model with savers and borrowers, and two types of financial institutions intermediating funds between these two groups: traditional banks and shadow banks. Both types of intermediaries are based on distinct microeconomic foundations that allow for structural differences with respect to regulatory coverage and market structure in the two sectors. Technically, we derive a heterogeneous financial system by combining elements of two canonical frameworks for modeling financial frictions in DSGE models: our commercial banking sector is based on the work by Gerali et al. (2010), whereas our shadow banking sector is modeled similar to the financial sector in Gertler and Karadi (2011). We then apply Bayesian techniques and rely on economic and financial data for the euro area to estimate our model. Finally, we discuss how the presence of intermediation via shadow banks can affect the setting of macroprudential policy, which is not directly enforceable on all financial intermediaries. The explicit policy tool we consider in this study are capital requirements, which, under Basel III, depict a key macroprudential tool regulators can apply to the commercial banking system to prevent banks from engaging in excessive leverage and risk-taking. A countercyclical requirement can be raised to avoid excessive credit growth in boom times, and lowered whenever credit developments are subdued. In a subsequent policy exercise we assess the ability of a coordinated monetary policy response in combinaton with the macroprudential policy to limit the leakage mechanism while still bringing about the desired reduction in aggregate lending.

Evidence on the effectiveness of macroprudential regulation in general, as well as on the relative advantage of different policy tools is still relatively scarce. In particular, the role of heterogeneity in the financial sector for both the design of effective macroprudential policies and for the interaction of respective tools with other policy areas has not yet been sufficiently evaluated. However, heterogeneity in financial intermediares' behavior, in combination with a varying degree of regulatory coverage of different financial market corporations, might have far-reaching implications for an adequate design of policy frameworks. We test whether macroprudential rules applied to commercial banks can stabilize credit cycles, which may ultimately increase welfare.

In the following section, we review the literature on both the current state of financial market-augmented macroeconomic models and on studies evaluating macropudential regulation and coordination with other policy areas. We then introduce the full-fledged DSGE model in Section 3. ${ }^{5}$ Sections 4 and 5 introduce the data we use and discuss the econometric procedure we employ to derive estimates of key parameters of the model. In Section 6 , we use our model to simulate the effects of neglecting shadow bank intermediation in

\footnotetext{
${ }^{5}$ We highlight the key mechanism entailing credit leakage towards shadow banks in the wake of tighter commercial banking regulation in a simplified two-period version of the model available in the separate Online Appendix.
} 
macroprudential policy, before we conclude in Section 7 .

\section{Literature}

In response to accusations of having neglected the role of financial markets for economic stability prior to the global financial crisis, the literature on DSGE models including financial intermediaries and frictions has expanded and developed in the past several years. The approach developed in Gertler and Karadi (2011) and Gertler and Kiyotaki (2011) depicts one of the earliest frameworks for incorporating financial intermediaries in otherwise standard dynamic stochastic general equilibrium (DSGE) models. In the former study, the authors implement a financial intermediary transfering funds between households and non-financial firms in a monetary DSGE framework as developed in Christiano et al. (2005) and Smets and Wouters (2007). They incorporate financial frictions modeled as an agency problem arising between banks and households by allowing banks to divert household funds away from investment projects for private benefit. Given that households are aware of potential misconduct, the ability of banks to obtain funding via deposits is limited. Ultimately, the study shows that shocks to capital quality can turn out to be more pronounced in terms of output decline when such frictions in financial intermediation are included in the model, providing scope for unconventional credit market interventions by central banks. In Gertler and Kiyotaki (2011), the framework is augmented by allowing for liquidity risk as also described in Kiyotaki and Moore (2012). However, in contrast to Gertler and Karadi (2011), the model does not incorporate nominal rigidities as the authors are particularly interested in credit market frictions and the role of credit policies instead of monetary policy effects.

Another strand of macro models incorporating frictions in the intermediation of funds between borrowers and lenders focuses on the role of collateral borrowers have to place with lenders in return for funding. Iacoviello and Guerrieri (2017) and Iacoviello (2005) introduce housing as collateral and relate the amount of borrowing undertaking by impatient households to movements in the value of collateral. According to an additionally introduced collateral constraint borrowers face, adverse developments in housing markets as well as changes in exogenously determined loan-to-value ratios can limit the amount of lending and affect consumption and investment in the economy. Extending the approach, Gerali et al. (2010) introduce a banking sector in a canonical New Keynesian model for the euro area and locate the collateral friction between borrowers and banks. By modeling the banking sector explicitly, they are able to incorporate specific characteristics of the euro area banking sector, such as market power and sluggish adjustment of bank interest rates in response to changes in the monetary policy rate. Estimating the model with Bayesian techniques, they find that commercial banks can on the one hand stabilize business cycles 
by shielding households and firms from shocks originating outside the financial sector. On the other hand, shocks to financial intermediaries can adversely affect business cycles whenever disruptions in bank balance sheets are transmitted to the real economy.

Several other approaches for incorporating financial frictions in macro models have been proposed. Relying on early contributions by Holström and Tirole (1997), some studies incorporate agency problems on both sides of the credit intermediation market ${ }^{6}$. In these frameworks, a moral hazard problem arises on the demand side of credit (between the banks and entrepreneurs) as entrepreneurs can divert funds received by banks away from investment activities to derive private benefits due to the costs of monitoring the bank faces. In addition, another agency problem arising on the supply side of funds (between banks and depositors) constrains households from detecting whether financial intermediaries are effectively monitoring investment activities of firms. By now, bankingaugmented infinite horizon models are frequently employed in the evaluation of different aspects of financial stability, such as the mechanics of bank runs ${ }^{7}$ or the effectiveness of (un-)conventional fiscal and monetary policies in times of financial distress ${ }^{8}$.

Turning to the role of financial intermediaries for macroprudential regulation, Angelini et al. (2014) implement collateral constraints and a macroprudential policy maker adjusting capital requirements according to a simple rule in addition to the central bank in an estimated euro area New Keynesian model. They find that macroprudential policy is particularly effective in times of financial distress, i.e. when shocks affecting credit supply hit the economy, compared to "normal times" where aggregate supply shocks appear to be more relevant. By employing a modeling framework based on the Holström and Tirole (1997) intermediation setup with rule-based policy makers in place, Christensen et al. (2011) find that strongly countercyclical regulatory policy can have beneficial stabilization properties relative to time-invariant regulation when the economy faces shocks originating in the banking sector.

Some studies evaluate the optimal degree of coordination between macroprudential policy makers and monetary policy. Angeloni and Faia (2013) use a bank-augmented DSGE model to evaluate rule-based monetary policies and capital regulation. Within a class of simple policy rules, the best combination includes countercyclical capital ratios and a response of monetary policy to asset prices or bank leverage. Gelain and Ilbas (2014) estimate a version of the Smets and Wouters (2007) New Keynesian DSGE model augmented by a Gertler and Karadi (2011) financial intermediary framework for US data. In addition to an inflation-targeting central bank, they introduce a macroprudential regulator adjusting a tax/subsidy on bank capital according to a simple policy rule aiming at

\footnotetext{
${ }^{6}$ See Chen (2001), Meh and Moran (2010), Christensen et al. (2011), or Silvo (2015).

${ }^{7}$ See for instance Gertler and Kiyotaki (2015); Gertler et al. (2016).

${ }^{8}$ See for instance Gertler and Karadi (2011) or Cúrdia and Woodford (2010a,b, 2011).
} 
stabilizing both nominal credit growth and the output gap. They find that a higher weight placed on output gap stabilization (the joint policy objective of both policy makers) by the macroprudential regulator is beneficial for reducing macroeconomic volatility. However, increasing the focus on credit growth stabilization relative to output increases the benefits of a non-cooperative setup for the macroprudential regulator, whereas the central bank performs worse in the absence of coordination. In a similar approach, Bean et al. (2010) rely on a model incorporating a Gertler and Karadi (2011) banking setup to study policy rules based on quadratic loss functions, with the physical capital gap being the financial stability objective. They find that a combination of monetary and macroprudential policies appears to be more effective as a means of leaning against the wind than relying on traditional monetary policy alone.

Beau et al. (2012) define four different policy regimes depending on whether financial stability depicts an explicit objective of monetary policy, and whether a separate macroprudential regulator is in place. By employing an estimated Euro Area DSGE model, they find that, over the business cycle, conflicts among both policy makers should be limited. In particular, shocks to housing preferences and credit, the most important sources of instability for macroprudential policy, only marginally account for inflation dynamics in their model.

In Aikman et al. (2018), optimal coordination between monetary and macroprudential policy is evaluated in a calibrated New Keynesian DSGE model that allows for credit booms by employing an ad-hoc loss function augmented by a financial stability criterion that reflects the monetary policy objective of reducing the probability of a financial crisis. The authors find that the introduction of countercyclical capital regulation is particularly welfare-improving when monetary policy is the only tool employed. In one of the case studies, they furthermore discuss the role of credit intermediation by market-based financial institutions that do not represent traditional banks for optimal coordination. They introduce scope for credit leakage in response to changes in regulation and conduct a similar analysis to the one in this study. However, they do not derive the credit leakage mechanism based on microfoundations of the financial system, and instead introduce the leakage mechanism in a stylized way and calibrate the leakage elasticity to empirical estimates for the United Kingdom.

All of the above studies rely on ad-hoc specified macroprudential policy rules in their models. However, first attempts have been initiated to assess the optimal degree of policy coordination by deriving jointly optimal Ramsey policies instead of implementing rulebased policies alone. Collard et al. (2014) focus on different types of lending instead of volumes alone and study jointly Ramsey-optimal monetary and macroprudential policies in a New Keynesian banking model. In the famework, limited liability and deposit insurance cause excessive risk-taking in the financial sector. Silvo (2015) uses a New Keynesian 
framework augmented by Holström and Tirole (1997) to evaluate Ramsey-optimal policies. In line with Angelini et al. (2014), she finds that macroprudential policies play a modest stabilizing role in response to aggregate supply shocks, but are highly effective when the financial sector is the source of fluctuations.

In all of the macro models described so far, the financial sector is modeled as one single representative agent. Only recently, focus has shifted towards allowing for heterogeneity among financial intermediaries in infinite horizon models. In a recent study, Gertler et al. (2016) augment the canonical Gertler and Karadi (2011) framework by replacing the representative intermediary by a bipolar banking system consisting of wholesale as well as retail banks. In their model, wholesale banks representing the shadow banking part of the financial system exclusively engage in interbank borrowing to fund loans, whereas retail banks follow a more traditional business model by collecting household deposits to lend to both the wholesale and the non-financial sector ${ }^{9}$. By abstracting from the production side of the economy, the authors use the three-sector model to study both anticipated and unanticipated bank runs on the wholesale sector. Meeks and Nelson (2017) use a calibrated model to show how the interaction between shadow banks and commercial banks through markets for securitized assets can affect dynamics in credit and that securitization in combination with high leverage in the shadow banking sector can have adverse effects on macroeconomic stability. As in our study, Verona et al. (2013) develop a model where shadow banks directly engage in intermediation of funds between households and firms. In contrast to our model, they assume shadow banks act under monopolistic competition to derive a positive spread between the lending rate of shadow banks and the risk-free rate $^{10}$. They show that incorporating shadow banks increases the magnitude of boombust dynamics in response to an extended period of loose monetary policy. Mazelis (2016) develops a model including traditional banks, shadow banks, and investment funds and studies the relevance of different types of credit for macroeconomic volatility. He concludes that a more equity based financial system can mitigate the credit crunch during recessions when the economy is stuck at the zero lower bound of nominal interest rates (ZLB).

Similar to our study, Begenau and Landvoigt (2016) and Fève and Pierrard (2017) employ macroeconomic models to evaluate how the existence of shadow banks can alter the effectiveness of capital requirements as proposed by the Basel frameworks. In the former study, a general equilibrium model calibrated to the US economy and featuring both shadow and commercial banks is used to show that tightening regulation for commercial

\footnotetext{
${ }^{9}$ The notion of a wholesale banking sector has already been introduced in Gertler and Kiyotaki (2015). Furthermore, Gertler and Kiyotaki (2011) already discuss interbank borrowing. However, no distinct separation between wholesale and retail banks has been undertaken in these studies.

${ }^{10}$ In our model, the positive spread emerges from the relatively higher default risk the saver faces when placing funds with shadow banks compared to low-risk commercial bank deposits.
} 
banks can result in a shift of intermediation away from safer commercial banks towards unregulated and more fragile shadow banking institutions, such that the net benefit of raising capital requirements for commercial banks only depends on the initial level of fragility in the financial system. Fève and Pierrard (2017) estimate a real business cycle model featuring both commercial and shadow banks with US data and, like Begenau and Landvoigt (2016), identify a leaking of intermediation towards shadow banks and conclude that the intended overall stabilizing effect of higher capital requirements for commercial banks can be dampened when more funds are channeled via the shadow banking sector. ${ }^{11}$

\section{A Sketch of the DSGE Model}

In this section, we introduce shadow banking in a full-fledged DSGE model in the spirit of the euro area banking model developed by Gerali et al. (2010) and Gambacorta and Signoretti (2014). ${ }^{12}$ We furthermore provide a detailed description of the implication of introducing shadow banks for the effectiveness of commercial bank regulation in a stylized two-period model presented in the Online Appendix of this study. In the full-fledged DSGE model, patient households serve as savers and provide funds to impatient entrepreneurs that act as borrowers, represented by different values for the discount factor used in the utility functions of both agents. Households cannot directly provide funds to borrowing firms, but have to place deposits in financial intermediaries which then provide loans to firms which use the funds for production. ${ }^{13}$ Households can allocate savings between two types of intermediaries: shadow banks and commercial banks. Commercial banks face regulatory capital requirements, whereas shadow banks are not obliged by regulation to back a minimum of assets with equity. As in Gerali et al. (2010), commercial banks exert market power when setting interest rates on loans and deposits and adjust these rates incompletely in response to policy changes.

In contrast to commercial banks, shadow banks act under perfect competition. They are neither subject to macroprudential regulation, nor do they have recourse to government support schemes such as deposit insurance and central bank liquidity facilities. Consequently, saving in shadow banks is more risky from the household perspective. Default risk

\footnotetext{
${ }^{11}$ Alternative microfoundations for the leakage of credit towards shadow bank institutions in response to rising capital requirements were derived in the theoretical banking literature. See for instance Ordonez (2018), Farhi and Tirole (2017), Plantin (2015), or Harris et al. (2014).

${ }^{12}$ The complete nonlinear DSGE model is presented in Appendix A.

${ }^{13}$ As in Gambacorta and Signoretti (2014), we assume that all debt contracts are indexed to current inflation. In this respect, we deviate from the framework in Gerali et al. (2010) and Iacoviello (2005) by eliminating the nominal debt channel from the model. This channel potentially affects the redistribution of funds between borrowers and savers and thus macroeconomic developments in response to unexpected changes in the price level, which we do not consider here.
} 
can thus result in a positive spread between the rates households demand from shadow banks compared to commercial banks. To capture the dependence of shadow banks on market funding, we draw on the incentive constraint in Gertler and Karadi (2011). We assume that the lack of regulation is akin to the risk that shadow bankers can divert a share of funds, defaulting on the remaining liabilities in the process. Whenever the benefits from doing so exceed the returns from behaving honestly, shadow bankers face an incentive to disappear from the market and leave investors with losses on their investments. Households are aware of this risk and will limit their funding to an amount that motivates the shadow banker of continuing operations rather than diverting a share and defaulting on the rest.

The implicit default risk the household faces when placing funds in shadow banks thus results in a spread between shadow bank and commercial bank deposit rates, as households demand higher compensation when placing funds in these institutions.

On the loan market, regulation only applies with respect to commercial banks, as entrepreneurs have to fulfil an externally set loan-to-value ratio when demanding funds from commercial banks. Consequently, entrepreneurs can only borrow up to a certain amount of their collateral value at hand, which is given by the stock of physical capital that they own and use for production purposes. However, they can use their remaining collateral for borrowing from shadow banks. ${ }^{14}$

Households provide labor to entrepreneurs and either consume or save in financial intermediaries. Entrepreneurs produce intermediate goods and sell them on a competitive market to retailers, who differentiate, repackage and sell them on in a monopolistically competitive market, resulting in a final goods price that includes a mark-up on the marginal cost. Furthermore, capital goods producers are introduced to derive a market price for capital. The central bank conducts monetary policy by setting the nominal short-term rate according to a Taylor rule ${ }^{15}$.

In the baseline model, macroprudential regulation is determined exogenously, before we introduce a macroprudential regulator that follows a countercyclical policy rule for capital requirements in section 6 . In this respect, our baseline model used in the estimation procedure of section 5 reflects the regulatory framework in the euro area in place before the introduction of Basel III. Under the preceding Basel II regulations, countercyclical adjustments of capital requirements for commercial banks were not set systematically.

\footnotetext{
${ }^{14}$ Details on the microfoundation of the entrepreneur's credit constraints and the superiority of commercial bank credit are provided in the Online Appendix.

${ }^{15}$ In this model, we abstract from any unconventional monetary policy and assume that the economy is not at the zero lower bound (ZLB) of nominal interest rates.
} 


\subsection{Households}

The representative patient household $i$ maximizes the expected utility

$$
\max _{c_{t}^{P}(i), l_{t}^{P}(i), d_{t}^{P, C}(i)} E_{0} \sum_{t=0}^{\infty} \beta_{P}^{t}\left[\left(1-a^{P}\right) \varepsilon_{t}^{z} \log \left(c_{t}^{P}(i)-a^{P} c_{t-1}^{P}\right)-\frac{l_{t}^{P}(i)^{1+\phi^{P}}}{1+\phi^{P}}\right]
$$

subject to the budget constraint

$$
c_{t}^{P}(i)+d_{t}^{P, C}(i)+d_{t}^{P, S}(i) \leq w_{t} l_{t}^{P}(i)+\left(1+r_{t-1}^{d C}\right) d_{t-1}^{P, C}(i)+\left(1+r_{t-1}^{d S}\right) d_{t-1}^{P, S}(i)+t_{t}^{P}(i)
$$

where $c_{t}^{P}(i)$ depicts current consumption and lagged aggregate consumption is given by $c_{t-1}^{P}$. Working hours are given by $l_{t}^{P}$ and labor disutility is determined by $\phi^{P}$. Preferences are subject to a disturbance $\varepsilon_{t}^{z}$ affecting consumption. The flow of expenses includes current consumption and real deposits to be made to both commercial and shadow banks, $d_{t}^{P, C}(i)$ and $d_{t}^{P, S}(i)$. Resources consist of wage earnings $w_{t}^{P} l_{t}^{P}(i)$ (where $w_{t}$ is the real wage rate for the labor input of each household), gross interest income on last period deposits $\left(1+r_{t-1}^{d C}\right) d_{t-1}^{P, C}(i)$ and $\left(1+r_{t-1}^{d S}\right) d_{t-1}^{P, S}(i)$, and lump-sum transfers $t_{t}^{P}$ that include dividends from firms and banks (of which patient households are the ultimate owners).

\subsection{Entrepreneurs}

Entrepreneurs use labor provided by households as well as capital to produce intermediate goods that retailers purchase in a competitive market. Each entrepreneur $i$ derives utility from consumption $c_{t}^{E}(i)$, which it compares to the lagged aggregate consumption level of all entrepreneurs. He maximizes expected utility

$$
\max _{c_{t}^{E}(i), l_{t}^{P}(i), b_{t}^{E, C}(i)} E_{0} \sum_{t=0}^{\infty} \beta_{E}^{t} \log \left(c_{t}^{E}(i)-a^{E} c_{t-1}^{E}\right)
$$

subject to the budget constraint

$$
\begin{aligned}
c_{t}^{E}(i)+w_{t} t_{t}^{P}(i)+\left(1+r_{t-1}^{b c}\right) b_{t-1}^{E, C}(i) & +\left(1+r_{t-1}^{b s}\right) b_{t-1}^{E, S}(i)+q_{t}^{k} k_{t}^{E}(i) \\
& =\frac{y_{t}^{E}(i)}{x_{t}}+b_{t}^{E, C}(i)+b_{t}^{E, S}(i)+q_{t}^{k}(1-\delta) k_{t-1}^{E}(i)
\end{aligned}
$$

with $\delta$ depicting the depreciation rate of capital, $q_{t}^{k}$ the market price for capital in terms of consumption, and $x_{t}$ determining the price markup in the retail sector.

Entrepreneurs face a constraint on the amount they can borrow from commercial banks which depends on the value of collateral the firm holds. The collateral value of the entrepreneurs is determined by their expected physical capital stock in the period of 
repayment $(t+1)$, which is given by $E_{t}\left[(1-\delta) k_{t}^{E} \Pi_{t+1}\right] .{ }^{16}$ Whereas a regulatory loan-tovalue (LTV) ratio $m_{t}^{C}$ applies for funds borrowed from commercial banks, shadow bank funding is not prone to regulation. As outlined in detail in the Online Appendix, due to a positive spread between interest rates charged for shadow bank and commercial bank loans, entrepreneurs have an incentive to borrow from commercial banks first and turn to shadow bank lending only whenever the possible amount of commercial bank funds, determined by $m_{t}^{C} k_{t}^{E}(i)$, is reached. Further borrowing can be obtained from shadow banks by using capital holdings not reserved for commercial bank funds, $\left(1-m_{t}^{C}\right) k_{t}^{E}(i)$. Thus, the two respective borrowing constraints are given by

$$
\begin{gathered}
\left(1+r_{t}^{b c}\right) b_{t}^{E, C}(i) \leq m_{t}^{C} E_{t}\left[q_{t+1}^{k}(1-\delta) k_{t}^{E}(i)\right] \\
\left(1+r_{t}^{b s}\right) b_{t}^{E, S}(i) \leq\left(1-m_{t}^{C}\right) E_{t}\left[q_{t+1}^{k}(1-\delta) k_{t}^{E}(i)\right]
\end{gathered}
$$

where the LTV ratio for commercial banks $m_{t}^{C}$ set exogenously by the regulator and follows an exogenous $\mathrm{AR}(1)$ process.

We follow Iacoviello (2005) and assume that the borrowing constraints bind around the steady state such that uncertainty is absent in the model. ${ }^{17}$ Thus, in equilibrium, entrepreneurs face binding borrowing constraints, such that equations 5 and 6 both hold with equality.

\subsection{Banks}

In our model, we have two financial market agents that intermediate funds between households and firms: commercial banks and shadow banks. While they both engage in intermediation in a similar fashion, we assume the two types of agents to be structurally different along various dimensions.

First, we assume that commercial banks are covered by banking regulation, which implies that they have to fulfill requirements on the amount of capital they have to hold compared to the size of their balance sheet. Second, they are eligible for central bank liquidity assistance and government guarantees such as deposit insurance schemes. ${ }^{18}$ Thus,

\footnotetext{
${ }^{16}$ In Iacoviello (2005), entrepreneurs use commercial real estate as collateral. However, we follow Gerali et al. (2010) by assuming that creditworthiness of a firm is judged by its overall balance sheet condition where real estate housing only depicts a sub-component of assets.

${ }^{17}$ Iacoviello (2005) discusses the deviation from the certainty equivalence case in the Appendix $\mathrm{C}$ of his paper.

${ }^{18}$ Even though not explicitly modeled, the assumption of an existing insurance scheme lies behind the idea of shadow bank deposits being more risky than deposits placed with commercial banks.
} 
for households and firms, commercial banks depict safe deposit institutions, given that they are both covered by regulation and have access to government support schemes. We furthermore assume market power in the loan and deposit markets for commercial banks, ${ }^{19}$ and model it using the same Dixit-Stiglitz framework as employed in Gerali et al. (2010). Thus, in both loan and deposit markets, commercial banks are able to charge some markup on loan rates and pay deposit rates conditional on a markdown. In line with Gerali et al. (2010), we model commercial banks by distinctively separating a single bank into three units: two retail branches responsible for retail lending and retail deposits, respectively, and one wholesale branch that manages the bank capital position. While the two retail branches operate under monopolistic competition, we assume lending and deposit taking between retail and wholesale units to operate perfectly competitively.

Shadow banks, in contrast, face no regulatory burden but in turn are not covered by structural support schemes. Consequently, the shadow banking sector increasingly depends on creditor trust, which is captured by a moral hazard problem that governs the degree of leverage of shadow bank institutions. Furthermore, whereas commercial banks' charter values as well as their funding opportunities via central banks basically insulate them from immediate default in case of illiquidity, shadow banks are exposed to funding pressures that can lead to instantaneous exit from participation in the market. On the other hand, reduced regulatory burdens in the establishment of shadow banking operations supports regular inflow to this market. As a consequence, while we assume commercial banks to be infinitely lived in our model, we allow for frequent entry to and exit from the shadow banking system.

\subsubsection{Commercial Banks}

In the following, we discuss the maximization problem of the wholesale unit of the commercial bank as the capital requirement set by regulators applies directly to this branch of the commercial bank. ${ }^{20}$ Due to space limitations, we will not discuss the maximization problems of the retail deposit and loan branches here as they are identical to the problems outlined in Gerali et al. (2010) and we refer to their study.

Wholesale Unit The wholesale branches of commercial banks operate under perfect competition and are responsible for the capital position of the respective commercial bank. On the asset side, they hold funds they provide to the retail loan branch, $b_{t}^{C}$, and these

\footnotetext{
${ }^{19}$ The existence of market power in the euro area was indicated in various empirical studies, see for instance Fungáčová et al. (2014) or De Bandt and Davis (2000).

${ }^{20}$ Thus, the modeling of the wholesale unit closely resembles the commercial bank outlined in section 1.3.1. in the Online Appendix.
} 
retailers ultimately lend the funds to entrepreneurs as credit $b_{t}^{E, C}$. As retailers act under monopolistic competition, the retail rate $r_{t}^{b c}$ comprises a markup over the wholesale loan rate $r_{t}^{C}$. On the liability side, the wholesale unit combines commercial bank net worth, or capital, $k_{t}^{C}$, with wholesale deposits, $d_{t}^{C}$, that are provided by the retail deposit branch, but originally stem from deposits placed in the retail branch by patient households $\left(d_{t}^{P, C}\right)$. Furthermore, the capital position of the wholesale branch is prone to a regulatory capital requirement, $\nu_{t}^{C}$. Moving away from the regulatory requirement imposes a quadratic cost to the bank, which is proportional to the outstanding amount of bank capital and parameterized by $\kappa_{k}^{C}$.

The wholesale branch maximization problem can be expressed as

$$
\max _{b_{t}^{C}, d_{t}^{C}} r_{t}^{C} b_{t}^{C}-r_{t}^{d C} d_{t}^{C}-\frac{\kappa_{k}^{C}}{2}\left(\frac{k_{t}^{C}}{b_{t}^{C}}-\nu_{t}^{C}\right)^{2} k_{t}^{C}
$$

subject to the the balance sheet condition

$$
b_{t}^{C}=k_{t}^{C}+d_{t}^{C} .
$$

The first-order conditions yield the following expression:

$$
r_{t}^{C}=r_{t}^{d C}-\kappa_{k}^{C}\left(\frac{k_{t}^{C}}{b_{t}^{C}}-\nu_{t}^{C}\right)\left(\frac{k_{t}^{C}}{b_{t}^{C}}\right)^{2}
$$

As the commercial bank has access to central bank funding in the model, we assume that the rate paid on wholesale deposits gathered from the retail deposit unit of the commercial bank (and so originally from households and firms) has to be equal to the risk-free policy rate, $r_{t}$, via arbitrage:

$$
r_{t}^{d C}=r_{t}
$$

such that the spread between the loan and deposit rates on the wholesale level is given by

$$
r_{t}^{C}=r_{t}-\kappa_{k}^{C}\left(\frac{k_{t}^{C}}{b_{t}^{C}}-\nu_{t}^{C}\right)\left(\frac{k_{t}^{C}}{b_{t}^{C}}\right)^{2}
$$

This expression indicates that the marginal benefit from further lending, the spread earned on intermediation at the margin, has to be equal to the marginal costs from doing so in equilibrium. This marginal cost increases whenever the deviation of commercial bank capital holdings from the regulatory requirement increases.

Assuming symmetry between banks and reinvestment of profits in banks, aggregate bank capital $K_{t}^{C}$ is accumulated from retained earnings only:

$$
K_{t}^{C}=\left(1-\delta^{C}\right) K_{t-1}^{C}+J_{t-1}^{C}
$$

where $J_{t}^{C}$ depicts aggregate commercial bank profits derived from the three branches of the bank, see Gerali et al. (2010). Capital management costs are captured by $\delta^{C}$. 


\subsubsection{Shadow Banks}

In contrast to the commercial banking sector, shadow banks do not operate under monopolistic competition. The shadow banking sector is assumed to consist of a multitude of differenciated and specialized business entities, which, taken together, engage in similar intermediation activity as commercial banks. Given the flexibility and the heterogeneity of the shadow banking system, we assume shadow banks operate under perfect competition.

Instead of being constrained by regulation, as commercial banks are, shadow banks' ability to acquire external funds is constrained by a moral hazard problem that limits the creditors' willingness to provide external funds. To avoid excessive equity capital accumulation - and eventual exclusive financing via equity rather than debt - shadow bankers are assumed to have a finite lifetime: Each shadow banker faces an i.i.d. survival probability $\sigma^{S}$ with which he will be operating in the next period. This exit probability functions in the maximization problem of the shadow banker as an additional discount factor, which ensures that they are always net debtors to the households. To make up the outflow, every period new shadow bankers enter with an initial endowment of $w^{S}$ they receive in the first period of existence, but not thereafter. The number of shadow bankers in the system is constant. ${ }^{21}$

For the shadow banker, as long as the real return on lending, $\left(r_{t}^{b S}-r_{t}^{d S}\right)$ is positive, it is profitable to accumulate capital until it exits the intermediation sector. Thus, the shadow bank's objective to maximize expected terminal wealth, $v_{t}(j)$, is given by

$$
v_{t}(j)=\max E_{t} \sum_{i=0}^{\infty}\left(1-\sigma^{S}\right) \sigma^{S^{i}} \beta^{S^{i+1}} k_{t+1+i}^{S}(j)
$$

We introduce a moral hazard problem that leads to the possibility of positive spreads earned by shadow banks. ${ }^{22}$ We allow for the possibility that shadow banks divert a fraction of available funds, $\theta^{S}$, and use them for private benefits ${ }^{23}$ at the beginning of each period. Households can consequently only recover the leftover share $\left(1-\theta^{S}\right)$ afterwards. However, diverting funds and 'running away' is equivalent to declaring bankruptcy for the shadow bank, such that it will only do so if the return of declaring bankruptcy is larger than the discounted future return from continuing and behaving honestly:

$$
v_{t}(j) \geq \theta^{S} q_{t}^{k} b_{t}^{E, S}(j)
$$

\footnotetext{
${ }^{21}$ The complete derivation of the shadow bank problem and a deeper discussion of the approach used is presented in section A.3.2 of in appendix A.

${ }^{22}$ See section 2 in the Online Appendix.

${ }^{23}$ We assume that shadow banks are owned by households, such that the funds are ultimately transfered back to the parent household of shadow bank $j$. However, we follow Gertler and Karadi (2011) and assume that households cannot use their own shadow banker for intermediation, but place savings with a shadow bank owned by a different household.
} 
Equation 13 depicts the incentive constraint the shadow banker faces when trying to acquire funds from households. ${ }^{24}$. As we assume some shadow bankers to exit each period and new bankers to enter the market, aggregate capital $k_{t}^{S}$ is determined by the capital of continuing shadow bankers, $k_{t}^{S, c}$, and the capital of new bankers that enter, $k_{t}^{S, n}$

$$
k_{t}^{S}=k_{t}^{S, c}+k_{t}^{S, n}
$$

and combining the expressions for $k_{t}^{S, c}$ and $k_{t}^{S, n}$ derived in appendix A yields the following law of motion for shadow bank capital:

$$
k_{t}^{S}=\sigma^{S}\left[\left(r_{t-1}^{b S}-r_{t-1}^{d S}\right) \phi_{t-1}^{S}+\left(1+r_{t-1}^{d S}\right)\right] k_{t-1}^{S}+\omega^{S} q_{t}^{k} b_{t-1}^{E, S}
$$

The shadow bank balance sheet condition

$$
q_{t}^{k} b_{t}^{E, S}(j)=d_{t}^{P, S}(j)+k_{t}^{S}(j)
$$

in combination with the demand for shadow bank credit by borrowers given by equation 6 determines shadow bank lending $b_{t}^{E, S}(j)$ and ultimately shadow bank savings, $d_{t}^{P, S}(j)$.

Finally, we assume a non-negative spread between the interest rates earned on shadow bank deposits, $r_{t}^{d S}$, and on the deposits households can place with commercial banks, $r_{t}^{d C}$, which is again determined by the parameter $\tau^{S}$, with $0 \leq \tau^{S} \leq 1$. In section 1.1. of the Online Appendix, we provided a microfoundation for the existence of a positive spread, and use the results to incorporate a relationship between the two deposit rates similar to the relation stated in equation 4 in the two-period model:

$$
1+r_{t}^{d S}=\frac{1+r_{t}^{d C}}{1-\tau^{S} \varepsilon_{t}^{\tau}}
$$

As in the two-period version of the model, the parameter $\tau^{S}$ determines the spread between the gross rates on both deposit types and is implicitly related to the default probability of shadow banks. As a shortcut, we will calibrate $\tau^{S}$ and assume the existence of a spread shock $\varepsilon_{t}^{\tau}$ following an autoregressive process to motivate exogenous swings in the spread on interest rates earned on the two deposit types.

\footnotetext{
${ }^{24}$ Compared to equation 37 in the Online Appendix, the interest rate term on the right-hand side is missing here, as we do not have fixed shadow bank capital anymore, but interest returns from the previous period are booked into shadow bank capital at the end of a respective period. In the infinite-horizon case, the timing of events is such that at the beginning of any period $t$, shadow banks use net worth $k_{t}^{S}(j)$ together with deposits $d_{t}^{P, S}(j)$ to lend out financial claims $b_{t}^{E, S}(j)$. Afterwards, the shadow banker decides whether to run away or not. In case of behaving honestly, he receives net returns $r_{t}^{b S}-r_{t}^{d S}$ on intermediation at the end of period $t$, and these returns are then part of the capital stock in the next period, $k_{t+1}^{S}(j)$
} 


\section{Data}

All real economic variables used in the estimation exercise are drawn from the European System of Accounts (ESA 2010) quarterly financial and non-financial sector accounts, provided by the ECB and Eurostat. ${ }^{25}$ For the real economy, we include information on real gross domestic product, real consumption, real investment, and consumer price as well as wage inflation. Information on commercial bank balance sheets - commercial bank deposits held by private households, commercial bank loans granted to the non-financial corporate sector - is gathered from the data set in "Monetary Financial Institutions" (MFIs) collected by the ECB. Data on commercial bank interest rates on household deposits and firm loans are drawn from different sources within the ECB Statistical Data Warehouse and harmonized in line with the procedure recommended by Gerali et al. (2010). We also use the short-term EONIA rate as a quarterly measure of the policy rate. For shadow bank variables, we use information provided in the ECB data base on different monetary and other financial institutions, as discussed in detail in Appendix B.

\section{Estimation}

We use the data set described in the previous chapter and apply full-information Bayesian techniques to estimate some of the model parameters. Our baseline sample covers the period between 1999:Q1 and 2013:Q4, as we assume that the zero lower bound (ZLB) on nominal interest rates was reached in 2014 in the euro area. ${ }^{26}$. Furthermore, as the effective implementation of the Basel III framework under the Capital Requirements Directive IV (CRD IV) of the European Union took place from 2014:Q1 onwards, we estimate our baseline model reflecting the regulatory landscape under Basel II for the period before the implementation of the new framework. ${ }^{27}$ In total, we use twelve time series, ${ }^{28}$ and we apply the Metropolis-Hastings algorithm to derive draws from the posterior distribution, by running five chains with 100,000 draws each in the baseline estimation. We evaluate convergence in the estimation by considering the approach of Brooks and Gelman (1998).

\footnotetext{
${ }^{25}$ See Appendix B for a detailed description of the data set.

${ }^{26}$ See for instance Coeuré for a discussion of the beginning of the ZLB period in the euro area. We provide evidence on a shorter sample period in Appendix C.1 to account for the fact that the effective ZLB was potentially thought to have been reached before that date.

${ }^{27}$ In the euro area, the implementation of Basel III is governed by the Capital Requirements Directives IV (CRD IV) and the subsequent Regulation on Prudential Requirements for Credit Institutions and Investment Firms (CRR), which came into force on January 1, 2014. Thus, as euro area countries did not implement the policy measures put forward under Basel III before the beginning of 2014, we are effectively covering the pre-Basel III era of banking regulation in the euro area with our sample for the baseline estimation.

${ }^{28}$ See charts in Figure 5 of Appendix B
} 
We furthermore check for the identification of parameters following Ratto and Iskrev (2011). ${ }^{29}$

\subsection{Calibration and Prior Distributions}

Table 1 shows values for the calibrated parameters. In most cases, we apply the calibration used by Gerali et al. (2010). We adjust parameters on the loan (deposit) rate markup (markdown) for commercial bank lending $\varepsilon^{b E}\left(\varepsilon^{d}\right)$ to match the average spreads in our extended sample. As the loan rate markup (deposit rate markdown) is given by $\frac{\varepsilon^{b E}}{\varepsilon^{b E}-1}$ $\left(\frac{\varepsilon^{d}}{\varepsilon^{d}-1}\right)$, we set parameters to match the average annualized loan rate spread (deposit rate spread) with respect to the EONIA of 240 basis points (35 basis points) in our extended sample. ${ }^{30}$ In addition, by incorporating shadow banks and macroprudential regulation in the model, we introduce three new parameters: $\tau^{S}, \theta^{S}$, and $\sigma^{S}$. Given our broad definition of shadow banks, finding empirical equivalents to shadow bank deposit returns is not straightforward. The shadow bank aggregate we consider covers institutions with highly diverse investment portfolios, different types of investors placing funds, and ultimately highly varying returns on the specific activity they are engaged in. We calibrate $\tau^{S}$ such that the implied default probability of shadow banks is approximately five percent per quarter and the resulting annualized spread between shadow bank and commercial bank deposit rates is approximately two percentage points in steady state, while acknowledging that the variation in actual returns on the micro-level can be large.

Furthermore, we ensure in the calibration that the share of shadow bank intermediation in total intermediation is approximately one-third in steady state and that the size of the average shadow bank loan portfolio is one-third the size of shadow bank assets. These values are comparable to statistical figures derived in empirical studies in the euro area shadow banking sector based on similar data (Bakk-Simon et al., 2012; Malatesta et al., 2016) and resemble average values in our data set. The latter calibration allows us to treat $\sigma^{S}$ as a transformed parameter in the estimation, and the resulting post-estimation value is given by 0.944 . Our value of $\theta^{S}$, the share of divertible funds, turns out to be lower than the calibrated value in Gertler and Karadi (2011), where the authors settled on a value of 0.381 in the calibration of the US model. ${ }^{31}$. Furthermore, we set the steady state commercial bank capital requirement, $\overline{\nu^{C}}$, equal to 8 percent, which resembles the

\footnotetext{
${ }^{29}$ Details on convergence statistics and identification tests are available upon request.

${ }^{30}$ In Gerali et al. (2010), the retail deposit rate spread is stated to be 125 basis points. However, we include the period after 2008 in our sample, where bank market power was adversely affected by the global financial crisis and the debt crisis in Europe and thus lending and deposit margins for commercial banks were reduced significantly.

${ }^{31}$ An economic interpretation of the lower share that intermediaries can divert in the euro area could be given by a higher degree of creditor protection.
} 
Table 1: Calibrated Parameters

\begin{tabular}{lll} 
Parameter & Description & Value \\
\hline$\tau^{S}$ & Deposit rate spread parameter & 0.05 \\
$\theta^{S}$ & SB Share of Divertible Funds & 0.2 \\
$\sigma^{S}$ & SB Survival Probability & 0.944 \\
$\overline{\nu^{C}}$ & Steady state capital requirement & 0.08 \\
$\phi^{P}$ & Inverse Frisch elasticity of labour supply & 1 \\
$\beta_{P}$ & Discount factor of household & 0.9943 \\
$\beta_{E}$ & Discount factor entrepreneur & 0.975 \\
\hline$m^{C}$ & Steady state LTV ratio vs. Commercial banks & 0.3 \\
$\alpha$ & Capital share in production function & 0.2 \\
$\varepsilon^{d}$ & Deposit rate markdown given by $\frac{\varepsilon^{d}}{\varepsilon^{d}-1}$ & -0.9 \\
$\varepsilon^{b E}$ & Loan rate markup given by $\frac{\varepsilon^{b E}}{\varepsilon^{b E}-1}$ & 2 \\
$\varepsilon^{y}$ & Goods market markup given by $\frac{\varepsilon^{y}}{\varepsilon^{y}-1}$ & 6 \\
$\varepsilon^{l}$ & Labor market markup given by $\frac{\varepsilon^{l}}{\varepsilon^{l}-1}$ & 5 \\
$\delta^{k}$ & Depreciation rate physical capital & 0.025 \\
$\delta^{b}$ & Bank capital management cost & 0.1049 \\
\hline \hline
\end{tabular}

overall level of capital-to-asset holdings demanded from commercial banks under Basel II. The steady state LTV ratio for commercial banks $\overline{m^{C}}$ is calibrated following Gerali et al. (2010), implying relatively strict regulation on collateral and a significant scope for shadow bank lending based on collateral criteria. ${ }^{32}$

For the prior distributions, we widely follow Gerali et al. (2010) for the parameters originally estimated in their study. As we apply a Calvo pricing framework instead of Rotemberg, we rely on a prior distribution similar to those introduced by Smets and Wouters $(2003,2007)$ for the Calvo parameter $\theta^{p}$. We choose a slightly tighter prior distribution for the Taylor-rule parameter on inflation and change the distibution on the respective output parameter to a Beta-distribution compared to the Normal distribution used in the original study, as we are not willing to use a prior distribution that would theoretically allow for negative values of the parameter. Tables 2 to 4 report prior and posterior distributions for structural parameters as well as parameters describing exogenous processes. In contrast to Gerali et al. (2010), we take the posterior modes as parameter estimates, whereas the median values of the posterior were used in the original study, which we also report for comparability.

For the parameter that governs the cost of deviation from the capital requirement, $\kappa_{C}$, we assume a uniform distribution ranging from 0 to 25 . Since this parameter is difficult to

\footnotetext{
${ }^{32}$ Changing the LTV ratio to higher levels did not change the estimation results dramatically.
} 
identify in an observable empirical counterpart, the non-informative nature of this prior in principle allows sufficient flexibility for the posterior to assume a broad range of values depending on the highest likelihood of the entire model and parameter set.

We finally use the same priors for all exogenous process parameters, including the parameters related to the two newly introduced shocks to commercial bank capital requirements $\left(\varepsilon_{t}^{\nu}\right)$ and the spread between shadow bank and commercial bank returns $\left(\varepsilon_{t}^{\tau}\right)$, as can be seen in Tables 3 and 4 . 
Table 2: Prior and Posterior Distributions: Baseline Structural Parameters

\begin{tabular}{|c|c|c|c|c|c|c|c|c|c|}
\hline \multirow[b]{2}{*}{ Parameter } & & \multicolumn{3}{|c|}{ Prior Distribution } & \multicolumn{4}{|c|}{ Posterior Distribution } & \multirow{2}{*}{$\begin{array}{c}\text { GNSS (2010) } \\
\text { (Median) }\end{array}$} \\
\hline & & Distribution & Mean & Std.Dev. & 5 Perc. & Median & 95 Perc. & Mode & \\
\hline$\theta^{p}$ & Calvo Parameter & Beta & 0.5 & 0.10 & 0.81 & 0.84 & 0.88 & 0.84 & - \\
\hline$\kappa^{i}$ & Investm. Adj. Cost & Gamma & 2.5 & 1.0 & 4.54 & 6.08 & 7.59 & 5.99 & 10.18 \\
\hline$\kappa^{d}$ & Deposit Rate Adj. Cost & Gamma & 10.0 & 2.5 & 9.91 & 13.16 & 16.29 & 13.13 & 3.50 \\
\hline$\kappa^{b E}$ & Loan Rate Adj. Cost & Gamma & 3.0 & 2.5 & 4.69 & 7.88 & 10.87 & 7.51 & 9.36 \\
\hline$\kappa_{k}^{C}$ & CCR Deviation Cost & Uniform & 0.0 & 25.0 & 2.64 & 12.53 & 24.98 & 16.41 & 11.07 \\
\hline$\phi^{\pi}$ & TR Coefficient $\pi$ & Gamma & 1.5 & 0.5 & 1.45 & 1.91 & 2.34 & 1.92 & 1.98 \\
\hline$\phi^{y}$ & TR Coefficient $y$ & Gamma & 0.20 & 0.05 & 0.13 & 0.22 & 0.31 & 0.21 & 0.35 \\
\hline$\phi^{r}$ & Interest Rate Smoothing & Beta & 0.75 & 0.10 & 0.82 & 0.86 & 0.90 & 0.86 & 0.77 \\
\hline$a^{P}$ & HH Habit Formation & Beta & 0.50 & 0.10 & 0.67 & 0.75 & 0.82 & 0.74 & 0.86 \\
\hline
\end{tabular}

Note: Results are based on 5 chains with 100,000 draws each based on the MH algorithm. GNSS (2010) refers to the results reported in Gerali et al. (2010). 
Table 3: Prior and Posterior Distributions: Baseline Exogenous Processes (AR Coefficients)

\begin{tabular}{|c|c|c|c|c|c|c|c|c|c|}
\hline \multirow[b]{2}{*}{ Parameter } & & \multicolumn{3}{|c|}{ Prior Distribution } & \multicolumn{4}{|c|}{ Posterior Distribution } & \multirow{2}{*}{$\begin{array}{c}\text { GNSS (2010) } \\
\text { (Median) }\end{array}$} \\
\hline & & Distribution & Mean & Std.Dev. & 5 Perc. & Median & 95 Perc. & Mode & \\
\hline$\rho^{\tau}$ & Deposit Rate Spread & Beta & 0.8 & 0.1 & 0.66 & 0.82 & 0.96 & 0.82 & - \\
\hline$\rho^{\nu}$ & Capital Requirement & Beta & 0.8 & 0.1 & 0.66 & 0.83 & 0.97 & 0.86 & - \\
\hline$\rho^{z}$ & Consumer Preference & Beta & 0.8 & 0.1 & 0.89 & 0.93 & 0.96 & 0.93 & 0.39 \\
\hline$\rho^{a}$ & Technology & Beta & 0.8 & 0.1 & 0.68 & 0.76 & 0.85 & 0.76 & 0.94 \\
\hline$\rho^{m E}$ & Entrepreneur LTV & Beta & 0.8 & 0.1 & 0.92 & 0.94 & 0.97 & 0.94 & 0.89 \\
\hline$\rho^{d}$ & Deposit Rate Markdown & Beta & 0.8 & 0.1 & 0.30 & 0.40 & 0.50 & 0.40 & 0.84 \\
\hline$\rho^{b E}$ & Loan Rate Markup & Beta & 0.8 & 0.1 & 0.50 & 0.64 & 0.77 & 0.63 & 0.83 \\
\hline$\rho^{q k}$ & Investment Efficiency & Beta & 0.8 & 0.1 & 0.38 & 0.50 & 0.62 & 0.50 & 0.55 \\
\hline$\rho^{y}$ & Price Markup & Beta & 0.8 & 0.1 & 0.21 & 0.32 & 0.43 & 0.31 & 0.31 \\
\hline$\rho^{l}$ & Wage Markup & Beta & 0.8 & 0.1 & 0.84 & 0.89 & 0.95 & 0.89 & 0.64 \\
\hline$\rho_{k}^{C}$ & Commercial Bank Capital & Beta & 0.8 & 0.1 & 0.92 & 0.95 & 0.99 & 0.95 & 0.81 \\
\hline
\end{tabular}

Note: Results are based on 5 chains with 100,000 draws each based on the MH algorithm. GNSS (2010) refers to the results reported in Gerali et al. (2010). 
Table 4: Prior and Posterior Distributions: Baseline Exogenous Processes (Standard Deviations)

\begin{tabular}{|c|c|c|c|c|c|c|c|c|c|}
\hline \multirow[b]{2}{*}{ Parameter } & & \multicolumn{3}{|c|}{ Prior Distribution } & \multicolumn{4}{|c|}{ Posterior Distribution } & \multirow{2}{*}{$\begin{array}{c}\text { GNSS (2010) } \\
\text { (Median) }\end{array}$} \\
\hline & & Distribution & Mean & Std.Dev. & 5 Perc. & Median & 95 Perc. & Mode & \\
\hline$\sigma^{\tau}$ & Deposit Rate Spread & Inverse Gamma & 0.01 & 0.05 & 0.002 & 0.007 & 0.019 & 0.006 & - \\
\hline$\sigma^{\nu}$ & Capital Requirement & Inverse Gamma & 0.01 & 0.05 & 0.002 & 0.007 & 0.017 & 0.005 & - \\
\hline$\sigma^{z}$ & Consumer Preference & Inverse Gamma & 0.01 & 0.05 & 0.008 & 0.012 & 0.018 & 0.013 & 0.027 \\
\hline$\sigma^{a}$ & Technology & Inverse Gamma & 0.01 & 0.05 & 0.014 & 0.017 & 0.019 & 0.017 & 0.006 \\
\hline$\sigma^{m E}$ & Entrepreneur LTV & Inverse Gamma & 0.01 & 0.05 & 0.010 & 0.011 & 0.013 & 0.011 & 0.007 \\
\hline$\sigma^{d}$ & Deposit Rate Markdown & Inverse Gamma & 0.01 & 0.05 & 0.001 & 0.002 & 0.002 & 0.002 & 0.032 \\
\hline$\sigma^{b E}$ & Loan Rate Markup & Inverse Gamma & 0.01 & 0.05 & 0.002 & 0.002 & 0.003 & 0.002 & 0.063 \\
\hline$\sigma^{q k}$ & Investment Efficiency & Inverse Gamma & 0.01 & 0.05 & 0.001 & 0.002 & 0.002 & 0.002 & 0.019 \\
\hline$\sigma^{r}$ & Monetary Policy & Inverse Gamma & 0.01 & 0.05 & 0.001 & 0.001 & 0.002 & 0.001 & 0.002 \\
\hline$\sigma^{y}$ & Price Markup & Inverse Gamma & 0.01 & 0.05 & 0.001 & 0.002 & 0.002 & 0.001 & 0.598 \\
\hline$\sigma^{l}$ & Wage Markup & Inverse Gamma & 0.01 & 0.05 & 0.021 & 0.025 & 0.028 & 0.025 & 0.561 \\
\hline$\sigma_{k}^{C}$ & Commercial Bank Capital & Inverse Gamma & 0.01 & 0.05 & 0.006 & 0.007 & 0.008 & 0.007 & 0.031 \\
\hline
\end{tabular}

Note: Results are based on 5 chains with 100,000 draws each based on the MH algorithm. GNSS (2010) refers to the results reported in Gerali et al. (2010). 


\subsection{Posterior Distributions}

In Tables 2 to 4 we also report summary statistics of the posterior distributions for the model parameters. We furthermore provide marginal densities of the prior and posterior distributions for the structural parameter estimates in Figures 6 to 8 in the appendix.

Even though the mode of the posterior for the Calvo parameter turns out to be slightly lower than the estimate derived in Smets and Wouters (2003), price stickiness is a significant feature in the model. The posterior mode for the investment adjustment cost parameter $\kappa^{i}$ turns out to be of similar magnitude as the parameter derived in Smets and Wouters (2003), whereas Gerali et al. (2010) report a larger value for this parameter.

In the commercial banking sector, the degree of interest rate stickiness is generally higher as in Gerali et al. (2010), which could partly be attributed to the inclusion of the post-2008 period in the estimation (see discussion in section C.1). However, sluggish interest rate adjustment appears particularly strong in the market for commercial bank deposits, indicated by high posterior mode and median values for the deposit rate adjustment cost parameter $\kappa^{d}$. Furthermore, loan rates adjust more rapidly to changes in the policy rate compared to commercial bank deposit rates. Commercial banks therefore appear to react to changes in monetary policy by a more flexible adjustment of loan rates in response to competition from shadow banks which operate under perfect interest-rate pass through, compared to a situation where shadow banking is absent.

As indicated in the previous section, the uniform prior for the commercial bank capital requirement adjustment cost parameter $\kappa_{k}^{C}$ was selected due to a weak identification problem, and the resulting parameter estimate turns out to be slightly lower as in Gerali et al. (2010). ${ }^{33}$ Parameters related to monetary policy are broadly in line with results derived for instance in Gerali et al. (2010) and Smets and Wouters (2003), with our estimated posterior modes for the Taylor rule parameters $\phi^{\pi}, \phi^{y}$ and $\phi^{r}$ taking on values that lie in between the estimated parameters derived in these studies. Finally, household habit formation is slightly weaker than in Gerali et al. (2010).

For all shock processes, persistence turns out to be relatively high, with the processes for commercial bank deposit rate markdown shocks and price markup shocks depicting exceptions. In Figures 7 and 8, the parameters describing the shock processes for the spread between commercial and shadow bank deposit rates $(\tau)$ and for the commercial bank capital requirement $(\nu)$ indicate a weak identification problem.

\footnotetext{
${ }^{33}$ We conducted a sensitivity analysis to evaluate the robustness of the estimation and found that model dynamics are unchanged when this parameter is varied.
} 


\section{Policy Analyses}

We use our estimated model to evaluate whether disregarding credit intermediation via the shadow banking sector in macroprudential policy decisions has quantitative implications for policy decisions and the macroeconomy. In this context, we discuss potential implications for policy coordination between central banks and macroprudential regulators. Furthermore, in a counterfactual analysis, we assess how regulators would have set capital requirements under a countercyclical policy rule in the fashion of the Basel III regulatory framework, had it been in place throughout the existence of the common currency. To do so, we introduce a policymaker following a countercyclical rule in the pre-Basel III model and simulate the development of capital requirements over the course of the monetary union. Furthermore, we discuss to what extent the level of implied capital requirements would have changed if regulators took not only commercial bank credit, but overall credit into account.

\subsection{Macroprudential Regulation}

In the following analyses, we discuss different regulatory regimes, depending on the degree of shadow bank consideration. We therefore implement, in the estimated Basel II model, different types of regulators that follow countercyclical rules for adjusting commercial bank capital requirements. We thereby take into account key elements of the Basel III framework: countercyclical adjustment of capital requirements in response to swings in the credit cycle and the primary focus on commercial banking in the application of macroprudential policy. As indicated above, before the implementation of Basel III, the requirement on total capital holdings was 8 percent, and no countercyclical adjustment of requirements was intended. We raise the steady state capital requirement for all regulator types from 8 percent to 10.5 percent $^{34}$ and change the capital requirement equation in the model from an exogenous $\mathrm{AR}(1)$ process to a regulation-specific countercyclical rule described in more detail below. We leave the rest of the calibration and estimated parameters unchanged, as they were derived from the estimation using the true regulatory setup and economic data before the implementation of Basel III.

We discuss two different versions of the Basel III macroprudential regulator - in addition to the case without countercyclical capital regulation as under Basel II - that can apply capital requirements only to the commercial banking system, but cannot enforce explicit regulation on the shadow banking system. The difference between these types emerges from the degree to which shadow banking is considered when setting policy for

\footnotetext{
${ }^{34}$ The Basel III regulation capital requirement consist of different types of buffers banks have to hold: 8 percent (minimum Tier $1+2$ capital) plus 2.5 percent (capital conservation buffer), yielding 10.5 percent for total capital.
} 
commercial banks. The macroprudential policy rule resembles the countercyclical capital requirement on commercial bank balance sheets introduced with the Basel III accords in stating that the macroprudential authority raises the requirement on the capital-to-asset ratio whenever credit granted by the banking sector rises above the level perceived as stable, and lowers the requirement whenever the credit gap is negative. In the model, the regulator thus raises the capital-to-asset ratio $\nu_{t}^{C}$ above the steady state level of capital requirements $\overline{\nu^{C}}$ whenever aggregate bank credit - relative to output - deviates positively from its steady state value, and vice versa.

Under Basel III, the specific credit measure that should be applied is not stated explicitly in the regulatory statutes, and the primary focus of regulators lies on credit intermediated by commercial banks. Thus, in our analysis of different regulation frameworks, we differentiate with respect to the degree that shadow banks are indirectly taken into account when regulation on commercial banks is set. In a first-best situation, regulators would be able to adjust capital requirements/lending restrictions in a similarly structured and coherent framework for non-bank financial institutions as they do for commercial banks under the Basel regulations. However, given the large degree of heterogeneity and specialization in the shadow banking system, installing a macroprudential framework with a universal tool such as capital requirements is not feasible for shadow banks. Even though regulatory approaches towards special types of entities are under way and partly implemented (FSB, 2017), a unified framework for regulating non-bank finance is still out of reach.

\subsubsection{Macroprudential Regulation: The Moderate Regulator}

We first evaluate the policy setting of a moderate regulator that is aware of the existence of shadow banking, but only focuses on developments in commercial bank credit when setting capital requirements for commercial banks. The policy rule the moderate regulator follows resembles the rule derived in Angelini et al. (2014): ${ }^{35}$

$$
\nu_{t}^{C}=\left(1-\rho^{\nu}\right) \overline{\nu^{C}}+\left(1-\rho^{\nu}\right)\left[\chi_{\nu}\left(\frac{b_{t}^{E, C}}{Y_{t}}-\frac{\overline{b^{E, C}}}{\bar{Y}}\right)\right]+\rho^{\nu} \nu_{t-1}^{C}+\varepsilon_{t}^{\nu} .
$$

The regulator adjusts the bank capital requirement $\nu_{t}^{C}$ in response to deviations of the commercial bank credit-to-output ratio, $\frac{b_{t}^{E, C}}{Y_{t}}$, from its steady-state level. The reaction parameter $\chi_{\nu}$ determines the degree of policy sensitivity, and we calibrate it to a value of 7, which is broadly in line with the parameter values derived in Angelini et al. (2014). ${ }^{36}$

\footnotetext{
${ }^{35}$ As a robustness check, we have undertaken the same analyses with an alternative policy rule specification $\nu_{t}^{C}=\bar{\nu}^{\left(1-\rho^{\nu}\right)} \nu_{t-1}^{C}{ }^{\left(\rho^{\nu}\right)}\left(\frac{b_{t}^{E, C}}{b^{E, C}}\right)^{\phi^{\nu}} \varepsilon_{t}^{\nu}$. Our main findings were qualitatively similar under both rules.

${ }^{36}$ Results are not substantially affected when $\chi_{\nu}$ is changed.
} 
Furthermore, we allow for exogenous shocks to the capital requirement, indicated by $\varepsilon_{t}^{\nu}$, and assume an autoregressive shock process and smoothing in the adjustment of capital requirements, governed by parameter $\rho^{\nu}$ which we calibrate at a value of 0.9 .

The moderate regulator thus resembles the regulatory landscape in the euro area, as most European regulatory authorities are aware of and accept the relevance of shadow banking for financial intermediation and stability, but do not explicitly, at least with respect to their respective mandates, take shadow bank statistics into account when deciding on regulation for commercial banks.

\subsubsection{Macroprudential Regulation: The Prudent Regulator}

In addition, a prudent regulator is introduced that is not only aware of credit intermediation of shadow banks, but explicitly takes lending by the shadow banking sector into account when deciding on capital requirements for commercial banks. Despite the lack of a unifying regulatory framework for shadow bank institutions, the regulator is able to derive estimates of credit intermediation taking place outside the regulated banking sector, and can therefore potentially consider not only aggregate credit stemming from commercial banks he regulates in decision-making, but also movements of overall credit. The policy rule stated in equation 18 is thus altered for the prudent regulator such that:

$$
\nu_{t}^{C}=\left(1-\rho^{\nu}\right) \overline{\nu^{C}}+\left(1-\rho^{\nu}\right)\left[\chi_{\nu}\left(\frac{b_{t}^{E, C}+b_{t}^{E, S}}{Y_{t}}-\frac{\overline{b^{E, C}}+\overline{b^{E, S}}}{\bar{Y}}\right)\right]+\rho^{\nu} \nu_{t-1}^{C}+\varepsilon_{t}^{\nu}
$$

\subsection{Impulse Response Analysis}

In the following, we derive impulse responses for two policy shocks: a standard monetary policy shock and a shock to capital requirements. We analyze the first shock to evaluate whether our model is able to replicate stylized facts from the large literature on monetary policy shocks and whether commercial bank and shadow bank intermediation is differently affected by unexpected changes in monetary policy. We then evaluate the impact of an unanticipated increase of capital requirements to discuss potential leakage towards shadow bank intermediation in response to tighter regulation. We finally discuss the potential of policy coordination between the central bank and the macroprudential regulator to avoid potentially unintended side effects of tighter banking regulation, i.e. credit leakage towards the shadow banking sector. For each case, we take different degrees of shadow bank consideration by policymakers into account, as described in the previous section. 


\subsubsection{Impulse Responses: Monetary Policy Shock}

Several empirical studies have identified different reactions in credit intermediated within and outside the regular banking system in response to monetary policy shocks. Igan et al. (2013) find that some institutions (money market mutual funds, security broker-dealers) increase their asset holdings after monetary policy easing, whereas issuers of asset-backed securities (ABS) decrease their balance sheets after monetary policy tightening, with respective implications for intermediation activity by different institutions. Pescatori and Sole (2016) use a VAR framework including data on commercial banks, ABS issuers, and other finance companies, such as insurance companies and mortgage pools, as well as government-sponsored entities (GSEs). They find, inter alia, that monetary policy tightening decreases aggregate lending activity, even though the size of the nonbank intermediary sector increases, which indicates a relative dampening of the transmission channel as nonbanks step in as lenders whenever commercial banks reduce credit provisions. Similarly, Den Haan and Sterk (2011), using US flow-of-funds data, find that nonbank asset holdings increase in response to monetary tightening, even though overall credit declines or stays relatively flat. Mazelis (2016) distinguishes between commercial banks depending on deposit liabilities, shadow banks that are highly levered and depend on funding from other intermediaries, and investment funds that draw funding from real economic agents directly. He finds that, whereas commercial bank credit remains relatively flat after monetary tightening and is reduced only in the medium term, shadow banks and investment funds increase lending in response to monetary policy tightening in the short term. Nelson et al. (2015) find similar results when looking at aggregate balance sheets, even though their definition of shadow banks differs from that in Mazelis (2016). For European banks, Altunbas et al. (2009) show that institutions engaged to a large extent in nonbank activities, such as securitization, are less affected by monetary policy shocks, a finding in line with the above studies on US intermediaries: where a larger share of nonbank activity insulates credit intermediation from monetary policy shocks, thus dampening the transmission of policy shocks, ceteris paribus.

To evaluate whether our model is able to qualitatively replicate empirical evidence on heterogeneous responses in credit intermediated by commercial and shadow banks to monetary policy shocks, we evaluate the reaction of model variables to an unanticipated increase in the policy rate by 10 basis points in Figure 1. 
Figure 1: Impulse Responses: Monetary Policy Shock
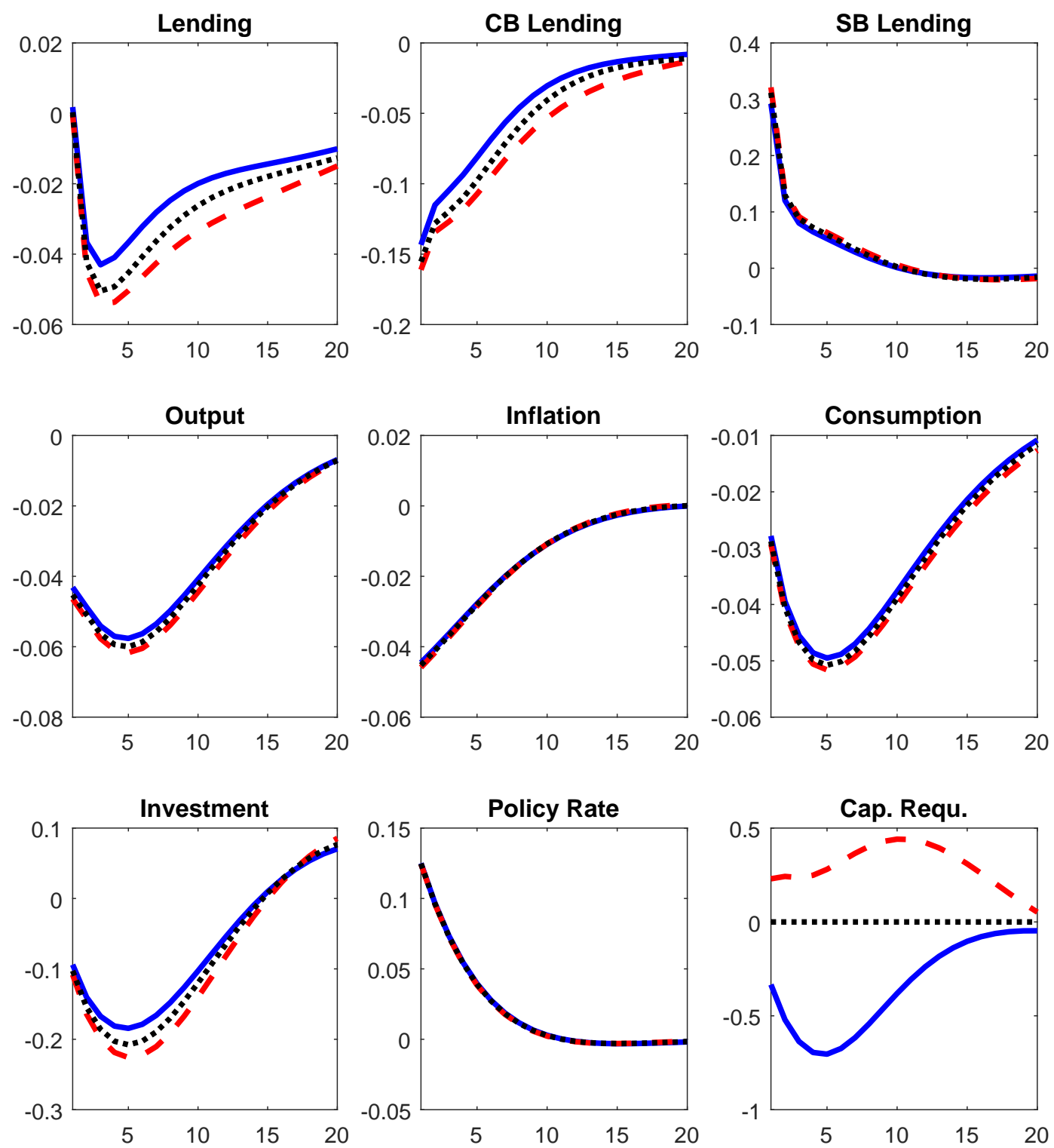

Moderate Regulator $=$ - Prudent Regulator ....... No Regulator

Note: Impulse responses to a one-standard-deviation monetary policy shock. Rates in absolute deviations from steady state, all other variables as percentage deviations from steady state.

In line with standard findings in the literature on New Keynesian models, aggregate output and its subcomponents - consumption and investment - decline and inflation is lowered in response to tighter monetary policy. Furthermore, total lending is reduced as credit costs increase due to higher interest rates and as aggregate demand deteriorates. ${ }^{37}$

${ }^{37}$ This finding is consistent with studies relying on a homogeneous description of the financial sector, see 
However, allowing for a detailed description of the financial sector reveals that the decline in commercial bank lending is partly counteracted by an increased intermediation activity of shadow banks. Whereas commercial bank credit falls by approximately 0.15 percent in response to higher interest rates, shadow bank credit increases by approximately 0.3 percent. We therefore confirm empirical evidence on the presence of credit leakage towards shadow banks in response to tighter monetary policy in our model.

Even though results on inflation and shadow bank lending do not significantly differ with respect to the macroprudential policy regime in place, we observe a lower reduction in commercial bank and ultimately total credit intermediation in the case of a moderate regulator. A macroprudential policymaker only concerned with developments in the commercial banking sector significantly lowers capital requirements in response to the reduced lending activity by commercial banks when confronted with higher interest rates. Quantitatively, capital requirements are lowered by four percent on impact, which depicts a reduction of roughly 50 basis points compared to the steady-state level of capital requirements. Compared to the case without countercyclical regulation, losses in output, consumption and investment are partly counteracted by looser macroprudential policy.

However, a regulator considering both commercial bank and shadow bank credit would actually increase capital requirements in our stylized simulation exercise. The significant increase in shadow bank credit in response to higher interest rates is sufficient to trigger a slight increase in capital requirements. In turn, the reduction in overall credit is even more pronounced in the prudent regulation case compared to the benchmark situation of no countercyclical policy maker, and hence the reduction in aggregate demand and output is slightly more pronounced in the case of a prudent macroprudential regulator.

We take this finding as indication that a different treatment of shadow banks in policy considerations can lead to different policy prescriptions in response to macroeconomic shocks, with respective consequences for macroeconomic developments and financial stability. Ultimately, the response by regulators depends on the primary objective of macroprudential policy. As we do not explicitly take the effect of shadow banking on financial stability into account, the results here only indicate that a regulator concerned with excessive lending by unregulated shadow banks - and a potentially resulting increase in financial instability - would prescribe a different policy for commercial banks when he explicitly accounts for developments in the shadow banking sector in his considerations. ${ }^{38}$ Based on the stylized analysis, the introduction of shadow banking and potential credit leakage appears to weaken the response of regulators to macroeconomic shocks, as cap-

for instance Gerali et al. (2010).

${ }^{38}$ As we do not derive welfare implications of shadow banking here, no discussion about the optimality or desirability of different described policy responses can be drawn from the presented results. Gebauer (2019) introduces such a welfare analysis in a simplified version of our model. 
ital requirements are raised (lowered) less strongly or, in extreme cases, even decreased (increased) in response to expansionary (adverse) shocks compared to the case of shadow bank absence. ${ }^{39}$

\subsubsection{Impulse Responses: Capital Requirement Shock}

In the previous section, we verify that our model is well-suited to generate responses by commercial and shadow banks to tighter monetary policy which are qualitatively in line with empirical evidence. The second set of impulse responses provides evidence on the macroeconomic implications of changes to commercial banking regulation in the presence of a credit leakage mechanism similar to the one described in the two-period model ${ }^{40}$. Empirical evidence on the effects of regulatory changes on credit intermediation is still relatively scarce, primarily due to issues of identifying unanticipated shocks to capital regulation on the macro level. ${ }^{41}$ Irani et al. (2018) use detailed US corporate loan data to evaluate the effect of capital requirement changes on the development of non-bank financial intermediation. Relying on data derived from a supervisory register on syndicated loans in the identification of surprise components in changes in regulatory capital requirements, they find that shadow bank credit intermediation increases in response to commercial bank capital constraints in response to tighter capital requirements. Similarly, Buchak et al. (2018) examine data on fintech lenders in residential mortgage markets and find that commercial banking contracted due to higher regulatory burden - such as higher bank capital requirements as well as mortage market related regulatory changes - and was partly replaced by unregulated shadow bank intermediation. To evaluate the effect of credit leakage towards shadow banks in response to tighter regulation, we simulate an unanticipated increase in commercial bank capital requirements by one percentage point (resembling a positive ten percent deviation from steady state) and provide impule responses in Figure 2.

\footnotetext{
${ }^{39}$ Such a weakening of countercyclical reactions due to credit leakage is also present in the optimal capital requirement rule derived in Gebauer (2019).

${ }^{40}$ See the Online Appendix.

${ }^{41}$ Compared to well-established procedures to identify monetary policy shocks, empirical identification of macroprudential policy shocks is less straightforward. First, policy decisions are not yet derived in a similarly structured process as monetary policy, where decisions are based on regular meetings of the decision bodies and announced in a timely and public manner in most economies. Second, as many of the macroprudential tools discussed now were only implemented over the last ten years, time series for respective measures are still short.
} 
Figure 2: Impulse Responses: Capital Requirement Shock
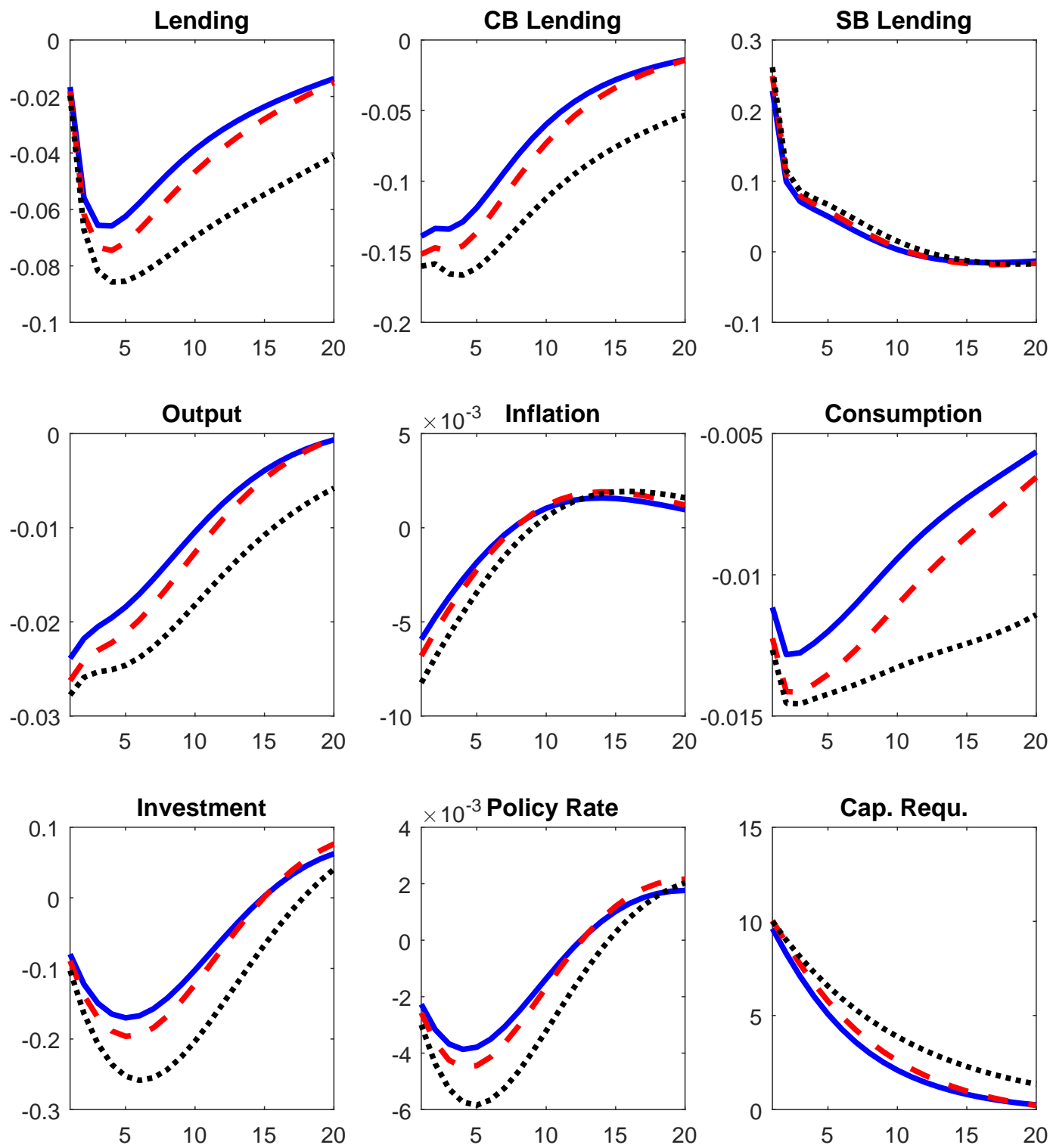

Moderate Regulator $=\quad$ - Prudent Regulator ....... No Regulator

Note: Impulse responses to a one-standard-deviation capital requirement shock. Rates in absolute deviations from steady state, all other variables as percentage deviations from steady state.

Tighter macroprudential regulation reduces overall lending activity and ultimately, due to lower credit supply, dampens economic activity. Lower aggregate demand reduces inflation, and monetary policy consequently responds by lowering interest rates. The macroprudential regulator counteractively responds to the unanticipated monetary policy change, thereby counteracting adverse macroeconomic effects to some degree. 
Whereas overall lending is reduced by increased bank capital requirements, lower credit intermediation by commercial banks is partly offset by increased shadow bank activity. Due to the leakage mechanism laid out in detail in the Online Appendix, higher capital requirements result in a deviation of actual capital-to-asset ratios held by commercial banks from the regulatory requirement and increase the cost of intermediation for commercial banks (equation 10). The resulting reduction of commercial bank credit and initially unaffected demand for credit by entrepreneurs and deposit supply by households leads to a less binding leverage constraint for shadow banks (equation 13). Ultimately, intermediation activity by shadow banks increases. ${ }^{42}$

The different degree of shadow bank consideration by policymakers has implications for the development of both credit and macroeconomic variables in the model. Following an unanticipated rise in capital requirements, a moderate regulator only concerned with the development of commercial bank credit would pursue a path of more rapid policy normalization compared to the case of no countercyclical regulation. In return, the drop in commercial bank lending is less pronounced on impact compared to the baseline case and credit returns more rapidly to its steady-state level. Therefore, the reduction in overall credit is relatively smaller in the case of the moderate regulator, and the described losses in aggregate demand are weaker. Inflation is reduced to a lesser extent and monetary policy reacts less aggressively in the case of less stringent regulations.

In contrast, a regulator not only concerned with commercial bank but also with shadow bank credit would keep higher capital requirements for a longer period and only return to the steady state level of capital requirements after some 20 periods. Therefore, the implied period of lower lending activity by commercial banks (and thus overall lending), with respective dampening effects on aggregate demand and inflation, turns out to be more pronounced compared to case of the moderate regulation case.

\subsubsection{Impulse Responses: Policy Coordination}

In the two preceding policy exercises, unexpected tightening by one policymaker triggered counteractive measures implemented by the other to mitigate adverse effects on price stability and output. Furthermore, tighter regulation and monetary policy initiated leakage towards the unregulated part of the financial system, the shadow banking sector. Both observations indicate a potential role for coordination among policymakers to mitigate dampening macroeconomic implications of tighter regulation and, in particular, to limit the unintended consequence of increased shadow bank intermediation - with potentially

\footnotetext{
${ }^{42} \mathrm{~A}$ similar rational for credit leakage effects in response to tighter regulation is provided in Aikman et al. (2018).
} 
adverse effects for financial stability - in response to tighter banking regulation. ${ }^{43}$

In the following exercise, we evaluate to what extent a coordinated reaction using monetary policy could limit the increase in shadow bank lending in response to tighter bank capital regulation in our model setup. Higher capital requirements indeed reduced lending activity by commercial banks and overall lending in the analysis of the previous section. However, the contemporaneous increase in shadow bank lending depicts a limitation of macroprudential policy efficiency. First, the intended reduction in lending activity is partly counteracted by an increase in shadow bank intermediation, resulting in a lower reduction in overall lending compared to a situation without shadow bank intermediation. Second, an increase in shadow bank lending potentially increases financial instability as a relatively larger share of intermediation is now conducted by unregulated financial institutions.

To discuss benefits from policy coordination in light of the limits on macroprudential regulation emerging from the existence of shadow banks, we evaluate whether monetary policy can be employed to avoid leakage of credit intermediation towards shadow banks. Whereas capital requirements can only be employed with respect to commercial banks, interest rates depict an universal tool that can be used to reach "all the cracks in the economy" (Stein, 2013). In this respect, we try to trace out the necessary monetary policy response to keep shadow bank intermediation at its steady-state level in response to the same capital requirement shock we discussed in the previous section.

Figure 3 depicts impulse responses to an unanticipated increase in commercial bank capital requirements by one percentage point followed by a contemporaneous response by the central bank that mitigates shadow bank intermediation. In the simulation, the reaction in shadow bank lending is negligible as the central bank lowers interest rates aggressively in response to tighter regulation. As indicated in section 6.2.1, commercial bank credit reacts inversely to monetary policy, and therefore the decrease in commercial bank lending is less pronounced in Figure 3 compared to the reduction in Figure 2. Therefore, even though monetary policy partly counteracts the intended reduction in overall lending stemming from an increase in capital requirements, it can help to mitigate potentially undesired leakage towards shadow banks as a side effect of tighter bank regulation, at the expense of a slightly less effective reduction of lending activity in the model simulation.

\footnotetext{
${ }^{43}$ Increasing shadow bank intermediation does not per se depict an undesired development. In some circumstances, technological advances as well as lower dependency on regulatory and institutional provisions of non-bank financial institutions can increase the efficiency in the intermediation process and increase overall welfare in the economy (Buchak et al., 2018; Ordonez, 2018). However, higher shares of intermediation being conducted by unregulated shadow institutions potentially increases risks to financial stability, which appears to be the predominant argument in the discussion on shadow banking in advanced economies.
} 
Figure 3: Impulse Responses: Policy Coordination
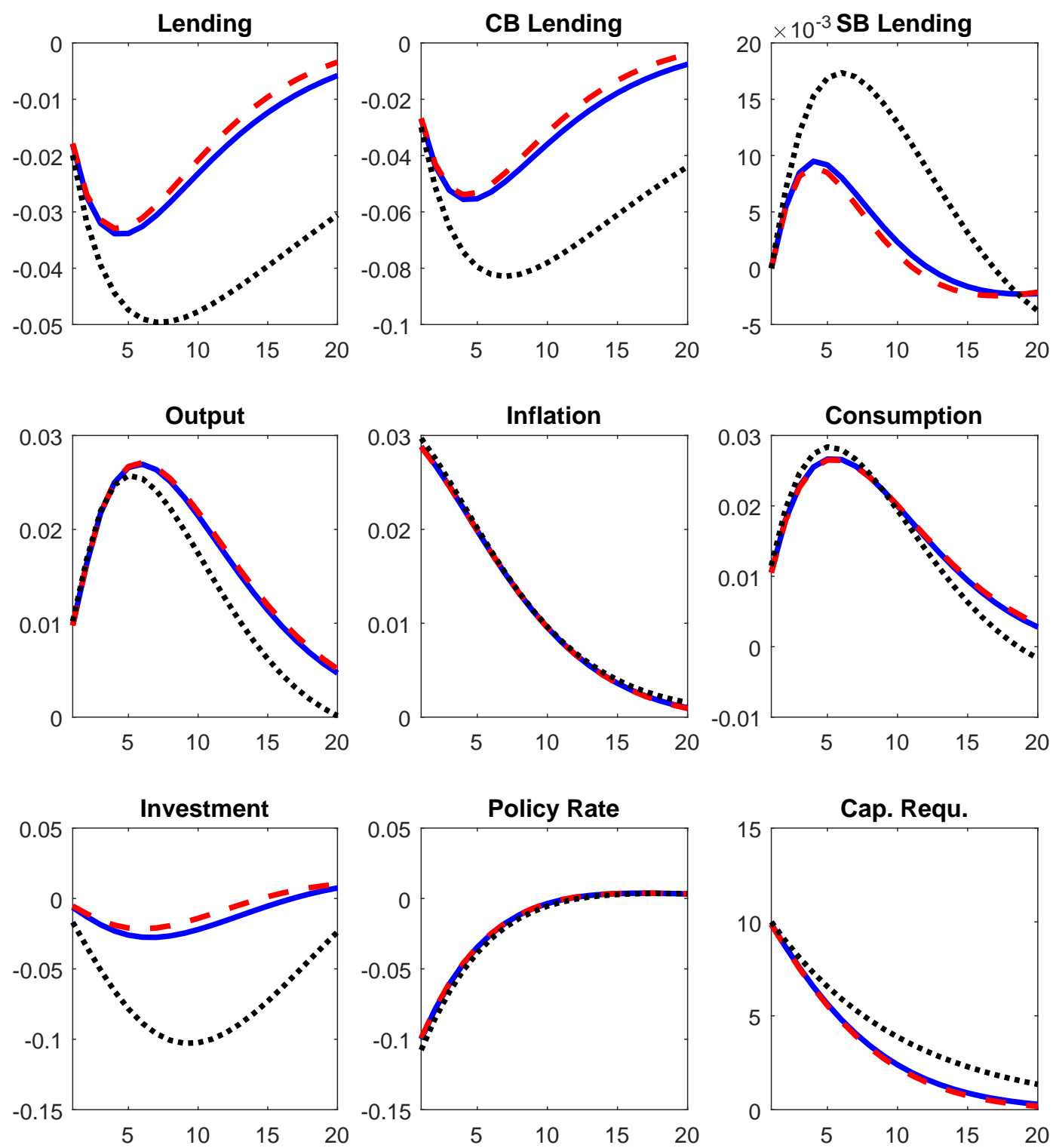

Moderate Regulator $=$ - Prudent Regulator ....... No Regulator

Note: Impulse responses to a one-standard-deviation capital requirement shock. Rates in absolute deviations from steady state, all other variables as percentage deviations from steady state.

\subsection{Counterfactual Simulation}

Finally, we evaluate how euro area regulators considering shadow banking to different degree would have set capital requirements under Basel III, if the framework would have been in place already in 1999 and throughout the existence of the common currency. For all regulatory regimes, we use the identified shock processes from the estimation of the 
Figure 4: Counterfactual Analysis: Different Regulatory Regimes

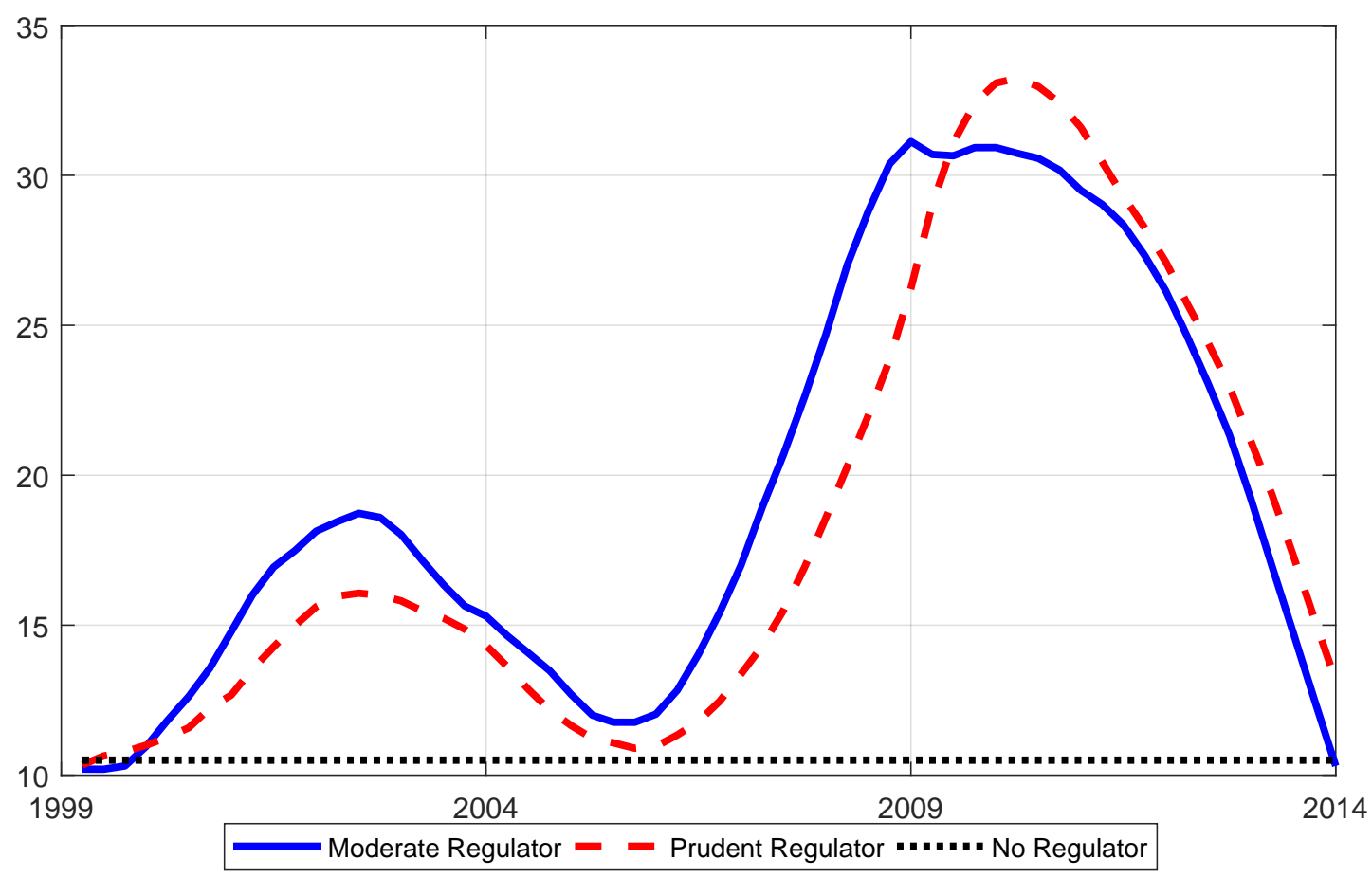

Note: Simulated path of capital requirements based on shock series identified in estimation of section 5 and for different regulators of section 6.1.

baseline model (section 5) to simulate the evolution of endogenous model variables over the period 1999 - 2014 and derive a time series of hypothetical capital requirements the respective regulator would have set in response. The respective time series for the three regulators are reported in Figure 4.

Both the moderate and the prudent regulator would have applied some form of countercyclical regulation by reducing capital requirements in times of financial distress and raising requirement in phases of excessive lending by commercial banks. All rules would have furthermore prescribed a sharp tightening of credit standards from the mid-2000s onwards, in response to massive credit growth in the European banking sector. Over the course of the global financial crisis starting in 2008 and the following European debt crisis, both regulators would have prescribed a sharp reduction in capital requirements due to subdued lending activity in the euro area.

Thereby, the moderate regulator would have raised capital requirements more aggressively in the years preceding the 2008 financial crisis compared to the moderate regulator. As the moderate regulator is only concerned with movements in the commercial bank credit, he would have raised capital requirements in response to a sharp increase in commercial bank lending in these years, neglecting the contemporaneous rise in shadow banking in the same years. In doing so, the moderate regulator neglects potential leakage 
towards shadow banking when tightening regulation and risks an even stronger increase in shadow bank lending as observed empirically in these years. In contrast, due to a potential leakage of credit towards the shadow banking sector, the prudent regulator adjusts capital requirements more moderately in response to movements in overall credit in the runup to the financial crisis. In this respect, acknowledging shadow banking can prevent regulators from raising capital requirements whenever they are concerned with increasing financial instability resulting from a larger share of shadow bank intermediation. In a situation of increased economic and financial activity, as in the years preceding the financial crisis in the euro area, financial stability concerns related to credit leakage in the shadow banking sector can actually prevent regulators from increasing capital requirements. At the same time, considering overall credit instead of commercial bank credit alone as the target variable for commercial bank capital requirements results in smoother path of capital adjustment, which should ultimately reduce macroeconomic volatility in response to policy changes.

Acknowledging the existence of shadow banking and the resulting tradeoff for financial regulation therefore requires a detailed understanding of the exact transmission mechanism of financial regulation, with the optimal level of capital requirements depending on the weight given to the concern of credit leakage towards shadow banks. Considering nonbank financial intermediation in regulation for commercial banks can, on the one side, result in lower leakage of credit towards unregulated institutions, but on the other side, if not supported by coordinated measures by other policy institutions, result in a less resolute policy response in reaction to an increase in overall credit. As shown in section 6.2.3, monetary policy can play an active role in mitigating shadow bank intermediation, and play a crucial part whenever leakage concerns limit the scope for tighter banking regulation.

\section{Conclusion}

We develop a DSGE model featuring two different types of financial intermediaries: regulated commercial banks and unregulated shadow banks. Methodologically, we combine two seminal strands of the literature for modeling financial frictions that were independently developed in recent years. In doing so, we exploit differences with respect to market power and regulatory coverage in the two frameworks and argue that they can be applied to structurally different financial institutions.

We highlight the key mechanism of bank capital requirements and evaluate how tighter regulation of commercial credit intermediation can result in higher intermediation activity by unregulated shadow banks. We estimate the structural parameters of the model via Bayesian methods using euro area data on both commercial and shadow banks. 
We use our estimated model to evaluate quantitative responses of macroeconomic variables to unexpected changes in macroprudential and monetary policy. We find that macroprudential tightening leads to a reduction in commercial bank credit, but increases intermediation by shadow banks. If a macroprudential rule is employed, this leakage mechanism can be reduced, but not eliminated.

Whereas capital requirements can only be employed with respect to commercial banks, interest rates depict a universal tool to reach though "all the cracks in the economy" (Stein, 2013). We evaluate whether monetary policy can be employed to counteract the leakage mechanism in a coordinated macroprudential and monetary interaction scenario. Even though monetary easing partly counteracts the intended reduction in overall lending stemming from an increase in capital requirements, it can help to mitigate potentially undesired leakage towards shadow banks as a side effect of tighter bank regulation.

We furthermore evaluate in a counterfactual analysis how regulation would have been set had it followed Basel III rules, and how this would have affected macro indicators through the global financial recession and the sovereign debt crisis. We evaluate three different types of regulators, ranging from completely ignoring shadow banking to an explicit consideration of shadow bank credit in the policy rule. We find macroprudential tightening during episodes of credit increases, and easing during credit crunches, generally reduces the volatility of the business cycle, and thereby likely promotes household welfare. 


\section{References}

Adrian, T. (2014). Financial Stability Policies for Shadow Banking. Federal Reserve Bank of New York Staff Report, (664).

Adrian, T. and Liang, N. (2014). Monetary Policy, Financial Conditions, and Financial Stability. Federal Reserve Bank of New York Staff Report, (690).

Aikman, D., Giese, J., Kapadia, S., and McLeay, M. (2018). Targeting Financial Stability: Macroprudential or Monetary Policy? Bank of England Staff Working Paper, (734).

Allen, F. and Gale, D. (2000). Financial Contagion. Journal of Political Economy, 108(1):1-33.

Altunbas, Y., Gambacorta, L., and Marques-Ibanez, D. (2009). Securitisation and the bank lending channel. European Economic Review, 53(8):996-1009.

Angelini, P., Neri, S., and Panetta, F. (2014). The Interaction between Capital Requirements and Monetary Policy. Journal of Money, Credit and Banking, 46(6):1073-1112.

Angeloni, I. and Faia, E. (2013). Capital Regulation and Monetary Policy with Fragile Banks. Journal of Monetary Economics, 60(2013):311-324.

Bakk-Simon, K., Borgioli, S., Giron, C., Hempell, H., Maddaloni, A., Recine, F., and Rosati, S. (2012). Shadow Banking in the Euro Area - An Overview. ECB Occasional Paper Series, (133).

Bean, C., Paustian, M., Penalver, A., and Taylor, T. (2010). Monetary Policy After the Fall. Bank of England Working Paper.

Beau, D., Clerc, L., and Mojon, B. (2012). Macro-Prudential Policy and the Conduct of Monetary Policy. Banque de France Working Paper, (390).

Begenau, J. and Landvoigt, T. (2016). Financial Regulation in a Quantitative Model of the Modern Banking System. Working Paper.

Borio, C. (2003). Towards a Macroprudential Framework for Financial Supervision and Regulation? CESifo Economic Studies, 49(2):181-215.

Borio, C. (2009). Implementing the Macroprudential Approach to Financial Regulation and Supervision. Financial Stability Review, 13:31-41.

Borio, C. (2011). Rediscovering the Macroeconomic Roots of Financial Stability Policy: Journey, Challenges, and a Way Forward. Annual Review of Financial Economics, $3(1): 87-117$. 
Borio, C. and Shim, I. (2007). What Can (Macro)-Prudential Policy Do to Support Monetary Policy? BIS Working Papers, 242.

Brooks, S. P. and Gelman, A. (1998). General Methods for Monitoring Convergence of Iterative Simulations. Journal of Computational and Graphical Statistics, 7(4):434-455.

Buchak, G., Matvos, G., Piskorski, T., and Seru, A. (2018). Fintech, regulatory arbitrage, and the rise of shadow banks. Journal of Financial Economics (forthcoming).

Calvo, G. A. (1983). Staggered Prices in a Utility-Maximizing Framework. Journal of Monetary Economics, 12(3):383-398.

Chen, N.-K. (2001). Bank Net Worth, Asset Prices and Economic Activity. Journal of Monetary Economics, 48(2001):415-436.

Christensen, I., Meh, C., and Moran, K. (2011). Bank Leverage Regulation and Macroeconomic Dynamics. Bank of Canada Working Paper, (2011-32).

Christiano, L. J., Eichenbaum, M. S., and Evans, C. L. (2005). Nominal Rigidities and the Dynamic Effects of a Shock to Monetary Policy. Journal of Political Economy, 113(1):1-44.

Cizel, J., Frost, J., Houben, A. G. F. J., and Wierts, P. (2016). Effective Macroprudential Policy; Cross-Sector Substitution from Price and Quantity Measures. IMF Working Papers 16/94, International Monetary Fund.

Coeuré, B. How binding is the zero lower bound? Speech at the conference "Removing the zero lower bound on interest rates", London, 18 May 2015.

Collard, F., Dellas, H., Diba, B., and Loisel, O. (2014). Optimal Monetary and Prudential Policies. Banque de France Working Paper, (413).

Cúrdia, V. and Woodford, M. (2010a). Conventional and Unconventional Monetary Policy. Federal Reserve Bank of St. Louis Review, 92:229-264.

Cúrdia, V. and Woodford, M. (2010b). Credit Spreads and Monetary Policy. Journal of Money, Credit and Banking, 42(s1):3-35.

Cúrdia, V. and Woodford, M. (2011). The Central-Bank Balance Sheet as an Instrument of Monetary Policy. Journal of Monetary Economics, 58(1):54-79.

De Bandt, O. and Davis, E. P. (2000). Competition, Contestability and Market Structure in European Banking Sectors on the Eve of EMU. Journal of Banking and Finance, 24(6):1045-1066. 
Den Haan, W. J. and Sterk, V. (2011). The Myth of Financial Innovation and the Great Moderation. The Economic Journal, 121(553):707-739.

Doyle, N., Hermans, L., Molitor, P., and Weistroffer, C. (2016). Shadow Banking in the Euro Area: Risks and Vulnerabilities in the Investment Fund Sector. ECB Occasional Paper Series, (174).

Farhi, E. and Tirole, J. (2017). Shadow Banking and the Four Pillars of Traditional Financial Intermediation. NBER Working Paper, (23930).

Fève, P. and Pierrard, O. (2017). Financial Regulation and Shadow Banking: A SmallScale DSGE Perspective. TSE Working Paper, 17-829.

FSB (2011). Shadow Banking: Scoping the Issues. A Background Note of the Financial Stability Board, (12).

FSB (2017). Assessment of Shadow Banking Activities, Risks and the Adequacy of PostCrisis Policy Tools to Address Financial Stability Concerns. Report to the G20, (July).

Fungáčová, Z., Solanko, L., and Weill, L. (2014). Does Competition Influence the Bank Lending Channel in the Euro Area? Journal of Banking and Finance, 49:356-366.

Gambacorta, L. and Signoretti, F. M. (2014). Should Monetary Policy Lean Against the Wind?: An Analysis Based on a DSGE Model With Banking. Journal of Economic Dynamics and Control, 43(June):146-174.

Gebauer, S. (2019). Welfare-Based Optimal Macroprudential Policy with Shadow Banks. mimeo.

Gelain, P. and Ilbas, P. (2014). Monetary and Macroprudential Policies in an Estimated Model with Financial Intermediation. National Bank of Belgium Working Paper, (258).

Gerali, A., Neri, S., Sessa, L., and Signoretti, F. M. (2010). Credit and Banking in a DSGE Model for the Euro Area. Journal of Money, Credit and Banking, 42(1):107-141.

Gertler, M. and Karadi, P. (2011). A Model of Unconventional Monetary Policy. Journal of Monetary Economics, 58(1):17-34.

Gertler, M. and Kiyotaki, N. (2011). Financial Intermediation and Credit Policy in Business Cycle Analysis. In Friedman, B. M. and Woodford, M., editors, Handbook of Monetary Economics. Elsevier.

Gertler, M. and Kiyotaki, N. (2015). Banking, Liquidity, and Bank Runs in an Infinite Horizon Economy. American Economic Review, 105(7):2011-2043. 
Gertler, M., Kiyotaki, N., and Prestipino, A. (2016). Wholesale Banking and Bank Runs in Macroeconomic Modelling of Financial Crises. In Taylor, J. B. and Uhlig, H., editors, Handbook of Macroeconomics. Elsevier.

Harris, M., Opp, C. C., and Opp, M. M. (2014). Higher Capital Requirements, Safer Banks? - Macroprudential Regulation in a Competitive Financial System. Chicago Booth Working Paper.

Holström, B. and Tirole, J. (1997). Financial Intermediation, Loanable Funds, and the Real Sector. The Quarterly Journal of Economics, 112(3):663-691.

Hristov, N., Hülsewig, O., and Wollmershäuser, T. (2014). The Interest Rate Pass-Through in the Euro Area During the Global Financial Crisis. Journal of Banking and Finance, 48:104-119.

Iacoviello, M. (2005). House Prices, Borrowing Constraints, and Monetary Policy in the Business Cycle. American Economic Review, 95(3):739-764.

Iacoviello, M. and Guerrieri, L. (2017). Collateral Constraints and Macroeconomic Asymmetries. Journal of Monetary Economics, 90:28-49.

Igan, D., Kabundi, A., Nadal de Simone, F., and Tamirisa, N. (2013). Monetary Policy and Balance Sheets. IMF Working Paper, (13/158).

Irani, R. M., Iyer, R., Meisenzahl, R. R., and Peydró, J.-L. (2018). The Rise of Shadow Banking: Evidence from Capital Regulation. Federal Reserve Board of Governors Finance and Economics Discussion Series, (2018-039).

Kiyotaki, N. and Moore, J. (2012). Liquidity, Business Cycles, and Monetary Policy. NBER Working Paper, (17934).

Kroszner, R. (2010). Interconnectedness, Fragility and the Financial Crisis. In Mimeograph The University of Chicago Booth School of Business, prepared for Financial Crisis Forum Financial Crisis Inquiry Commission, Washington DC, February.

Malatesta, F., Masciantonio, S., and Zaghini, A. (2016). The Shadow Banking System in the Euro Area: Definitions, Key Features and the Funding of Firms. Italian Economic Journal, pages 1-21.

Mazelis, F. (2016). Implications of Shadow Bank Regulation for Monetary Policy at the Zero Lower Bound. Working Paper.

Meeks, R. and Nelson, B. (2017). Shadow Banks and Macroeconomic Instability. Journal of Money, Credit and Banking, 49(1):1483-1516. 
Meh, C. and Moran, K. (2010). The Role of Bank Capital in the Propagation of Shocks. Journal of Economic Dynamics and Control, 34(3):555-576.

Nelson, B., Pinter, G., and Theodoridis, K. (2015). Do Contractionary Monetary Policy Shocks Expand Shadow Banking? Bank of England Working Paper.

Ordonez, G. (2018). Sustainable Shadow Banking. American Economic Journal: Macroeconomics, 10(1):33-56.

Pescatori, A. and Sole, J. (2016). Credit, Securitization and Monetary Policy: Watch Out for Unintended Consequences. IMF Working Paper, (16/76).

Plantin, G. (2015). Shadow Banking and Bank Capital Regulation. Review of Financial Studies, 28(1):146-175.

Pozsar, Z., Adrian, T., Ashcraft, A., and Boesky, H. (2010). Shadow Banking. Federal Reserve Bank of New York Staff Report, (458).

Ratto, M. and Iskrev, N. (2011). Identification Analysis of DSGE Models wwith DYNARE. MONFISPOL, 225149.

Silvo, A. (2015). The Interaction of Monetary and Macroprudential Policies in Economic Stabilisation. HECER Discussion Papers, (395).

Smets, F. and Wouters, R. (2003). An Estimated Dynamic Stochastic General Equilibrium Model of the Euro Area. Journal of the European Economic Association, 1(5):1123-1175.

Smets, F. and Wouters, R. (2007). Shocks and Frictions in US Business Cycles: A Bayesian DSGE Approach. American Economic Review, 97(3):586-606.

Stein, J. C. (2013). Overheating in credit markets: Origins, measurement and policy responses. Remarks at a Research Symposium sponsored by the Federal Reserve Bank of St. Louis.

Verona, F., Martins, M. M., and Drumond, I. (2013). (Un)anticipated Monetary Policy in a DSGE Model with a Shadow Banking System. International Journal of Central Banking, 9(3):78-124.

Von Borstel, J., Eickmeier, S., and Krippner, L. (2016). The Interest Rate Pass-Through in the Euro Area During the Sovereign Debt Crisis. Journal of International Money and Finance, 68:386-402. 


\section{A Appendix: The Full Nonlinear DSGE Model}

\section{A.1 Households}

The representative patient household $i$ maximizes the expected utility

$$
E_{0}=\sum_{t=0}^{\infty} \beta_{P}^{t}\left[\left(1-a^{P}\right) \varepsilon_{t}^{z} \log \left(c_{t}^{P}(i)-a^{P} c_{t-1}^{P}\right)-\frac{l_{t}^{P}(i)^{1+\phi^{P}}}{1+\phi^{P}}\right]
$$

which depends on current individual consumption $\left(c_{t}^{P}(i)\right)$ as well as lagged aggregate consumption $\left(c_{t}^{P}\right)$ and working hours $l_{t}^{P}$. Labor disutility is parameterized by $\phi^{P}$. Preferences are subject to a disturbance affecting consumption $\left(\varepsilon_{t}^{z}\right)$. Household choices are undertaken subject to the budget constraint:

$$
c_{t}^{P}(i)+d_{t}^{P, C}(i)+d_{t}^{P, S}(i) \leq w_{t} l_{t}^{P}(i)+\left(1+r_{t-1}^{d C}\right) d_{t-1}^{P, C}(i)+\left(1+r_{t-1}^{d S}\right) d_{t-1}^{P, S}(i)+t_{t}^{P}(i)
$$

The flow of expenses includes current consumption and real deposits to be made to both commercial and shadow banks, $d_{t}^{P, C}(i)$ and $d_{t}^{P, S}(i)$. Due to the difference in the discount factor for households $\left(\beta_{P}^{t}\right)$ and entrepreneurs $\left(\beta_{E}^{t}\right)$, households only place deposits, but do not borrow any funds from financial market agents. Resources consist of wage earnings $w_{t}^{P} l_{t}^{P}(i)$ (where $w_{t}$ is the real wage rate for the labor input of each household), gross interest income on last period deposits $\left(1+r_{t-1}^{d C}\right) d_{t-1}^{P, C}(i)$ and $\left(1+r_{t-1}^{d S}\right) d_{t-1}^{P, S}(i)$, and lumpsum transfers $t_{t}^{P}$ that include dividends from firms and banks (of which patient households are the ultimate owners). First-order conditions yield the consumption Euler equation and labor-supply condition:

$$
\begin{gathered}
\frac{\varepsilon_{t}^{z}}{c_{t}^{P}(i)}=\beta_{P}^{t} E_{t}\left[\frac{1+r^{d C}}{c_{t+1}^{P}(i)}\right] \\
l_{t}^{P}(i)^{\phi^{P}}=\frac{w_{t}}{c_{t}^{P}(i)}
\end{gathered}
$$

\section{A.2 Entrepreneurs}

Entrepreneurs use labor provided by households as well as capital to produce intermediate goods that retailers purchase in a competitive market. Each entrepreneur $i$ derives utility from consumption $c_{t}^{E}(i)$, which it compares to the lagged aggregate consumption level of all entrepreneurs. He maximizes expected utility

$$
E_{0} \sum_{t=0}^{\infty} \beta_{E}^{t} \log \left(c_{t}^{E}(i)-a^{E} c_{t-1}^{E}\right)
$$


by choosing consumption, the use of physical capital $k_{t}^{E}$, loans from both commercial and shadow banks $\left(b_{t}^{E, C}, b_{t}^{E, S}\right)$, and labor input from households. He faces the following budget constraint:

$$
\begin{aligned}
c_{t}^{E}(i)+w_{t} l_{t}^{P}(i)+\left(1+r_{t-1}^{b}\right) b_{t-1}^{E, C}(i) & +\left(1+r_{t-1}^{b}\right) b_{t-1}^{E, S}(i)+q_{t}^{k} k_{t}^{E}(i) \\
= & \frac{y_{t}^{E}(i)}{x_{t}}+b_{t}^{E, C}(i)+b_{t}^{E, S}(i)+q_{t}^{k}(1-\delta) k_{t-1}^{E}(i)
\end{aligned}
$$

with $\delta$ depicting the depreciation rate of capital and $q_{t}^{k}$ the market price for capital in terms of consumption. As we assume that intermediate goods are sold on a wholesale market at price $P_{t}^{w}$ and are transformed by retailers in a composite final good whose price index is $P_{t}$, we define $x_{t} \equiv \frac{P_{t}}{P_{t}^{w}}$ as the price markup of the final over the intermediate good. We thus express output produced by the entrepreneur $\left(y_{t}^{E}\right)$ in terms of the relative competitive price of the wholesale good, given by $\frac{1}{x_{t}}$ and which is produced according to the Cobb-Douglas technology

$$
y_{t}^{E}(i)=A_{t}^{E} k_{t-1}^{E}(i)^{\alpha} l_{t}^{E}(i)^{1-\alpha}
$$

where the (stochastic) total factor productivity (TFP) is given by $A_{t}^{E}$.

Entrepreneurs face constraints on the amount they can borrow from commercial and shadow banks as discussed in section 3 :

$$
\begin{gathered}
\left(1+r_{t}^{b c}\right) b_{t}^{E, C}(i) \leq m_{t}^{C} E_{t}\left[q_{t+1}^{k}(1-\delta) k_{t}^{E}(i)\right] \\
\left(1+r_{t}^{b s}\right) b_{t}^{E, S}(i) \leq\left(1-m_{t}^{C}\right) E_{t}\left[q_{t+1}^{k}(1-\delta) k_{t}^{E}(i)\right]
\end{gathered}
$$

where the LTV ratio for commercial banks $m_{t}^{C}$ set exogenously by the regulator and follows an exogenous $\mathrm{AR}(1)$ process.

\section{A.3 Banks}

In our model, we have two financial market agents that intermediate funds between households and firms: commercial banks and shadow banks. While they both engage in intermediation in a similar fashion, we assume the two types of agents to be structurally different along various dimensions, as discussed in section 3 . 


\section{A.3.1 Commercial Banks}

In the following, we discuss the maximization problem of the wholesale unit of the commercial bank as the capital requirement set by regulators applies directly to this branch of the commercial bank. Due to space limitations, we will not discuss the maximization problems of the retail deposit and loan branches here as they are identical to the problems outlined in Gerali et al. (2010) and refer to their study.

Wholesale Unit The wholesale branches of commercial banks operate under perfect competition and are responsible for the capital position of the respective commercial bank. On the asset side, they hold funds they provide to the retail loan branch, $b_{t}^{C}$, which ultimately lends these funds to entrepreneurs at a markup in the form of loans, $b_{t}^{E, C}$. On the liability side, it combines commercial bank net worth, or capital, $k_{t}^{C}$, with wholesale deposits, $d_{t}^{C}$, that are provided by the retail deposit branch, but originally stem from deposits placed in the retail branch by patient households $\left(d_{t}^{P, C}\right)$. The wholesale bank balance sheet is thus given by

$$
b_{t}^{C}=k_{t}^{C}+d_{t}^{C}
$$

Furthermore, the capital position of the wholesale branch is prone to a regulatory capital requirement, $\nu_{t}^{C}$. Moving away from the regulatory requirement imposes a quadratic $\operatorname{cost} c_{t}^{C}$ to the bank, which is proportional to the outstanding amount of bank capital and parameterized by $\kappa_{k}^{C}$ :

$$
c_{t}^{C}=\frac{\kappa_{k}^{C}}{2}\left(\frac{k_{t}^{c}}{b_{t}^{C}}-\nu_{t}^{C}\right)^{2} k_{t}^{C}
$$

The wholesale branch thus maximizes the discounted sum of real cash flows:

$$
\begin{array}{r}
\mathcal{L}^{w}=\max _{b_{t}^{C}, d_{t}^{C}} E_{0} \sum_{t=0}^{\infty} \Lambda_{0, t}^{P}\left[\left(1+r_{t}^{C}\right) b_{t}^{C}-b_{t+1}^{C} \Pi_{t+1}+d_{t+1}^{C} \Pi_{t+1}-\left(1+r_{t}^{d C}\right) d_{t}^{C}+\right. \\
\left.+\left(k_{t+1}^{C} \Pi_{t+1}-k_{t}^{C}\right)-\frac{\kappa_{k}^{C}}{2}\left(\frac{k_{t}^{C}}{b_{t}^{C}+b_{t}^{S}}-\nu_{t}^{C}\right)^{2} k_{t}^{C}\right]
\end{array}
$$

where we assume the net wholesale loan rate $r_{t}^{C}$ and the deposit rate $r_{t}^{d C}$ to be given from the perspective of the maximizing bank. We can use the objective together with the balance sheet constraint B.10 to get:

$$
r_{t}^{C} b_{t}^{C}-r_{t}^{d C} d_{t}^{C}-\frac{\kappa_{k}^{C}}{2}\left(\frac{k_{t}^{C}}{b_{t}^{C}}-\nu^{C}\right)^{2} k_{t}^{C}
$$


We can thus express the maximization problem as:

$$
\mathcal{L}^{w}=\max _{b_{t}^{C}, d_{t}^{C}} r_{t}^{C} b_{t}^{b}-r_{t}^{d C} d_{t}^{C}-\frac{\kappa_{k}^{C}}{2}\left(\frac{k_{t}^{C}}{b_{t}^{C}}-\nu_{t}^{C}\right)^{2} k_{t}^{C}
$$

The first-order conditions yield the following expression:

$$
r_{t}^{b}=r_{t}^{d C}-\kappa_{k}^{C}\left(\frac{k_{t}^{C}}{b_{t}^{C}}-\nu_{t}^{C}\right)\left(\frac{k_{t}^{C}}{b_{t}^{C}}\right)^{2}
$$

As the commercial bank has access to central bank funding in the model, we assume that the rate paid on wholesale deposits gathered from the retail deposit unit of the commercial bank (and so originally from households and firms) has to be equal to the risk-free policy rate, $r_{t}$, by arbitrage:

$$
r_{t}^{d C}=r_{t}
$$

such that the spread between the loan and deposit rates on the wholesale level is given by

$$
r_{t}^{b}-r_{t}=-\kappa_{k}^{C}\left(\frac{k_{t}^{C}}{b_{t}^{C}}-\nu_{t}^{C}\right)\left(\frac{k_{t}^{C}}{b_{t}^{C}}\right)^{2}
$$

Assuming symmetry between banks and reinvestment of profits in banks, aggregate bank capital $K_{t}^{C}$ is accumulated from retained earnings only:

$$
K_{t}^{C}=\left(1-\delta^{C}\right) K_{t-1}^{C}+J_{t-1}^{C}
$$

where $J_{t}^{C}$ depicts aggregate commercial bank profits derived from the three branches of the bank, see Gerali et al. (2010). Capital management costs are captured by $\delta^{C}$.

\section{A.3.2 Shadow Banks}

The balance sheet of each shadow bank $j$ in each period is given by

$$
q_{t}^{k} b_{t}^{E, S}(j)=d_{t}^{P, S}(j)+k_{t}^{S}(j)
$$

where the asset side is given by the funds lend to entrepreneurs, $b_{t}^{E, S}(j)$, multiplied with the relative price for these claims, $q_{t}^{k}$. Shadow banks' liabilities consist of household deposits $d_{t}^{P, S}(j)$ and net worth, or shadow bank capital $k_{t}^{S}(j)$.

Shadow bankers earn an interest rate on their claims $r_{t}^{b S}$. The net profits of shadow banks, i.e. the difference between real earnigns on financial claims and real interest payments to depositors, determine the evolution of shadow bank capital: 


$$
k_{t+1}^{S}(j)=\left(1+r_{t}^{b S}\right) q_{t}^{k} b_{t}^{E, S}(j)-\left(1+r_{t}^{d S}\right) d_{t}^{P, S}(j)
$$

or

$$
k_{t+1}^{S}(j)=\left(r_{t}^{b S}-r_{t}^{d S}\right) q_{t}^{k} b_{t}^{E, S}(j)+\left(1+r_{t}^{d S}\right) k_{t}^{S}(j)
$$

For the shadow banker, as long as the real return on lending, $\left(r_{t}^{b S}-r_{t}^{d S}\right)$ is positive, it is profitable to accumulate capital until it exits the shadow banking sector. Thus, the shadow bank's objective to maximize expected terminal wealth, $v_{t}(j)$, is given by

$$
v_{t}(j)=\max E_{t} \sum_{i=0}^{\infty}\left(1-\sigma^{S}\right) \sigma^{S^{i}} \beta^{S^{i+1}} k_{t+1+i}^{S}(j)
$$

or

$$
v_{t}(j)=\max E_{t} \sum_{i=0}^{\infty}\left(1-\sigma^{S}\right) \sigma^{S^{i}} \beta^{S^{i+1}}\left[\left(r_{t+i}^{b S}-r_{t+i}^{d S}\right) q_{t+i}^{k} b_{t+i}^{E, S}(j)+\left(1+r_{t+i}^{d S}\right) k_{t+i}^{S}(j)\right]
$$

We introduce a moral hazard probelmas discussed in section 3. Diverting funds and 'running away' is equivalent to declaring bankruptcy for the shadow bank, such that it will only do so if the return of declaring bankruptcy is larger than the discounted future return from continuing and behaving honestly:

$$
v_{t}(j) \geq \theta^{S} q_{t}^{k} b_{t}^{E, S}(j)
$$

Equation B.22 is the infinite-horizon incentive constraint in the two-period model the shadow banker faces when demanding funds from households. Following Gertler and Karadi (2011), we can rewrite it as:

$$
v_{t}(j)=\nu_{t}^{S} q_{t}^{k} b_{t}^{E, S}(j)+\eta_{t}^{S} k_{t}^{S}(j)
$$

with

$$
\nu_{t}^{S}=E_{t}\left\{\left(1-\sigma^{S}\right) \beta^{S}\left(r_{t}^{b S}-r_{t}^{d S}\right)+\beta^{S} \sigma^{S} \chi_{t, t+1}^{S} \nu_{t+1}^{S}\right\}
$$

and

$$
\eta_{t}^{S}=E_{t}\left\{\left(1-\sigma^{S}\right)+\beta^{S} \sigma^{S} z_{t, t+1}^{S} \eta_{t+1}^{S}\right\}
$$


where $\chi_{t, t+i}^{S} \equiv \frac{q_{t+i}^{k} b_{t+i}^{E, S}(j)}{q_{t}^{k} b_{t}^{E, S}(j)}$ depicts the gross growth rate in financial claims between $t$ and $t+i$, whereas $z_{t, t+i}^{S} \equiv \frac{k_{t+i}^{S}(j)}{k_{t}^{S}(j)}$ determines the gross growth rate of shadow bank capital. With these definitions, we can express the incentive constraint as

$$
\eta_{t}^{S} k_{t}^{S}(j)+\nu_{t}^{S} q_{t}^{k} b_{t}^{E, S}(j) \geq \theta^{S} q_{t}^{k} b_{t}^{E, S}(j)
$$

With constraint B.26 being binding, bank capital determines the amount that the shadow banker can lend out:

$$
q_{t}^{k} b_{t}^{E, S}(j)=\frac{\eta_{t}^{S}}{\theta^{S}-\nu_{t}^{S}} k_{t}^{S}(j)=\phi_{t}^{S} k_{t}^{S}(j)
$$

where $\phi_{t}^{S}$ is the asset-to-capital ratio, or the shadow bank leverage ratio. As shadow banks' incentive to divert funds increases with leverage, equation B.27 limits the shadow bank's leverage ratio to the point where costs and benefits of cheating are exactly leveled. Thus, due to the financial friction, shadow banks, even not facing an externally set capital requirement that limits their leverage, are prone to an endogenous capital constraint that limits their abilitiy to increase leverage. ${ }^{44}$

Rewriting bank capital as

$$
k_{t+1}^{S}(j)=\left[\left(r_{t}^{b S}-r_{t}^{d S}\right) \phi_{t}^{S}+\left(1+r_{t}^{d S}\right)\right] k_{t}^{S}(j)
$$

we get

$$
z_{t, t+1}^{S}=\frac{k_{t+1}^{S}(j)}{k_{t}^{S}(j)}=\left(r_{t}^{b S}-r_{t}^{d S}\right) \phi_{t}^{S}+\left(1+r_{t}^{d S}\right)
$$

and

$$
\chi_{t, t+1}^{S}=\frac{q_{t+1}^{k} b_{t+1}^{E, S}(j)}{q_{t}^{k} b_{t}^{E, S}(j)}=\frac{\phi_{t+1}^{S}}{\phi_{t}^{S}} z_{t, t+1}^{S}
$$

As none of the components of $\phi_{t}^{S}$ depends on firm-specific factors, we can drop the subscript $j$ by summing across individual shadow bankers to get for total shadow bank lending:

$$
q_{t}^{k} b_{t}^{E, S}=\phi_{t}^{S} k_{t}^{S}
$$

\footnotetext{
${ }^{44}$ We assume that in the simulations, parameters are set such that the constraint always binds within a local region around steady state in equilibrium. Similarly to condition 41 in the Online Appendix, an equilibrium with a binding incentive constraint is characterized by $0<\nu_{t}^{S}<\theta^{S}$, which can be shown with equation B.27.
} 
with $b_{t}^{E, S}$ depicting aggregate lending/financial claims the shadow banking sector provides and $k_{t}^{S}$ being the aggregate capital held by shadow banks in period $t$.

As we assume some shadow bankers to exit each period and new bankers to enter the market, we know that aggregate capital $k_{t}^{S}$ is determined by capital of continuing shadow bankers, $k_{t}^{S, c}$, and capital of new bankers that enter, $k_{t}^{S, n}$ :

$$
k_{t}^{S}=k_{t}^{S, c}+k_{t}^{S, n}
$$

As a fraction $\sigma^{S}$ of existing shadow bankers survives each period, we know that at period $t$, we have for $k_{t}^{S, c}$

$$
k_{t}^{S, c}=\sigma^{S}\left[\left(r_{t-1}^{b S}-r_{t-1}^{d S}\right) \phi_{t-1}^{S}+\left(1+r_{t-1}^{d S}\right)\right] k_{t-1}^{S}
$$

For new shadow bankers, we assume that they get some start-up capital from the household the shadow banker belongs to. This startup value is assumed to be proportional to the amount of claims exiting shadow bankers had intermediated in their final period. With i.i.d exit probability $\sigma^{S}$, total final period claims of exiting shadow bankers at $t$ are given by $\left(1-\sigma^{S}\right) q_{t}^{k} b_{t-1}^{E, S}$. We assume that each period the household transfers a fraction $\frac{\omega^{S}}{1-\sigma^{S}}$ of this value to entering bankers, such that in the aggregate, we get:

$$
k_{t}^{S, n}=\omega^{S} q_{t}^{k} b_{t-1}^{E, S}
$$

Combining equations B.32, B.33 and B.34, we get the following law of motion for shadow bank capital:

$$
k_{t}^{S}=\sigma^{S}\left[\left(r_{t-1}^{b S}-r_{t-1}^{d S}\right) \phi_{t-1}^{S}+\left(1+r_{t-1}^{d S}\right)\right] k_{t-1}^{S}+\omega^{S} q_{t}^{k} b_{t-1}^{E, S}
$$

Finally, we assume a non-negative spread between the interest rates earned on shadow bank deposits, $r_{t}^{d S}$, and on the deposits households can place with commercial banks, $r_{t}^{d C}$, which is again determined by the parameter $\tau^{S}$, with $0 \leq \tau^{S} \leq 1$. In the Online Appendix, we provide a microfoundation for the existence of a positive spread, and use the results to incorporate a relationship between the two deposit rates similar to the relation stated in the two-period model:

$$
1+r_{t}^{d S}=\frac{1+r_{t}^{d C}}{1-\tau^{S} \varepsilon_{t}^{\tau}}
$$

As in the two-period version of the model, the parameter $\tau^{S}$ determines the spread between the gross rates on both deposit types and is implicitly related to the default probability of shadow banks. As a shortcut, we will calibrate $\tau^{S}$ and assume the existence 
of a spread shock $\varepsilon_{t}^{\tau}$ following an autoregressive process to motivate exogenous swings in the spread on interest rates earned on the two deposit types.

\section{A.4 Capital goods producers and retailers}

Following Gerali et al. (2010), the first-order condition for capital goods producers is given by

$$
\begin{aligned}
1=q_{t}^{k}\left[1-\frac{\kappa^{i}}{2}\left(\frac{I_{t} \varepsilon_{t}^{q^{k}}}{I_{t-1}}-1\right)^{2}-\kappa^{i}\left(\frac{I_{t} \varepsilon_{t}^{q^{k}}}{I_{t-1}}-1\right) \frac{I_{t} \varepsilon_{t}^{q^{k}}}{I_{t-1}}\right]+ \\
+\beta_{E} E_{t}\left[\frac{\lambda_{t+1}^{E}}{\lambda_{t}^{E}} q_{t+1}^{k} \kappa^{i}\left(\frac{I_{t+1} \varepsilon_{t+1}^{q^{k}}}{I_{t}}-1\right)\left(\frac{I_{t+1} \varepsilon_{t+1}^{q^{k}}}{I_{t}}\right)^{2} \varepsilon_{t+1}^{q^{k}}\right]
\end{aligned}
$$

and capital accumulation is given by

$$
K_{t}=\left(1-\delta^{k}\right) K_{t-1}+\left[1-\frac{\kappa^{i}}{2}\left(\frac{I_{t} \varepsilon_{t}^{q^{k}}}{I_{t-1}}\right)^{2}\right]
$$

We assume price stickiness à la Calvo (1983) in the retail sector. ${ }^{45}$ Thus, only a share or retailers indicated by $\theta^{p}$ is able to adjust prices in a given period. Retailers' marginal costs are given by

$$
m c_{t}^{E}=\frac{1}{x_{t}}
$$

\section{A.5 Monetary Policy and Market Clearing}

The central bank sets the policy rate according to a Taylor-type rule given by

$$
\left(1+r_{t}\right)=(1+r)^{\left(1-\phi^{r}\right)}\left(1+r_{t-1}\right)^{\phi^{r}}\left(\frac{\pi_{t}}{\bar{\pi}}\right)^{\phi^{\pi}\left(1-\phi^{r}\right)}\left(\frac{y_{t}}{y_{t-1}}\right)^{\phi^{y}\left(1-\phi^{r}\right)} \varepsilon_{t}^{r}
$$

where the weights on inflation and output growth are given by $\phi^{\pi}$ and $\phi^{y}$, respectively. The steady state policy rate is given by $r$ and $\varepsilon_{t}^{r}$ defines a white noise monetary policy shock.

The market clearing condition is given by the aggregate resource constraint

\footnotetext{
${ }^{45}$ In the studies by Gerali et al. (2010) and Gambacorta and Signoretti (2014), price stickiness was modeled using Rotemberg pricing. However, we decided to use the more convenient Calvo pricing approach in the model.
} 


$$
Y_{t}=C_{t}+q_{t}^{k}\left(K_{t}-\left(1-\delta^{k}\right) K_{t-1}\right)+\frac{\delta^{k} K_{t-1}^{b}}{\pi_{t}}+A C_{t}
$$

with $A C_{t}$ determining the overall adjustment costs and composite consumption given by $C_{t}=c_{t}^{P}+c_{t}^{E}$. 


\section{B Appendix: Data and Estimation}

We derive our data set from the European System of Accounts (ESA 2010) quarterly financial and non-financial sector accounts, provided by the ECB and Eurostat. Commercial bank balance sheet data is gathered from the data set on "Monetary Financial Institutions" (MFIs), whereas shadow bank data is based on statistics on "Other Financial Institutions" (OFIs) as well as on data on investment funds and money market funds (MMFs) provided by the ECB. Commercial bank interest rate data is combined from different sources, as indicated below. All variables except for interest rates are seasonally and working day adjusted and expressed in real terms. We furthermore detrend macroeconomic variables (real GDP, real consumption, real investment) and intermediary loans and deposits by applying log-differences. We then substract the sample means from the log-differenced data to have average growth rates of zero for these variables. Interest rates and price and wage inflation variables are also demeaned. A detailed description of each variable is given below, and the final time series used in the estimations are plotted in Figure 5 .

\section{B.1 Real Economic and Commercial Bank Data}

For the real economy, we include information on real gross domestic product, real consumption, real investment, and consumer price as well as wage inflation. We furthermore use data on commercial bank deposits held by private households, commercial bank loans granted to the non-financial corporate sector, the short-term EONIA rate as a quarterly measure of the policy rate, and measures for interest rates on household deposits and firm loans. We detrend nonstationary seasonally adjusted data (real consumption, real investment, bank deposits and loans) by using demeaned log-differenced data and demean all interest and inflation rates.

Real GDP: Real gross domestic product, euro area 19 (fixed composition), deflated using GDP deflator (index), calendar and seasonally adjusted data (National accounts, Main aggregates (Eurostat ESA2010)).

Real consumption: Real consumption expenditure of households and non-profit institutions serving households (NPISH), euro area 19 (fixed composition), deflated using Consumption deflator (index), calendar and seasonally adjusted data (National accounts, Main aggregates (Eurostat ESA2010)).

Real investment: Real gross fixed capital formation (GFCF), euro area 19 (fixed composition), deflated using GFCF deflator (index), calendar and seasonally adjusted data (National accounts, Main aggregates (Eurostat ESA2010)). 
Inflation: Harmonized index of consumer prices (HICP) overall index, quarterly changes, euro area (changing composition), net inflation rate, calendar and seasonally adjusted data. Wage inflation: Labour cost index, OECD data, euro area 19 (fixed composition), wages and salaries, business economy, net wage inflation, calendar and seasonally adjusted data. Nominal interest rate (policy rate): EONIA rate, ECB money market data.

Commercial bank loans: Real outstanding amounts of commercial bank (MFIs excluding ESCB) loans to non-financial corporations, euro area (changing composition), deflated using HICP, calendar and seasonally adjusted data.

Commercial bank deposits: Real deposits placed by euro area households (Overnight deposits, with agreed maturity up to two years, redeemable with notice up to 3 months), outstanding amounts, euro area (changing composition), deflated using HICP, calendar and seasonally adjusted data.

Interest rate on commercial bank loans: Annualized agreed rate (AAR) on commercial bank loans to non-financial corporations with maturity over one year, euro area (changing composition), new business coverage. Before 2003: Retail interest Rates Statistics (RIR), not harmonized data. Starting Q1 2003: MFI Interest Rate Statistics (MIR), harmonized data.

Interest rate on commercial bank deposits: Commercial bank interest rates on household deposits, weighted rate from rates on overnight deposits, with agreed maturity up to two years, redeemable at short notice (up to three months), euro area (changing composition), new business coverage. Before 2003: Retail interest Rates Statistics (RIR), not harmonized data. Starting Q1 2003: MFI Interest Rate Statistics (MIR), harmonized data.

\section{B.2 Shadow Bank Data}

In addition to the variables on commercial bank and real activity, we include data on the shadow banking sector in the euro area in our sample. In comparison to lending provided by commercial banks, we derive a time series on shadow bank lending to non-financial corporates and furthermore include information on shadow bank capital. ${ }^{46}$ In doing so, we are able to include an empirical measure of shadow bank leverage, in our model defined as shadow bank capital in relation to total lending provided, in the estimation.

Deriving information on the European shadow banking system is challenging since 1) a wide variety of shadow bank definitions are used among scholars and practitioners and 2) euro area data on financial institutions that could be classified as shadow banks is

\footnotetext{
${ }^{46}$ See Appendix B.
} 
available at a much lower level of detail and in a less structured manner than information on commercial banks. Therefore, one has to compromise between the conceptional definition of shadow banks used and the empirical counterparts that can be analyzed with available data.

In practice, the shadow banking system consist of a multitude of financial institutions partly fulfilling highly specialized task in a prolonged chain of credit intermediation (Adrian, 2014; Adrian and Liang, 2014; Pozsar et al., 2010). Given the diverse nature of non-bank financial institutions, a variety of definitions of shadow banks have been proposed, covering either a particular set of institutions (institutional approach) or a range of activities different entities are jointly engaged in (activity approach). We base our empirical measures of shadow banks on the "broad" definition of the shadow banking system provided by the Financial Stability Board (FSB, 2017, 2011), which states that the shadow banking system is "the system of credit intermediation that involves entities and activities outside the regular banking system" (FSB, 2011, p.2) and that "...this implies focusing on credit intermediation that takes place in an environment where prudential regulatory standards and supervisory oversight are either not applied or are applied to a materially lesser or different degree than is the case for regular banks engaged in similar activities" (FSB, 2011, p.3).

More precisely, we follow the institutional approach employed by ECB staff to apply the FSB broad defintion to available euro area data (Malatesta et al., 2016; Doyle et al., 2016; Bakk-Simon et al., 2012). The core of this approach depicts the use of the "Other Financial Intermediaries" (OFIs) aggregate in the Eurosystem's financial accounts data. Within the aggregate, all activites of financial intermediaries not classified as "Monetary Financial Institutions" (MFIs) are captured. Thus, the OFI aggregate depicts a residual component and not only includes institutions universally accepted as shadow banks. For instance, the insurance corporations and pension funds sector (ICPFs) is mainly engaged in activities that are not related to shadow bank activities, and we therefore exclude balance sheet items of these institutions from our shadow bank aggregates. Furthermore, the OFI aggregate is lacking information on money market funds (MMFs), which are classified as MFIs. However, there is a broad consensus in the literature that MMFs engage in activities that could possibly be counted as shadow bank intermediation ${ }^{47}$, and we therefore include MMF information in the shadow bank aggregate. Our benchmark shadow bank definition (1) therefore closely resembles the broad shadow bank definition by the FSB and covers the whole range of OFIs except for ICPFs, plus MMFs (Scenario 1 in Table 5). ${ }^{48}$

\footnotetext{
${ }^{47}$ See for instance Adrian (2014), Adrian and Liang (2014), Pozsar et al. (2010), or FSB (2017, 2011)

${ }^{48}$ Detailed information on the composition of the OFI sector has only recently been provided by the ECB. For instance, the collection of detailed balance sheet data on investment funds and financial vehicle corporations (FVCs) was only initiated in 2008 and 2009, respectively. Also, harmonized data on MMFs
} 
Table 5: Different Definitions of Shadow Banks Based on the OFI Aggregate

\begin{tabular}{cccc} 
Scenario & $\begin{array}{c}\text { Including } \\
\text { Investment Funds }\end{array}$ & $\begin{array}{c}\text { Including } \\
\text { Money-Market Funds }\end{array}$ & $\begin{array}{c}\text { Lending } \\
\text { Counterparties }\end{array}$ \\
\hline 1 & $\mathrm{X}$ & $\mathrm{X}$ & NFCs \\
2 & & $\mathrm{X}$ & Total economy \\
\hline
\end{tabular}

The OFI sector, in line with the broad definition of shadow banks given by the FSB, covers non-MMF investment funds ${ }^{49}$. Whereas some studies highlight the increasing role of direct investment fund lending to the non-financial private sector in the euro area since the recent global financial crisis (Doyle et al., 2016), other studies discuss the special role investment funds play in the financial system and question the adequacy of considering these institutions as intermediaries between real economy borrowers and lenders. For instance, Bakk-Simon et al. (2012) argue that investment funds are indeed covered by regulation, even though substantially different than commercial banks, and therefore question whether the definition of shadow banks being intermediaries outside the regulatory system given by the FSB applies to investment funds. We therefore use as a robustness check alternative measures of shadow banks equity and loans that exclude investment fund values in a second estimation of the model (Scenario 2 in Table 5). However, we are not able to gather counterparty information for investment fund lending before 2008, and therefore use total lending of the OFI sector less investment fund lending in this second estimation, instead of lending to non-financial corporations only.

Shadow bank loans (including investment funds): Loans of other financial intermediaries (OFI) to non-financial corporations, excluding insurance corporations and pension funds, including investment funds, euro area 19 (fixed composition), deflated using HICP, calendar and seasonally adjusted data.

Shadow bank equity (including investment funds): Equity issued by OFI sector, excluding insurance corporations and pension funds, including investment fund shares/units, including money market fund (MMF) shares/units, euro area 19 (fixed composition), deflated using HICP, calendar and seasonally adjusted data.

Shadow bank loans (excluding investment funds): Loans of other financial inter-

is available only from 2006 onwards in the MFI statistics, but can be gathered from other sources for earlier years (see Appendix B). Balance sheet information on these institutions accounts for approximately 50 percent of the total OFI sector, with the rest being characterized by smaller and more heterogeneous entities. As highlighted by Doyle et al. (2016), one should therefore be aware of the fact that not all institutions in the remaining half of the OFI aggregate could unambiguously be declared as shadow banks.

${ }^{49}$ In contrast to investment funds, MMFs provide no direct lending to real economic agents, and are therefore naturally abscent from any shadow bank lending aggregate in the study. However, as MMFs are still of all of our shadow bank definitions applied, they will be considered in the aggregate equity holding of the shadow banking sector. 
mediaries (OFI) to total economy, excluding insurance corporations and pension funds, excluding investment fund assets (deposits, loans, and financial derivatives), euro area 19 (fixed composition), deflated using HICP, calendar and seasonally adjusted data.

Shadow bank equity (excluding investment funds): Equity issued by OFI sector, excluding insurance corporations and pension funds, excluding investment fund shares/units, including money market fund (MMF) shares/units, euro area 19 (fixed composition), deflated using HICP, calendar and seasonally adjusted data.

Figure 5: Euro Area Observable Time Series Used in Estimation
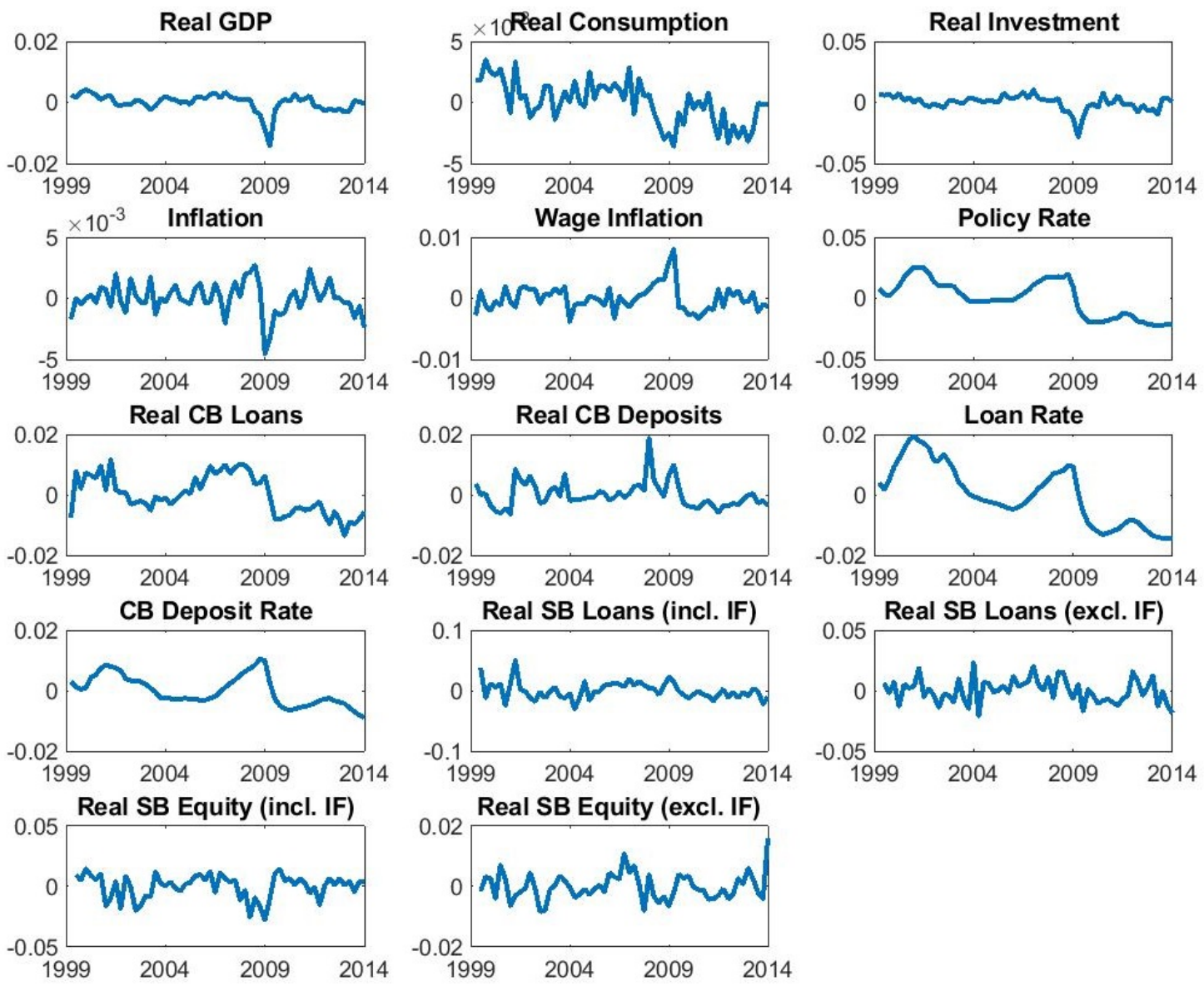

Note: Real stock and volume data (real GDP, real consumption, real investment, loans and deposits by commercial and shadow banks) are expressed as demeaned log-differences. Wage and price inflation and interest rates are quarterly net rates and expressed in absolute deviations from sample means.

\section{B.3 Prior and posterior distributions}

Figures 6 to 8 report the prior and posterior distributions for the baseline estimation reported in Tables 2 to 4 . 
Figure 6: Prior and Posterior Distributions: Baseline Structural Parameters
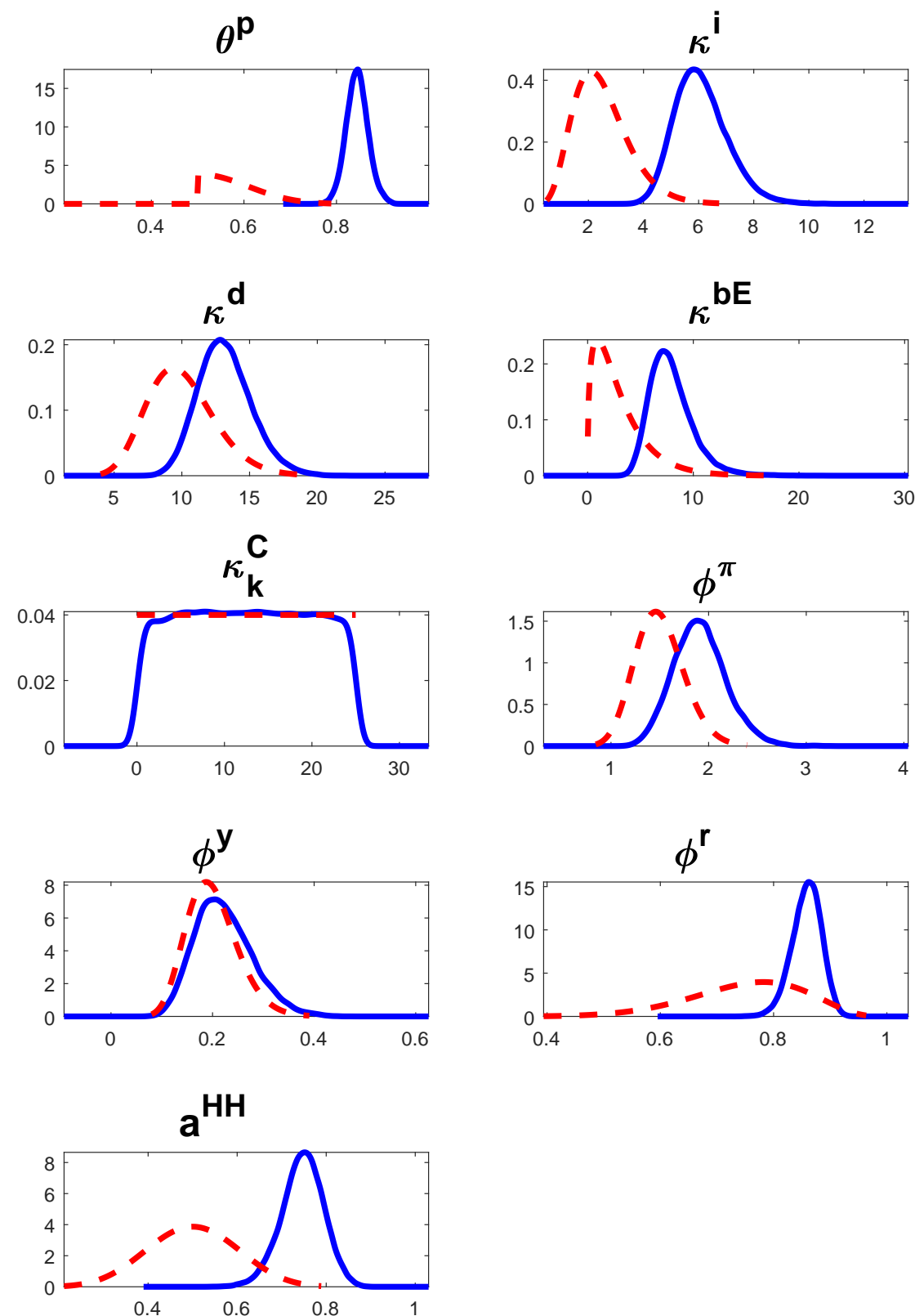

Posterior $=$ Prior 
Figure 7: Prior and Posterior Distributions: Baseline Exogenous Processes (AR Coefficients)
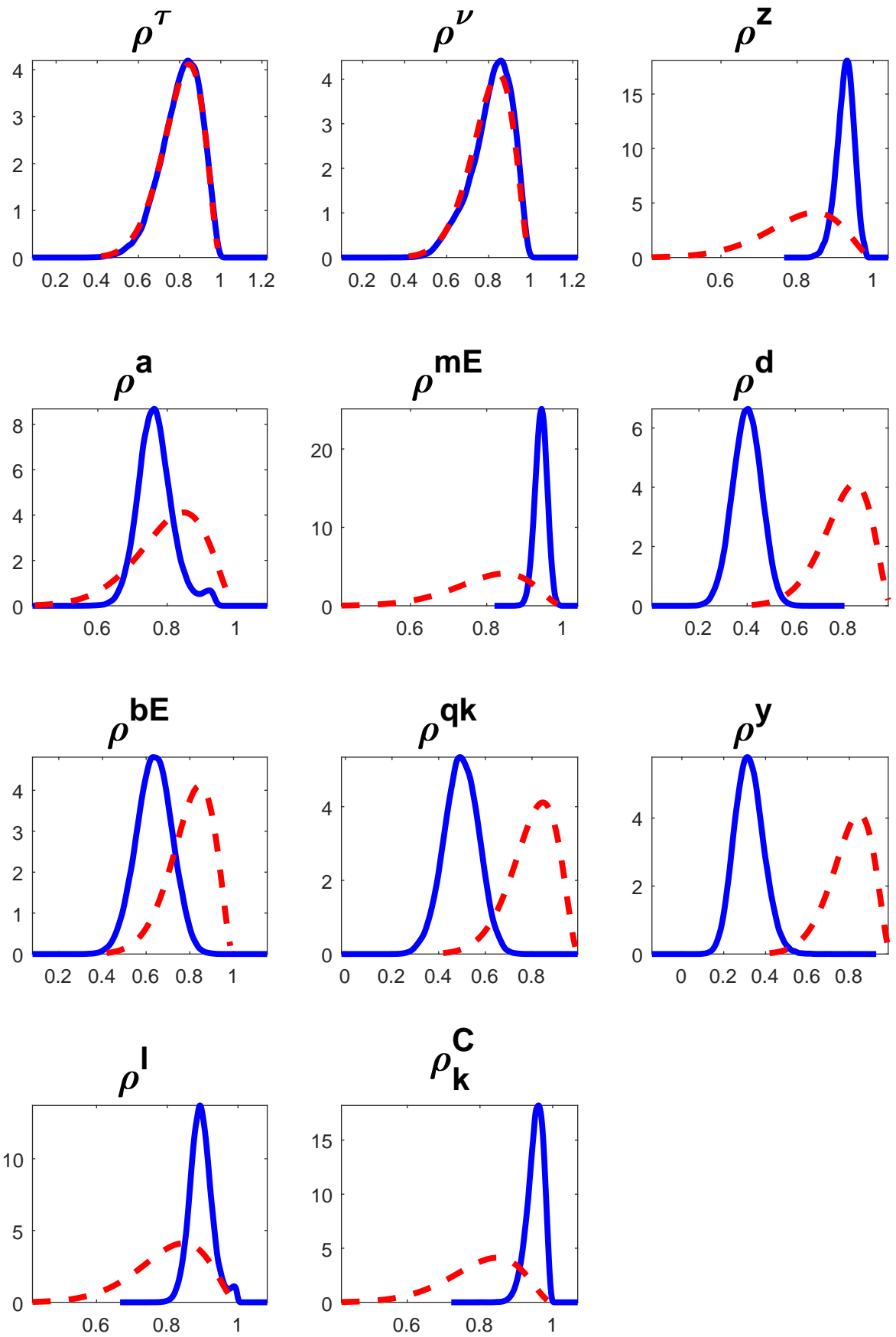

Posterior $=-$ Prior 
Figure 8: Prior and Posterior Distributions: Baseline Exogenous Processes (Standard Deviations)
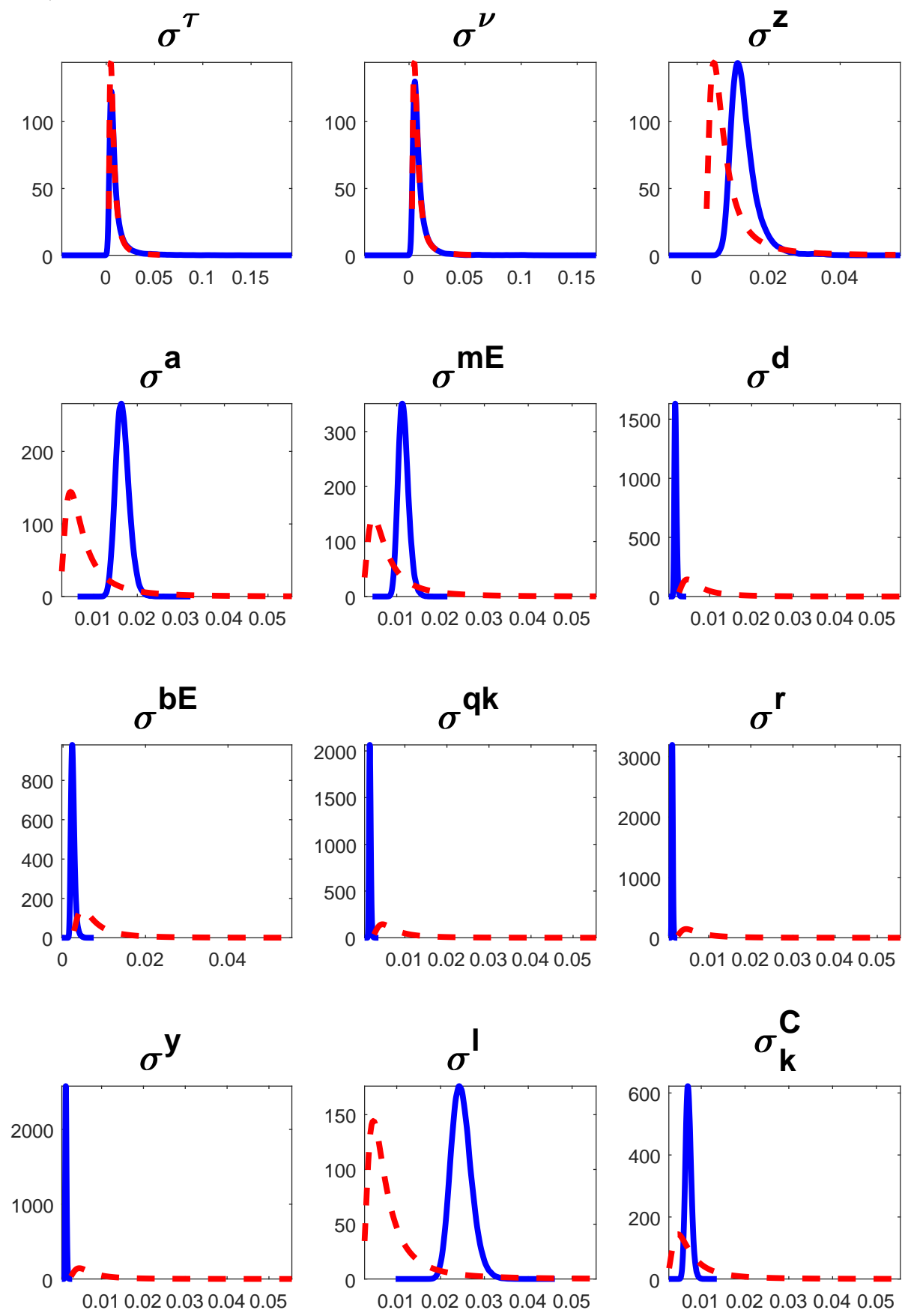


\section{Appendix: Robustness Checks}

\section{C.1 Robustness and Evaluation}

In the following, we estimate our baseline model on two different specifications of the sample. First, to account for uncertainty around the exact date of the beginning of the ZLB phase in the euro area, we provide evidence on estimated parameters when using an earlier end date as in the baseline specification. We are also aware of structural changes in the financial system after the 2007/2008 financial crisis and over the course of the subsequent European debt crisis which potentially altered the role and effectiveness of shadow banking in the euro area. To take these considerations into account, we re-estimate our model for the period of 1999:Q1 to 2008:Q4, thereby excluding both the post-financial crisis and ZLB period from the estimation. In addition, excluding the period after 2008 allows for a straightforward comparison of results to Gerali et al. (2010), who used the same period in the estimation. Estimation results are reported in Table 6. In Addition, we restate our baseline estimation results for comparison.

Whereas result from the pre-crisis period estimation are qualitatively comparable to the baseline estimates, some slight quantitative differences in parameter estimates can be observed. The mode estimates for parameters governing investment and interest rate adjustment costs turn out to be lower in the estimation using the pre-crisis sample. By including the years after 2008 - a period characterized by the aftermath of the global financial crisis and by the subsequent European sovereign debt crisis - the rise in investment adjustment costs could be driven by higher investment volatility - due to a significant fall in investment activity in the post-crisis years and the more moderate growth thereafter - in the post-2008 period. Furthermore, substantial changes in interest rates due to expansionary monetary policy - with the ECB key interest rate falling from 2.5 percent in December 2008 to 0.25 percent in April 2009, followed by an increase to 0.75 percent in July 2011 and a renewed fall to 0.25 until November 2013 - increased bank adjustment costs in the second half of the sample, as commercial banks only sluggishly adjusted interest rates to preserve markups. ${ }^{50}$

Second, we re-estimate our model by applying a different definition of shadow banks, i.e. by excluding investment funds from the shadow bank aggregate, as discussed in Section

\footnotetext{
${ }^{50}$ There is evidence for a change in the transmission of interest rate policy in the euro area over the course of the global financial and the subsequent sovereign debt crisis. For instance, Hristov et al. (2014) find that the pass-through of changes in the policy rate to retail banking rates became significantly distorted in the period after 2008, with a lower degree of transmission compared to the pre-crisis period. Von Borstel et al. (2016) discuss the interest rate pass-through over the course of the sovereign debt crisis in the euro area. They find that expansionary conventional monetary policy did not lower bank markups, even though the transmission of interest rate cuts was largely unaffected by the crisis.
} 
4 (Scenario 2 in Table 5). We report parameter estimates in Table 7, again in comparison to our baseline estimation.

Our baseline results are not substantially affected when investment fund information is excluded. Commercial bank loan rate adjustment costs turn out to be slightly lower when investment fund information is excluded from the estimation, whereas other structural parameters - based on the comparison of posterior modes - do not differ from baseline results. 
Table 6: Prior and Posterior Distributions: Structural Parameters Whole Sample and Pre-Crisis Period

Baseline

Posterior Distribution

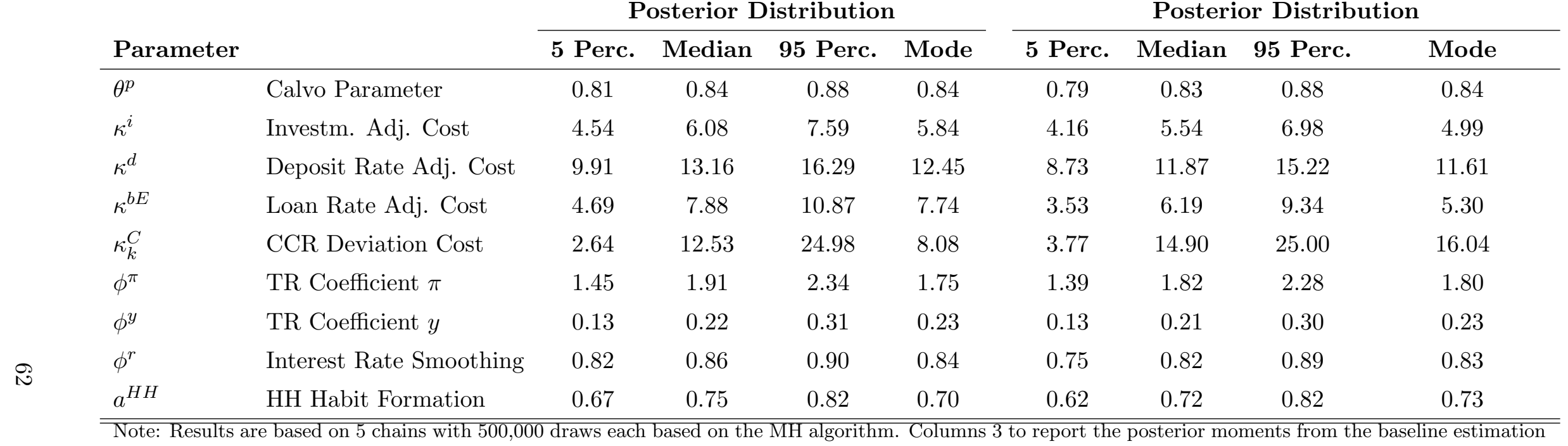

in Table 2, whereas columns 7 to 10 report results from the estimation using the sample 1999 Q:1 to 2008:Q4.

Pre-Crisis

Posterior Distribution

(1) 
Table 7: Prior and Posterior Distributions: Structural Parameters with and without Investment Funds

Baseline

Posterior Distribution

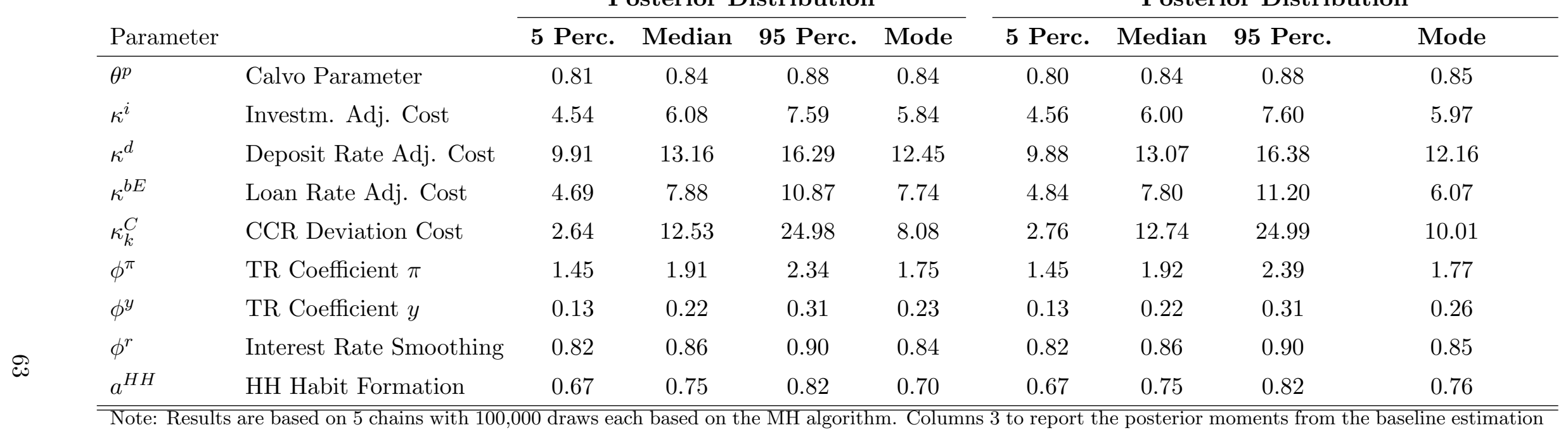

Excluding Investment Funds

Posterior Distribution

\footnotetext{
in Table 2, whereas columns 7 to 10 report results from the estimation using shadow banking data excluding information on investment funds.
} 


\title{
Macroprudential Regulation and Leakage to the Shadow Banking Sector
}

\author{
Stefan Gebauer* Falk Mazelis ${ }^{\dagger}$ \\ Online Appendix \\ July 23, 2019
}

*DIW Berlin, Freie Universität Berlin. E-mail address: sgebauer@diw.de.

$\dagger$ European Central Bank. E-mail address: falk.mazelis@ecb.int.

The views in this paper are those of the authors and do not necessarily reflect the views of the European Central Bank or DIW Berlin. 


\section{Benchmark Model}

In the following, we present a stripdown version of the full DSGE model we derive in the paper. We use the simple model to explain the key mechanism, i.e. the effects of regulatory changes in the commercial banking sector (a change in capital requirements) and the interplay of the two intermediaries, shadow and commercial banks. ${ }^{1}$ The complete model presented in Section 3 of the paper implements the key mechanism in an infinite horizon general equilibrium framework where we introduce a multitude of features such as habit formation in consumption, labor and capital decisions by households and firms, monopolistic competition in the goods and commercial banking sectors, nominal rigidities, and adjustment costs for investment and bank capital that aim to increase the richness and fit of our model. We abstract from all those features here to shed light on the distinct working of exogenous changes in capital requirements in our model. The model we describe in this section is a two-period model in which agents can borrow (lend) in the first period, either via commercial or shadow banks, and repay (receive) outstanding principle plus interest in the second period. The funds intermediated are used for consumption purposes, and all resources are used by the end of the second period.

\section{$1.1 \quad$ Savers}

There is an infinite amount of identical savers ${ }^{2}$ that use resources for consumption of real goods. ${ }^{3}$ The saver can transfer consumption from the first to the second period by placing deposits in one of the two financial intermediaries, and he withdraws his funds in period two, receives interest, and uses the gross return for period-two consumption. Only deposits placed with the commercial bank will act as safe assets, as they are covered by full deposit insurance, which will not be the case for shadow bank deposits. When considering shadow banks, the savers face a probability $p$ of retaining full shadow bank deposits and interest return in period two, and a probability $1-p$ with which they will receive zero, affecting period-two consumption

\footnotetext{
${ }^{1}$ The model presented here partly relies on the two-period version of the Gertler and Karadi (2011) model derived by Lawrence Christiano and Tao Zha. The material can be found here.

${ }^{2}$ In our full model, savers will be households and borrowers will be entrepreneurs.

${ }^{3}$ In this version of the model, we abstract from nominal price changes, such that all variables and interest rates are expressed in real terms here.
} 
respectively. The first-period budget constraint of the saver is given by

$$
c+d^{c}+d^{s} \leq y
$$

where $c$ depicts the level of consumption in period one, and $d^{c}$ and $d^{s}$ constitute the amount of deposits placed in commercial and shadow banks, respectively. The saver funds these expenses by an initial endowment of output, $y$, that he receives at the beginning of period one.

In the second period, the saver either receives full deposit returns from both banks to fund period-two consumption $\left(C^{+}\right)$, or has only his returns from commercial bank deposits at hand to fund consumption $\left(C^{-}\right)$, due to an exogenous default of shadow bank deposits. The second-period budget constraint in case of full repayment is thus given by

$$
C^{+} \leq\left(1+r^{d c}\right) d^{c}+\left(1+r^{d s}\right) d^{s}
$$

and in case of shadow bank deposit default by

$$
C^{-} \leq\left(1+r^{d c}\right) d^{c}
$$

where

$$
1+r^{d s} \equiv \frac{1+r^{d c}}{1-\tau^{s}}
$$

with

$$
0 \leq \tau^{s} \leq 1
$$

The saver earns net interest $r^{d c}$ and $r^{d s}$ on each type of deposits, and receives profits $\pi$ which are exogenous to the saver, as he is the ultimate owner of firms and banks in the model. The interest rate spread between commercial and shadow bank deposits is determined by the parameter $\tau^{s}$, and the saver takes the interest rate returns, and thus $\tau^{s}$, as given.

The maximization problem of the saver is thus given by

$$
\max _{c, C^{+}, C^{-}, d^{c}, d^{s}} u(c)+\beta^{s}\left[p u\left(C^{+}\right)+(1-p) u\left(C^{-}\right)\right]
$$

where $\beta^{s}$ depicts the discount factor savers apply.

Subject to constraints 1, 2 and 3 in equation 5, the first-order conditions of the saver can be combined to yield:

$$
1+r^{d c}=\frac{u^{\prime}(c)}{\beta^{s}\left[p u^{\prime}\left(C^{+}\right)+(1-p) u^{\prime}\left(C^{-}\right)\right]}
$$




$$
1+r^{d s}=\frac{u^{\prime}(c)}{\beta^{s}\left[p u^{\prime}\left(C^{+}\right)\right]}
$$

With log-utility, taking ratios of equations 6 and 7, we get

$$
\frac{1+r^{d s}}{1+r^{d c}}=1+\frac{1-p}{p} \frac{C^{+}}{C^{-}}
$$

and plugging in constraints 2 and 3 yields

$$
\frac{d^{s}}{d^{c}}=\frac{\left(1+r^{d s}\right) p-\left(1+r^{d c}\right)}{\left(1+r^{d s}\right)(1-p)}
$$

Proposition 1. The ratio of shadow bank vs. commercial bank deposits is

- increasing in the shadow bank deposit return $r^{d s}$ and

- increasing in the no-default probability $p$

We make sure that no negative amount of deposits are placed with any of the two banks and exclude cases where no deposits are placed with shadow banks. Even though a possible outcome, no placement with shadow banks would eliminate shadow bank intermediation completely in our model, and we exclude this case from our analysis. ${ }^{4}$ This implies that

$$
\left(1+r^{d s}\right) p-\left(1+r^{d c}\right) \geq 0
$$

and thus

$$
p \geq \frac{1+r^{d c}}{1+r^{d s}}
$$

and thus

$$
1+r^{d s} \geq \frac{1+r^{d c}}{p}
$$

This condition has to hold and implies that a higher shadow bank default probability $1-p$ (a decrease in $p$ ) has to be compensated with a higher gross return on shadow bank deposits $\left(1+r^{d s}\right)$ to make savers invest a positive amount in shadow banks at all, ceteris paribus.

\footnotetext{
${ }^{4}$ In the simulation, we will choose parameters such that $\frac{d^{s}}{d^{c}}>0$ holds.
} 
If we rewrite the condition with equality such that

$$
1+r^{d s}=\frac{1+r^{d c}}{p}
$$

and define a relation between the spread parameter $\tau^{s}$ and the no-default probability $p$ such that

$$
\tau^{s}=1-p
$$

we get the relationship

$$
1+r^{d s}=\frac{1+r^{d c}}{1-\tau^{s}}
$$

Proposition 2. The deposit rate spread $\tau^{s}$ is negatively related to the no-default probability $p$, indicating the higher the probability of shadow banks meeting their obligations, the lower the risk spread between deposit rates savers demand to place funds in shadow banks.

We can now derive an expression for commercial bank deposits from equation 9:

$$
d^{c}=\frac{\left(1+r^{d s}\right)(1-p)}{\left(1+r^{d s}\right) p-\left(1+r^{d c}\right)} d^{s}
$$

We furthermore get from equation 7 that

$$
d^{s}=\frac{\beta^{s} p}{1+\beta^{s} p} y-\frac{\left(1+r^{d s}\right) \beta^{s} p+\left(1+r^{d c}\right)}{\left(1+r^{d s}\right)\left(1+\beta^{s} p\right)} d^{c}
$$

and using equation 9 we get

$$
d^{s}=\frac{\beta^{s} p}{1+\beta^{s} p} y-\frac{\left(1+r^{d s}\right) \beta^{s} p+\left(1+r^{d c}\right)}{\left(1+r^{d s}\right)\left(1+\beta^{s} p\right)} \frac{\left(1+r^{d s}\right)(1-p)}{\left(1+r^{d s}\right) p-\left(1+r^{d c}\right)} d^{s}
$$

Solving for $d^{s}$ yields

$$
d^{s} \frac{\left(1+\beta^{s} p\right)\left[\left(1+r^{d s}\right) p-\left(1+r^{d c}\right)\right]+(1-p)\left[\left(1+r^{d s}\right) \beta^{s} p+\left(1+r^{d c}\right)\right]}{\left(1+\beta^{s} p\right)\left[\left(1+r^{d s}\right) p-\left(1+r^{d c}\right)\right]}=\frac{\beta^{s} p}{1+\beta^{s} p} y
$$

Define the numerator of the term on the left-hand side of the above equation as $x$ such that

$$
x \equiv\left(1+\beta^{s} p\right)\left[\left(1+r^{d s}\right) p-\left(1+r^{d c}\right)\right]+(1-p)\left[\left(1+r^{d s}\right) \beta^{s} p+\left(1+r^{d c}\right)\right]
$$


Then

$$
x \equiv\left(1+r^{d s}\right) p\left(1+\beta^{s}\right)-\left(1+r^{d c}\right) p\left(1+\beta^{s}\right)
$$

Plugging back in yields

$$
d^{s}=\frac{\beta^{s}}{1+\beta^{s}} \frac{\left(1+r^{d s}\right) p-\left(1+r^{d c}\right)}{r^{d s}-r^{d c}} y
$$

Whenever equation 10 holds with equality, savers are indifferent between commercial and shadow bank deposits, and place zero deposits with shadow banks according to equation 13. By choosing adequate calibration, we will make sure that some share of funds is placed with shadow banks by savers and therefore shadow banking exists in our model.

Commercial bank deposits are thus given by

$$
d^{c}=\frac{\beta^{s}}{1+\beta^{s}} \frac{\left(1+r^{d s}\right)(1-p)}{r^{d s}-r^{d c}} y
$$

Finally, using equations 13 and 14 in constraint 1, with equality we get

$$
c=y\left(\frac{1}{1+\beta^{s}}\right)
$$

Thus, the saver always consumes a fixed share of endowment $y$ in the first period, which depends only on the discount factor $\beta^{s}$. A higher discount factor, i.e. a higher appreciation of utility derived from period-two consumption by the saver, reduces period-one consumption and results in a higher share of $y$ being invested in deposits. Compared to a standard Fisher consumption/saving problem where there is only one intermediary and therefore one savings rate, the introduction of the second intermediary (shadow banks) changes the decision rules of the saver fundamentally. Now, the problem is not one of intertemporal saving vs. consumption anymore, where the single savings rate determines in addition to the discount factor the amount consumed in period one and the amount consumed in period two. Here, the difference in the two rates $r^{d c}$ and $r^{d s}$, in combination with the default probability $1-p$, determines how much is invested in commercial vs. shadow bank, whereas the total amount of investment and of consumption are only dependent on the discount factor $\beta^{s}$. 
Proposition 3. The saver always consumes a fixed share of endowment $y$ in the first period, which depends only on the discount factor $\beta^{s}$. Compared to a standard Fisher consumption/saving problem where there is only one intermediary and therefore one savings rate, the introduction of the second intermediary (shadow banks) changes the decision rules of the saver as the difference in the two rates $r^{d c}$ and $r^{d s}$, in combination with the default probability $1-p$, determines how much is invested in commercial vs. shadow bank, whereas the total amount of investment and of consumption are only dependent on the discount factor $\beta^{s}$.

We know from the first-order condition for shadow bank deposits that

$$
C^{+}=c \beta^{s} p\left(1+r^{d s}\right)
$$

such that

$$
C^{+}=\beta^{s} p\left(1+r^{d s}\right) y\left(\frac{1}{1+\beta^{s}}\right)
$$

Using equation 8, we finally get

$$
C^{-}=\frac{1-p}{p} \frac{1+r^{d c}}{r^{d s}-r^{d c}} C^{+}
$$

such that

$$
C^{-}=\frac{(1-p)\left(1+r^{d c}\right)}{r^{d s}-r^{d c}} \beta^{s}\left(1+r^{d s}\right) y\left(\frac{1}{1+\beta^{s}}\right)
$$

\subsection{Borrowers}

Borrowers fund consumption in period one by taking up loans from either commercial or shadow banks, whereas for now, the two credit types act as perfect substitutes in the model, such that one can aggregate total credit holdings. The first period budget constraint of the borrower is thus given by

$$
c^{b} \leq \underbrace{b^{c}+b^{s}}_{b}
$$

In the second period, borrowers receive an exogenous endowment $y^{b}$ that they use to fund period-two consumption $C^{b}$ and to repay period-one debt plus interest. The second-period budget constraint is thus given by 


$$
C^{b}+\left(1+r^{b c}\right) b^{c}+\left(1+r^{b s}\right) b^{s} \leq y^{b}
$$

or, assuming interest on both homogeneous loan types to be equal,

$$
C^{b}+\left(1+r^{b}\right) b \leq y^{b}
$$

The maximization problem of the borrower is given by

$$
\max _{c^{b}, C^{b}, b^{c}, b^{s}} u\left(c^{b}\right)+\beta^{b} u\left(C^{b}\right)
$$

Plugging in constraints 18 and 19, the maximization yields

$$
\begin{gathered}
\max _{b^{c}, b^{s}} u(b)+\beta^{b} u\left(y^{b}-\left(1+r^{b}\right) b\right) \\
1+r^{b}=\frac{u^{\prime}\left(c^{b}\right)}{\beta^{b} u^{\prime}\left(C^{b}\right)}
\end{gathered}
$$

Assuming log-utility we get

$$
1+r^{b}=\frac{C^{b}}{\beta^{b} c^{b}}
$$

Solving equation 19 for $b$ and plugging in equation 18 yields the intertemporal budget constraint

$$
c^{b}+\frac{C^{b}}{1+r^{b}} \leq \frac{y^{b}}{1+r^{b}}
$$

Equation 24 states that present discounted value of borrower consumption cannot exceed present discounted wealth.

Solving 23 for $C^{b}$ and substituting in 24 yields

$$
c^{b} \leq \frac{y^{b}}{\left(1+r^{b}\right)\left(1+\beta^{b}\right)}
$$

indicating that period-one consumption decreases in the lending rate $r^{b}$ and in the discount factor $\beta^{b}$.

Combining equations 18 and 25 ultimately gives

$$
b \leq \frac{y^{b}}{\left(1+r^{b}\right)\left(1+\beta^{b}\right)}
$$

From the intertemporal budget constraint 24 we get with equality 


$$
C^{b}=y^{b}-\left(1+r^{b}\right) c^{b}
$$

such that

$$
C^{b}=y^{b} \frac{1}{1+\beta^{b}}
$$

Proposition 4. An increase in the borrowing rate $r^{b}$ decreases marginal utility from consumption in period one, as financing the marginal unit of period-one consumption $\left(c^{b}\right)$ becomes more costly. Also, period-one consumption decreases in the discount factor $\beta^{b}$. Borrowers trade period one consumption for now relatively more attractive consumption in period two $\left(C^{b}\right)$. In addition, present discounted value of borrower consumption cannot exceed present discounted wealth.

\subsection{Banks}

Our model features two financial intermediaries (commercial banks and shadow banks) that are structurally different in terms of business model, market power, and regulatory coverage, but ultimately fulfill the same task, channeling funds from savers to borrowers. We will first derive the benchmark case in which shadow banks act under perfect competition, with the main difference between the two banks being given by the degree of regulatory coverage. We will then introduce a financial friction to the shadow banking sector leading to potentially positive returns on shadow bank intermediation.

\subsubsection{Commercial Banks}

In this version of the model, there is a continuum of commercial banks that consist of two entities, a wholesale unit and a retail loan unit. The wholesale unit of the representative commercial bank holds net worth $n^{c}$ and collects deposits $d^{c}$ from savers on which it pays the deposit rate $r^{d c}$. The wholesale unit also issues wholesale loans $b^{c}$ on which it earns the wholesale rate $R^{b}$. Furthermore, commercial banks have to fulfil a regulatory capital requirement, and face a cost whenever they hold a level of net worth relative to assets that deviates from the target capital-to-asset ratio.

The wholesale unit of the representative commercial bank thus faces two constraints it has to take into account when maximizing the discounted sum of real cash flow: 


$$
\begin{gathered}
b^{c}=n^{c}+d^{c} \\
c^{b}=\frac{\kappa}{2}\left(\frac{n^{c}}{b^{c}}-\nu\right)^{2} n^{c}
\end{gathered}
$$

The first constraint 28 describes the balance sheet constraint, whereas the second constraint 29 depicts the capital adequacy constraint, stating the quadratic cost whenever the capital-to-asset ratio deviates from the target value $\nu$ set by the regulating authority.

The wholesale branch chooses deposits and loans to maximize profits, taking both constraints into account:

$$
\max _{d^{c}, b^{c}} R^{b} b^{c}-r^{d c} d^{c}-\frac{\kappa}{2}\left(\frac{n^{c}}{b^{c}}-\nu\right)^{2}\left(b^{c}-d^{c}\right) .
$$

The first-order condition gives

$$
R^{b}=r^{d c}-\kappa\left(\frac{n^{c}}{b^{c}}-\nu\right)\left(\frac{n^{c}}{b^{c}}\right)^{2}
$$

We assume that the retail branch of the bank has some market power and is thus able to set a markup when granting loans to borrowers. The retail unit takes on wholesale loans, differentiates them at no cost and resells them to borrowers. Thereby, the retail branch charges a markup $\mu^{c}$ on the wholesale borrowing rate. ${ }^{5}$ The retail loan rate $r^{b}$ is thus given by

$$
\begin{gathered}
r^{b}=R^{b}+\mu^{c} \\
r^{b}=r^{d c}-\kappa\left(\frac{n^{c}}{b^{c}}-\nu\right)\left(\frac{n^{c}}{b^{c}}\right)^{2}+\mu^{c}
\end{gathered}
$$

\subsubsection{Shadow Banks}

Shadow banks engage in a similar type of intermediation as commercial banks, i.e. they take on deposits from savers and lend them out to borrowers in period one and

\footnotetext{
${ }^{5}$ In the simplified version of the model, we assume the markup to be constant and additive. In the full DSGE model, the markup will be multipilicative, as in Gerali et al. (2010). This will then, as in the original model, introduce a positive correlation between the commercial bank spread and the policy rate.
} 
earn profits in period two on the intermediation activity. However, they differ from commercial banks in terms of competition and regulatory coverage. In contrast to commercial banks, shadow banks provide lending under perfect competition, and therefore take rates on the loan markets as given. For now, we assume a universal loan market where both commercial and shadow bank loans are not differntiable and thus shadow banks take the rate determined by commercial banks on the loan market as given, such that $r^{b}=r^{b c}=r^{b s}$. Furthermore, shadow banks are not subject to banking supervision but intermediate outside the regulated banking system. Thus, they do not have to comply to capital requirements, in contrast to commercial banks. Furthermore, as they are not part of the deposit insurance scheme set up by the regulator, placing deposits in shadow banks is risky from the point of savers. As depositors are aware of the issue, they will limit the amount of deposits they place in the shadow bank whenever shadow banks hold too little net worth. We therefore later introduce a moral hazard friction by allowing shadow banks to take on deposits and invest in loans in period one, and divert funds for private use before returns to savers materialize. This "running-away" problen has been introduced in Gertler and Karadi (2011).

Before introducing the moral hazard friction, we solve the frictionless benchmark optimization problem where shadow banks are as efficient as commercial banks, but are not affected by regulation. Shadow banks, like commercial banks, fund their lending activity $b^{s}$ in period one by issuing shadow bank deposits $d^{s}$ and fixed shadow bank capital $n^{s}$ :

$$
b^{s}=n^{s}+d^{s} .
$$

Like their regulated counterparts, they maximize their profits in period two, which are given by

$$
\max _{d^{s}, b^{s}}\left(1+r^{b}\right) b^{s}-\left(1+r^{d s}\right) d^{s}-b^{s}+d^{s}
$$

taking $r^{b}$ and $r^{d s}$ as given.

\subsection{Benchmark Equilibrium}

We are now able to define a benchmark equilibrium in which we assume no frictions in deposit or loan markets, such that the main difference between the two banks is regulatory coverage, i.e. that commercial banks are required to back a certain share 
of their assets (loans) by a minimum level of capital, and face costs whenever they deviate, whereas shadow banks are unconstrained in their intermediation decisions. We will subsequently introduce the key financial friction we are implementing in the full DSGE model, i.e. a moral hazard problem existing between shadow banks and savers (Gertler and Karadi, 2011).

In total, we have 13 endogenous variables in the model: $c, C^{+}, C^{-}, c^{b}, C^{b}, d^{c}$, $d^{s}, b^{c}, b^{s}, b, r^{d c}, r^{d s}, r^{b}$.

We therefore need 13 equations to solve the model:

(i) Equations 13 to 17 solve the saver problem

(ii) Equations 25 to 27 solve the borrower problem

(iii) Equations 28 and 33 solve the commercial bank problem

(iv) The shadow bank problem 35 is solved, see below.

(v) We furthermore have the securities market clearing condition

$$
b=b^{c}+b^{s}
$$

and

(vi) condition 10 which has to hold such that negative and zero values for deposits placed are excluded.

We derive the equilibrium condition emerging from the shadow bank maximization problem given by equation 35 . We derive this condition by making one further assumption about the exclusion of (uninteresting) corner solutions where we have either no or implausible high intermediation. Let an interior equilibrium be defined as a case where $c, C^{+}, C^{-}, c^{b}, C^{b}, d^{c}, d^{s}, b^{c}, b^{s}>0$. We can then verify that, given an interior equilibrium, the shadow bank maximization problem gives

$$
r^{b}=r^{d s}
$$

We can proof this by contradiction. Suppose we have an equilibrium with $r^{b}>$ $r^{d s}$. In this case, the value of $b^{s}$ that solves the shadow bank problem is $b^{s}=$ $+\infty$. However, this value exceeds the maximum possible amount of borrowing for borrowers, which is given by $b^{s} \leq y^{b}$. In this situation, (iii) is not satisfied and we do not have an equilibrium. Suppose now we have an equilibrium candidate 
with $r^{b}<r^{d s}$. In this case, the value of shadow bank borrowing that solves the maximization problem 35 is given by $b^{s}=0$, which contradicts the assumption of an interior equilibrium as this would indicate that no intermediation via shadow banks takes place at all. Thus, we can conclude that if we have an interior equilibrium, we have $r^{b}=r^{d s}$.

Furthermore, due to equation 33, we know that $r^{b}>r^{d c}$ whenever $\mu^{c}>0$, and thus $r^{d s}>r^{d c}$ in this case, which is consistent with equation 10 .

Proposition 5 (Benchmark equilibrium). In a benchmark equilibrium in which we assume both banks to be identical in their structure, such that the only difference between commercial and shadow banks is regulatory coverage, we can verify that, given an interior equilibrium, the shadow bank maximization problem gives

$$
r^{b}=r^{d s}
$$

such that shadow banks do not earn profits on intermediation in the benchmark case.

\section{Financial Friction: Incentive Constraint}

In the benchmark model, shadow banks were assumed to intermediate funds without frictions, which lead to the finding that they earn zero profits and solely intermediate funds efficiently whenever conditions for non-zero intermediation activity are met. We now introduce a financial friction to the shadow banker's problem that allows the shadow bank to earn a rent on intermediation activity, such that $r^{b}=r^{d s}$ does not hold in all circumstances anymore. We thereby rely on the incentive constraint framework as developed in Gertler and Karadi (2011).

\subsection{Shadow Banks}

The friction is located on the shadow bank deposit market, as the shadow banker faces two options now:

- no-default: The shadow bank issues deposits $d^{s}$ in period one, combines them with capital $n^{s}$ to lend out $b^{s}$. It earns profits $r^{b} b^{s}-r^{d s} d^{s}$ in period two. Whenever shadow banks do not default, we are in the case of the benchmark equilibrium. 
- default: The shadow bank issues deposits $d^{s}$ in period one, combines them with capital $n^{s}$ to lend out $b^{s}$. In period two, the bank decides to take a share $\theta\left(1+r^{b}\right) b^{s}$ for private benefit and not to pay the promised returns $\left(1+r^{d s}\right) d^{s}$ back to savers. Depositors thus only receive the part of returns not taken by the bank, i.e. $(1-\theta)\left(1+r^{b}\right) b^{s}$.

For the shadow bank, 'running away' with some of the funds secretly and not repaying their obligations is only worthwile if it increases profits compared to behaving honestly. Thus, the bank will choose the 'no-default' option if, and only if

$$
\left(1+r^{b}\right) b^{s}-\left(1+r^{d s}\right) d^{s} \geq \theta\left(1+r^{b}\right) b^{s}
$$

i.e. if the returns from behaving honestly exceed returns from defaulting. Rearranging yields the incentive constraint of the shadow banker

$$
(1-\theta)\left(1+r^{b}\right) b^{s} \geq\left(1+r^{d s}\right) d^{s}
$$

Savers are aware of the potential moral hazard problem between them and the shadow banker, and thus they would not place any deposit $d^{s}$ in a shadow bank whenever constraint 37 does not hold. If constraint 37 would be violated, the respective shadow bank would pay a return on $d^{s}$ that is below the market return $r^{d s}$. The shadow bank problem in equation 35 is thus changed to

$$
\max _{d^{s}, b^{s}}\left(1+r^{b}\right) b^{s}-\left(1+r^{d s}\right) d^{s}-b^{s}+d^{s}
$$

subject to constraint 37 .

\subsection{Incentive Constraint Equilibrium}

Introducing the moral hazard problem between savers and shadow banks changes the problem of the shadow banks and thus the resulting equilibrium differs from the benchmark case.

In total, we still have 13 endogenous variables in the model: $c, C^{+}, C^{-}, c^{b}, C^{b}$, $d^{c}, d^{s}, b^{c}, b^{s}, b, r^{d c}, r^{d s}, r^{b}$.

The 13 equations to solve the model are given by: 
(i) Equations 13 to 17 solve the saver problem

(ii) Equations 25 to 27 solve the borrower problem

(iii) Equations 28 and 33 solve the commercial bank problem

(iv) The shadow bank problem 38 is solved, see below.

(v) We furthermore have the securities market clearing condition

$$
b=b^{c}+b^{s}
$$

and

(vi) condition 10 which has to hold such that negative values for deposits placed are excluded.

The key distinction between the benchmark and the incentive friction equilibrium depicts the possibility of two types of equilibria instead of one, one type where the spread $r^{b}-r^{d s}$ is equal to zero (as in the benchmark case) and another type with $r^{b}>r^{d s}$.

We can rewrite constraint 37 such that

$$
(1-\theta)\left(1+r^{b}\right) n^{s} \geq\left[\theta\left(1+r^{b}\right)-\left(r^{b}-r^{d s}\right)\right] d^{s}
$$

In the case where the shadow banker chooses the no-default option, we know that he makes zero profits and thus the equilibrium value of shadow bank deposits $d^{s}$ is determined by savers, i.e. by equation 13. Furthermore, we know that $r^{b}=r^{d s}$. Plugging in the derived term for $d^{s}$ in equation 40 therefore yields

$$
(1-\theta)\left(1+r^{b}\right) \geq\left[\theta\left(1+r^{b}\right)-\left(r^{b}-r^{d s}\right)\right] \frac{\beta^{s}}{1+\beta^{s}} \frac{\left(1+r^{d s}\right) p-\left(1+r^{d c}\right)}{r^{d s}-r^{d c}} \frac{y}{n^{s}}
$$

Define

$$
B \equiv \frac{\beta^{s}}{1+\beta^{s}} \frac{\left(1+r^{d s}\right) p-\left(1+r^{d c}\right)}{r^{d s}-r^{d c}} \frac{y}{n^{s}}
$$

such that

$$
(1-\theta)\left(1+r^{b}\right) \geq\left[\theta\left(1+r^{b}\right)-\left(r^{b}-r^{d s}\right)\right] B
$$


and thus

$$
0 \leq \theta \leq \frac{1}{1+B}
$$

Given our assumptions on the spread between the two deposit rates, equation 11 , and on the non-negativity of model paramters $p, \beta^{s}$ and endowments $y$ and $n^{s}$, we know that $B>0$. Whenever $\theta$ is relatively small, i.e. the divertible share of assets is small, and when net worth $n^{s}$ is relatively large, constraint 40 is satisfied and shadow banks do not default and earn zero profits. In this case, the incentive friction and the benchmark equilibrium coincide.

Whenever condition 40 is violated for $r^{b}=r^{d s}$ and the no-default equilibrium value of $d^{s}$, we know that the amount of deposits savers want to place exceeds the amount consistent with the incentive constraint. From the expression of shadow bank deposits demanded by savers, equation 13, we know that $d^{s}$ is increasing in $r^{d s}$. Thus, to reach equilibrium at a lower value of $d^{s}$ as in the case where constraint 40 holds, $r^{d s}$ has to decrease such that we find an equilibrium with $r^{b}>r^{d s}$.

To find the equilibrium value of $d^{s}$, we introduce the term $d^{s, S}$ to indicate the level of deposits shadow banks want to supply, whereas the term $d^{s}$ still describes the demand for shadow bank deposits by savers, given by equation 13 . Whenever $r^{b}>r^{d s}$, we know that shadow bank profits are strictly increasing in $d^{s, S}$, such that shadow banks will provide the maximum amount of deposits feasible under the incentive constraint 40. Solving the constraint for $d^{s, S}$ with equality gives:

$$
d^{s, S}=\frac{(1-\theta)\left(1+r^{b}\right)}{r^{d s}-(1-\theta) r^{b}+\theta} n^{s}
$$

Thus, $d^{s, S}$ is a function of $r^{d s}$ defined over the interval

$$
\left((1-\theta) r^{b}-\theta, r^{b}\right]
$$

as we set the assumptions of strictly positive deposits and a non-negative spread $r^{b}-r^{d s}$. As $r^{d s}$ converges towards the upper limit of the interval, we get

$$
d^{s, S} \rightarrow \frac{1-\theta}{\theta} n^{s}
$$

We see from equation 42 that $d^{s, S}$ is strictly increasing when $r^{d s}$ decreases and approaches $+\infty$ as $r^{d s}$ converges towards to lower limit of the interval, $(1-\theta) r^{b}$. At the same time, deposit demand by savers, $d^{s}$, is strictly decreasing as $r^{d s}$ falls 
towards $(1-\theta) r^{b}$ and is a well-defined and positive number under the assumptions set on rates and model parameters. Given that

$$
\begin{gathered}
d^{s}>d^{s, S} \text { as } r^{d s} \rightarrow r^{b} \\
d^{s}<d^{s, S} \text { as } r^{d s} \rightarrow(1-\theta) r^{b}
\end{gathered}
$$

and given the continuity and monotonicity of functions 13 and 42 we know that a unique $r^{d s} \in\left((1-\theta) r^{b}, r^{b}\right]$ exists such that $d^{s}=d^{s, S}$. To find the equilibrium shadow bank deposit rate, we have to equate shadow bank deposit demand (equation 13) with supply of deposits by shadow banks (equation 42) and solve for $r^{d s}$ :

$$
\frac{\beta^{s}}{1+\beta^{s}} \frac{\left(1+r^{d s}\right) p-\left(1+r^{d c}\right)}{r^{d s}-r^{d c}} y=\frac{(1-\theta) r^{b}}{r^{d s}-(1-\theta) r^{b}} n^{s}
$$

Thus, whenever condition 41 is satisfied, the incentive constraint friction and the benchmark equilibrium coincide. If condition 41 is violated, the incentive constraint friction equilibrium is characterized by $r^{b}>r^{d s}$ and a unique value for $r^{d s}$ that solves the market for shadow bank deposits can be found.

Proposition 6 (Incentive constraint equilibrium). Whenever the share of divertible funds $\theta$ is sufficiently small or shadow bank net worth $n^{s}$ is sufficiently large, the incentive constraint does not bind and the benchmark and financial friction equilibrium coincide. In this case, shadow banks do not earn profits. Otherwise, the incentive constraint is binding, and shadow banks earn a positive spread on intermediation, i.e. $r^{b}>r^{d s}$.

\section{Financial Friction: Borrowing Constraint}

So far, we discussed potential model implication due to an incentive constraint friction for shadow banks on deposit markets but treated conditions on loan markets in a rather rudimentary fashion. We simply assumed loans from both shadow banks and commercial banks to be perfect substitutes that both intermediaries provide to the same type of borrowers. As a consequence, the rates charged on both shadow bank and commercial bank loans turned out to be identical.

We therefore introduce heterogeneity in loan markets and motivate differences in loan rates and volumes by a different degree of regulatory coverage in the two 
sectors: Whereas the regulator can directly affect the minimum amount of collateral a commercial bank demands from potential borrowers, loan-to-value (LTV) ratios cannot be introduced as a regulatory tool in the shadow banking sector. With respect to shadow bank lending, any constraint borrowers face emerges without direct regulation but only depends indirectly on commercial bank regulation as well as on the underlying risk with respect to the value of the collateral asset the borrower can provide. To do so, we introduce a second friction to the model which is located between the borrower and the intermediaries, affecting lending of both shadow banks and commercial banks. We follow Iacoviello (2005) and require borrowers to pose collateral to any bank whenever they want to borrow funds. In our model, both the commercial and the shadow bank require a certain share of their lending $b^{c}$ and $b^{s}$ to be backed by collateral, whereas commercial bank requirements are affected by direct regulation.

\subsection{Borrowers}

As in section 1.2, borrowers can acquire funding from both commercial and shadow banks. However, we introduce two additional constraints on borrowing, each related to one type of bank. Now, both banks lend funds only against some collateral the borrower has to provide. To introduce collateral to the model, we assume that borrowers, on top of the resource endowment $y^{b}$ they receive at period two, are holders of an externally given capital good $k$ that they receive at the beginning of period one. In this simple version of the model, $k$ depicts some wealth endowment that borrowers hold but cannot use for consumption or sell/rent out on a secondary market. ${ }^{6}$ They simply own the stock of $k$, which is only of value for them as it is accepted by intermediaries as collateral. Whereas the borrowers receive the endowment $k$ in the first period, some uncertainty about the capital holdings in period two, $K$, remain. More precisely, we assume that due to some external disturbances, some share of period-one capital $k$ could be destroyed in period two, and we assume two potential outcomes for the collateral holdings of the borrower in the second period:

$$
K= \begin{cases}k^{+}=k & \text { with probability } p^{b} \\ k^{-} & \text {with probability } 1-p^{b}\end{cases}
$$

\footnotetext{
${ }^{6}$ In the complete DSGE model, entrepreneurs which act as borrowers can provide physical capital they use in production as collateral to banks.
} 
We assume that whenever the bad state occurs in period two, borrowers suffer from some destruction of capital, such that $k^{-}<k$. The probability for remaining in the good state where no capital is destructed in period two is given by $p^{b}$. The expected period-two holdings of capital are thus given by

$$
E\{K\}=p^{b} k+\left(1-p^{b}\right) k^{-}
$$

When granting loans to borrowers, each intermediary can claim a share of collateral in case the borrower cannot repay his funds. However, we assume heterogeneity in the way the collateral claims emerge. In the case of commercial banks, we assume that borrowers have to fulfill an exogenous loan-to-value ratio $m^{c} \in(0,1)$ such that each unit of lending taken on in period one plus respective interest payments due in period two must be backed by a minimum amount of capital. While deciding on the level of $m^{c}$, the prudential regulator is aware of the fact that some capital might be destructed in period two, and therefore sets a limit on the amount commercial banks can lend to borrowers based on the expected level of collateral available in period two:

$$
\left(1+r^{b c}\right) b^{c} \leq E\{K\}
$$

Equation 45 states that borrowers can only borrow up to the limit to which their debt with commercial banks and the agreed interest payments in period two are backed by the expected amount of capital they hold in period two. By rewriting equation 45 such that

$$
\left(1+r^{b c}\right) b^{c} \leq \frac{E\{K\}}{k} k
$$

we get the commercial bank collateral constraint

$$
\left(1+r^{b c}\right) b^{c} \leq m^{c} k
$$

with $m^{c}=\frac{E\{K\}}{k}$

As the expected value of collateral held in period two depends on the probability $p^{b}$, the loan-to-value ratio demanded by the regulator depends on the probabilitiy of being in the good state. A higher likelihood of being in the good state where no capital is destroyed in period two raises the expected value of collateral $E\{K\}$, and 
therefore borrowers can aquire more funds relative to period-one capital holdings, as the loan-to-value ratio $m^{c}$ rises.

For shadow bank lending, we do not assume an explicit regulatory loan-to-value ratio that borrowers have to adhere to. We assume that even though aware of the risk of the occurence of the low-capital state in period two, shadow banks are willing to provide funds beyond the level borrowers can acquire from commercial banks. Thus, whereas in expectation all lending by commercial banks will be backed with collateral $K$ in period two, some share of shadow bank loans might not be backed by collateral and shadow bankers are aware of the risk that they will not be able to draw on borrower collateral in period two. They thus face potential losses in period two and are only willing to provide extra funding beyond the level backed by the expected period-two value of collateral in return for higher interest on their loans in comparison to commercial banks. The loan rate spread will depend on the probability of ending up in the high-capital regime $p^{b}$ :

$$
1+r^{b s}=\frac{1+r^{b c}}{p^{b}}
$$

Due to the higher rate charged on shadow bank loans whenever $0<p^{b}<1$, borrowers will turn to commercial banks first to acquire funding and only turn to shadow banks when they have reached the maximum amount of funding they can acquire under regulation $m^{c} \cdot{ }^{7}$ By receiving adequate compensation, shadow banks are willing to provide lending up to total capital holdings in period one, and given that borrowers only tap on shadow bank funding once the limit with commercial bank funding is reached, the shadow bank borrowing constraint is given by

$$
\left(1+r^{b}\right) b^{s} \leq k-E\{K\}
$$

or

$$
\left(1+r^{b}\right) b^{s} \leq\left(1-\frac{E\{K\}}{k}\right) k
$$

\footnotetext{
${ }^{7}$ Generally, borrowers could decide not to tap on the full borrowing capacity and not turn to shadow bank borrowing if their expected capital holdings are large enough to back their demand for lending with commercial bank credit. In this case, there would be no need for shadow banking and all loan demand could be met by commercial banks. We assume that the marginal benefit from period-one consumption is sufficiently large in relation to interest rate charges by shadow banks, such that acquiring further funds from shadow banks is profitable for borrowers.
} 
or

$$
\left(1+r^{b}\right) b^{s} \leq\left(1-m^{c}\right) k
$$

In any case, borrowers will be able to borrow against the total amount of capital $k$ they hold in period one, independent of the risk of capital losses in period two. Whenever commercial banks refuse to provide funding beyond the expected value of period-two capital, $E\{K\}$, shadow banks will step in and provide more risky funding, $k-E\{K\}$. In this way, the model features some form of subprime lending conducted in the shadow banking sector, a major threat to financial stability discussed among policy makers. The budget constraints for periods one and two are thus given by

$$
c^{b} \leq b^{c}+b^{s}
$$

and

$$
C^{b}+\left(1+r^{b c}\right) b^{c}+\left(1+r^{b s}\right) b^{s} \leq y^{b}+k
$$

The maximization problem of the borrower is now given by

$$
\max _{c^{b}, C^{b}, b^{c}, b^{s}} u\left(c^{b}\right)+\beta^{b} u\left(C^{b}\right)
$$

or

$$
\max _{b^{c}, b^{s}} u\left(b^{c}+b^{s}\right)+\beta^{b} u\left(y^{b}+k-\left(1+r^{b c}\right) b^{c}-\left(1+r^{b s}\right) b^{s}\right)
$$

s.t. constraints 47 and 49 .

From constraint 49 we know that

$$
\frac{\left(1+r^{b s}\right) b^{s}}{1-m^{c}} \leq k
$$

and thus, assuming equality of constraints 47 and $49^{8}$, we get

$$
\left(1+r^{b c}\right) b^{c}=m^{c} \frac{1+r^{b s}}{1-m^{c}} b^{s}
$$

${ }^{8}$ We assume that borrowers tap on the complete borrowing capacity, as we will assume the respective constraints to be binding in the steady state of the DSGE model described in the paper. 
or

$$
b^{c}=\frac{m^{c}}{1-m^{c}} \underbrace{\frac{1+r^{b s}}{1+r^{b c}}}_{\frac{1}{p^{b}}} b^{s}
$$

The maximization problem is thus given by

$$
\max _{b^{s}} u\left(\frac{m^{c}}{1-m^{c}} \frac{1}{p^{b}} b^{s}+b^{s}\right)+\beta^{b} u\left(y^{b}+k-\left(1+r^{b c}\right) \frac{m^{c}}{1-m^{c}} \frac{1}{p^{b}} b^{s}-\left(1+r^{b s}\right) b^{s}\right)
$$

Again, we assume log-utility such that the first-order condition yields

$$
C^{b}=\beta^{b}\left[\frac{\left(1+r^{b c}\right) \frac{1}{p^{b}}\left(\frac{m^{c}}{1-m^{c}}+1\right)}{\frac{m^{c}}{1-m^{c}} \frac{1}{p^{b}}+1}\right] c^{b}
$$

Using constraints 47, 49 and 50 as well as equation 56, we can simplify such that

$$
C^{b}=\beta^{b} k
$$

Using this expression for $C^{b}$ in the period-two budget constraint 51, assuming equality and using condition 48 and equation 56 again, yields

$$
b^{s}=\left[y^{b}+k\left(1-\beta^{b}\right)\right] \frac{p^{b}\left(1-m^{c}\right)}{1+r^{b c}}
$$

Using equation 60 in equation 56 , we can derive

$$
b^{c}=\frac{m^{c}}{1+r^{b c}}\left[y^{b}+k\left(1-\beta^{b}\right)\right]
$$

Finally, we can derive an expression for period-one consumption $c^{b}$ by combining equation 61 and the period-one budget constraint 50:

$$
c^{b}=\frac{m^{c}+p^{b}\left(1-m^{c}\right)}{1+r^{b c}}\left[y^{b}+k\left(1-\beta^{b}\right)\right]
$$

\subsection{Borrowing Constraint Equilibrium}

Having introduced a second set of financial frictions, we are now able to state the equilibrium conditions for the model featuring both an incentive constraint problem 
on the deposit market as well frictions arising from collateral constraints on the loan market.

By introducing heterogeneity to loan markets, the model now features interest rates on both shadow bank and commercial bank loans $-r^{d s}$ and $r^{d c}$, respectively instead of a single loan rate as in the previous section. Thus, the model now features 14 endogenous variables: $c, C^{+}, C^{-}, c^{b}, C^{b}, d^{c}, d^{s}, b^{c}, b^{s}, b, r^{d c}, r^{d s}, r^{b c}, r^{b s}$.

The 14 equations solving the model are now given by:

(i) Equations 13 to 17 solve the saver problem

(ii) Equations 59, to 62 solve the borrower problem

(iii) Equations 28 and 33 solve the commercial bank problem

(iv) The shadow bank problem 35 is solved as in section 2.1, assuming a case of a binding incentive constraint.

(v) We furthermore have the securities market clearing condition

$$
b=b^{c}+b^{s}
$$

and

(vi) condition 10 which has to hold such that negative values for deposits placed are excluded.

The results for borrowers derived in the section 3.1 can be summarized as in Proposition 7.

Proposition 7 (Borrowing constraint equilibrium). Whenever regulators set the loan-to-value ratio $m^{c}$ equal to the expected value of period-two capital holdings, $E\{K\}$, borrowers will use period-one collateral not reserved for commercial bank loans and turn to shadow banks, once the borrowing capacity for commercial bank funds is exhausted. As shadow bank lending is not necessarily backed by collateral, the spread between shadow bank and commercial bank loan rates is positive. 


\section{Evaluation}

\subsection{Deposit Market Equilibrium: The Incentive Constraint Friction}

We now evaluate the effects of changes in capital requirements in the benchmark model and how introducing the incentive constraint to the shadow bank problem affects responses to regulation. In the analysis, we evaluate the reactions on and interplay between the two markets for shadow bank and commercial bank deposits whenever capital requirements are changed. Our parameterization ensures that a positive amount of deposits is placed with shadow banks and that the wholesale units of commercial banks operate at the capital requirement $\nu$ in the benchmark equilibrium. For the incentive constraint model, we choose parameters such that the friction and benchmark equilibria do not coincide. When introducing the incentive constraint friction, we calibrate $\theta$, and set all other parameters as in the benchmark case, see Table $1 .{ }^{9}$ We also choose parameters such that commercial banks operate at the regulatory capital requirement in equilibrium, such that the positive spread earned on intermediation by commercial banks is determined by the markup retail banks can charge, $\mu^{c}$ alone (equation 33 ).

Table 1: Parameter Values Benchmark Model

\begin{tabular}{lc} 
Parameter & Value \\
\hline$p$ & 0.9951 \\
$\beta^{s}$ & 0.95 \\
$\beta^{b}$ & 0.9 \\
$n^{c}$ & 0.02 \\
$n^{s}$ & 0.0011 \\
$y$ & 1 \\
$y^{b}$ & 1 \\
$\kappa$ & 100 \\
$\nu$ & 0.075 \\
$\mu^{c}$ & 0.01 \\
$\theta$ & 0.5 \\
\hline \hline
\end{tabular}

\footnotetext{
${ }^{9}$ We set most parameters close to the values later used in the DSGE model calibration. For deviating parameters, for instance the shadow bank net wort $n^{s}$ and the commercial bank capital adjustemnt cost $\kappa$, values are chosen to get interpretable results in the simulation exercise.
} 
In Figure 1, we report equilibrium values of endogenous variables for a grid of values of the capital requirement $\nu$, both for the benchmark model and the incentive constraint model described above. In both versions of the model, the total amount of lending is determined on the loan market only by demand for loans from borrowers, and thus not (directly) affected by capital requirements. The shares of lending undertaken by commercial and shadow banks, however, are affected by the level of capital requirements set by the regulator for commercial banks, with increasing capital requirements resulting in an increasing share of shadow bank lending. We now evaluate both deposit markets in detail to shed more light on the causes of the shift towards shadow bank deposits whenever commercial bank capital requirements increase. Figures 2 and 3 depict both deposit markets in a stylized fashion. On both markets, savers supply deposits according to an upward-sloping supply curve, as indicated by equations 13 and 14. Banks are depicted as demanders of deposits whereas commercial banks are characterized by a downward-sloping demand curve, as indicated by equation 33, assuming that borrowing $b^{c}$ and deposits $d^{c}$ move in the same direction (Figure 3). In the shadow bank deposit market described by the benchmark model, we know that $r^{b}=r^{d s}$ and therefore shadow bank deposit demand is characterized by a horizontal demand curve, $d_{d 1}^{s}$.

According to equation 33, an increase in capital requirements widens the gap between the actual level of capital to assets the commercial bank holds and the regulatory capital-to-asset ratio, if we assume that commercial banks originally operated with capital-to-asset ratios equal to the requirement. ${ }^{10}$ In this case, the marginal cost of intermediation, indicated by the right-hand side of equation 31, rises. To reduce marginal costs, commercial banks can reduce their lending, $b^{s}$, and, given bank capital $n^{c}$ to be fixed in the short run, thereby reduce their demand for household deposits, resulting in a shift of the deposit demand curve $d_{d 1}^{c}$ of commercial banks to the left in Figure $2\left(d_{d 2}^{c}\right)$. As a consequence, deposit levels and rates fall with rising capital requirements, as observed in the simulation results in Figure 1. Thus, higher capital requirements for commercial banks, by raising marginal costs of intermediation, result in lower lending activity and ultimately squeeze marginal

\footnotetext{
${ }^{10}$ We do not consider cases where $\frac{n^{c}}{b^{c}} \geq \nu$ for two reasons. First, whenever $\frac{n^{c}}{b^{c}} \geq \nu$, commercial banks would hold more capital than required by the regulator and thus hold inefficiently high levels of costly capital compared to deposits, which would only be justfied in the case of precautionary motives, which we do not consider here. Furthermore, according to equation $33, \frac{n^{c}}{b^{c}} \geq \nu$ would indicate a negative spread between commercial bank lending and deposit rates, in which case optimal intermediation by commercial banks would be zero.
} 
Figure 1: Changes in Capital Requirements
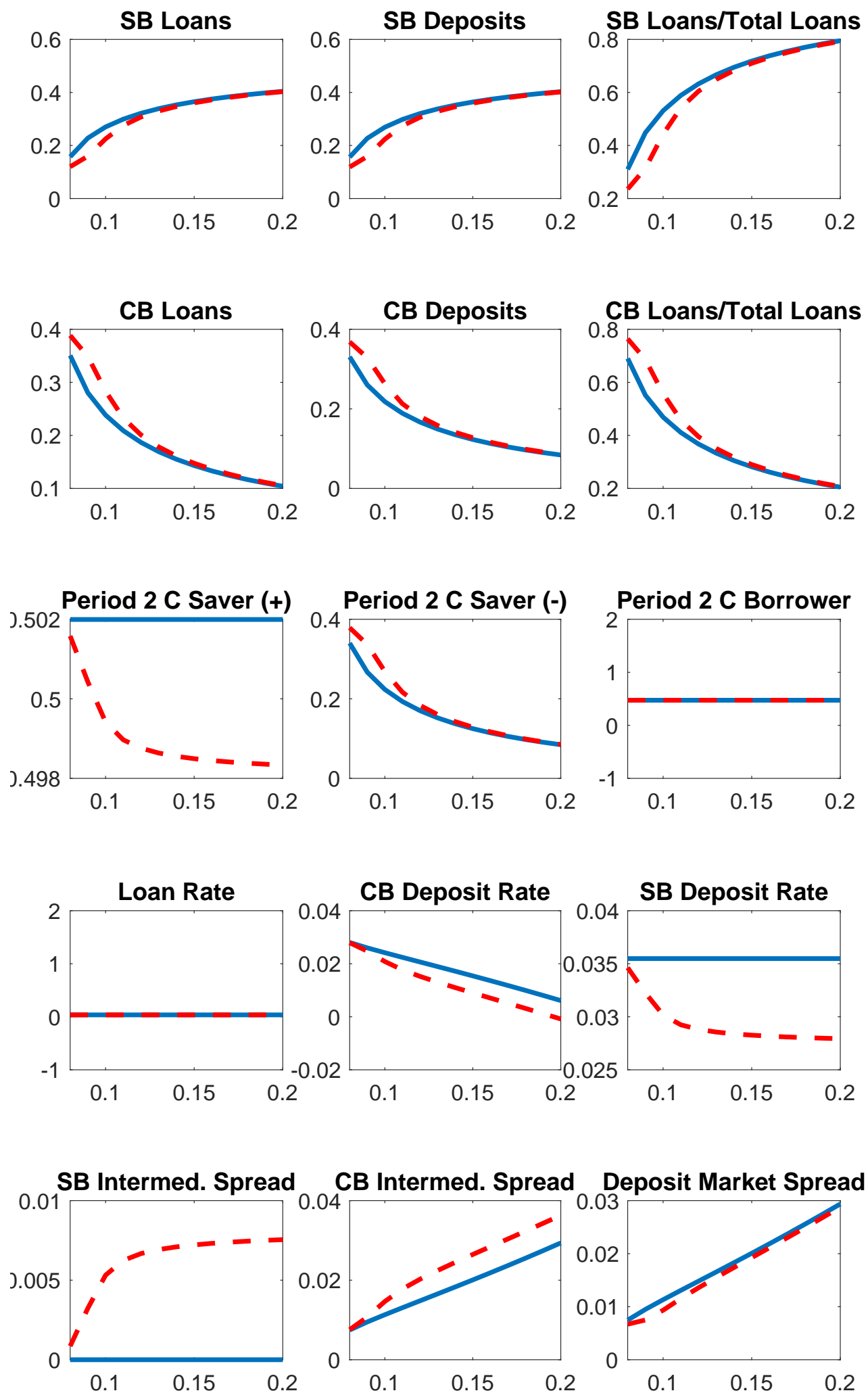

Benchmark - Incentive Constr. 
Figure 2: Commercial Bank Deposit Market

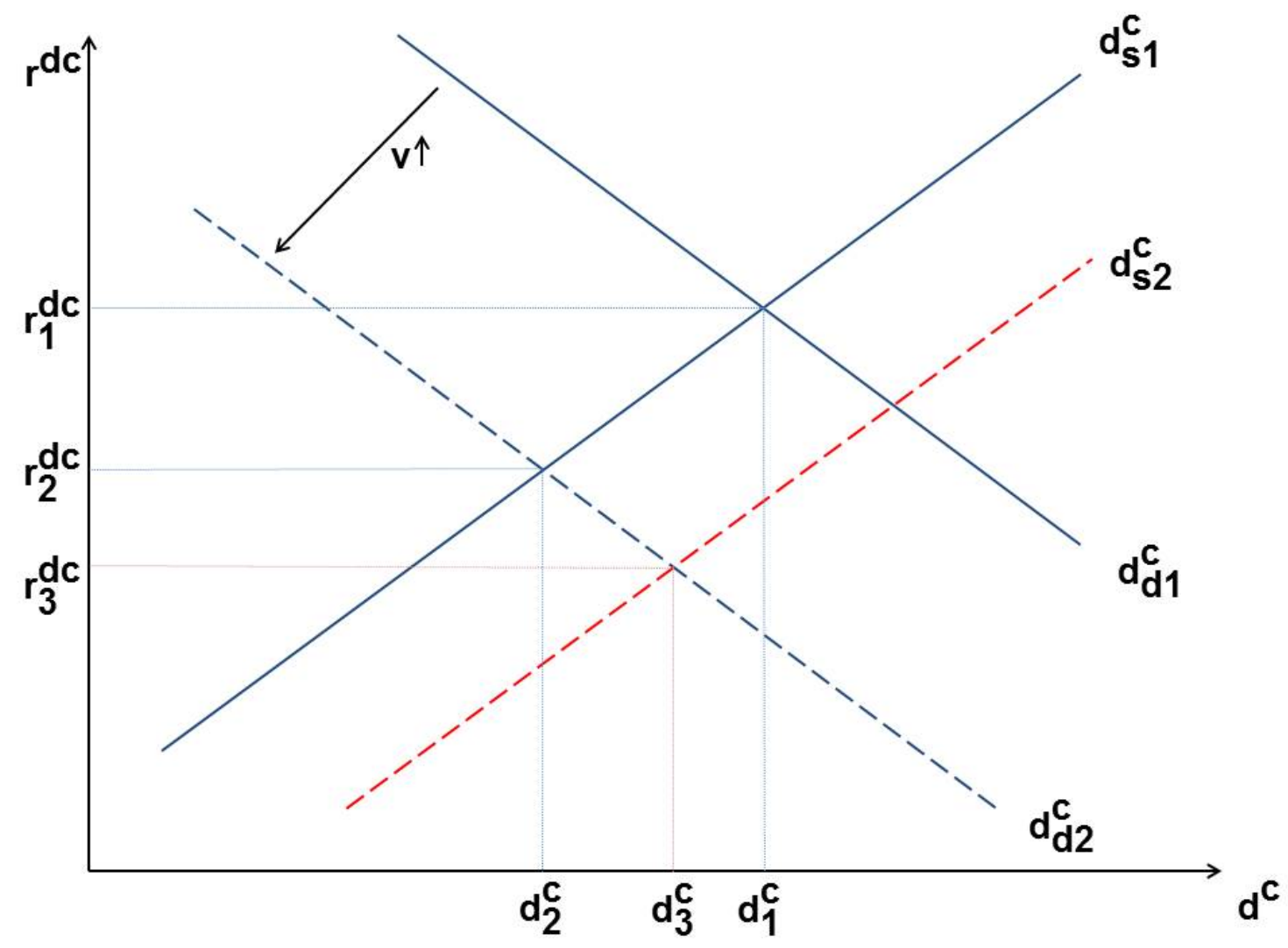


Figure 3: Shadow Bank Deposit Market

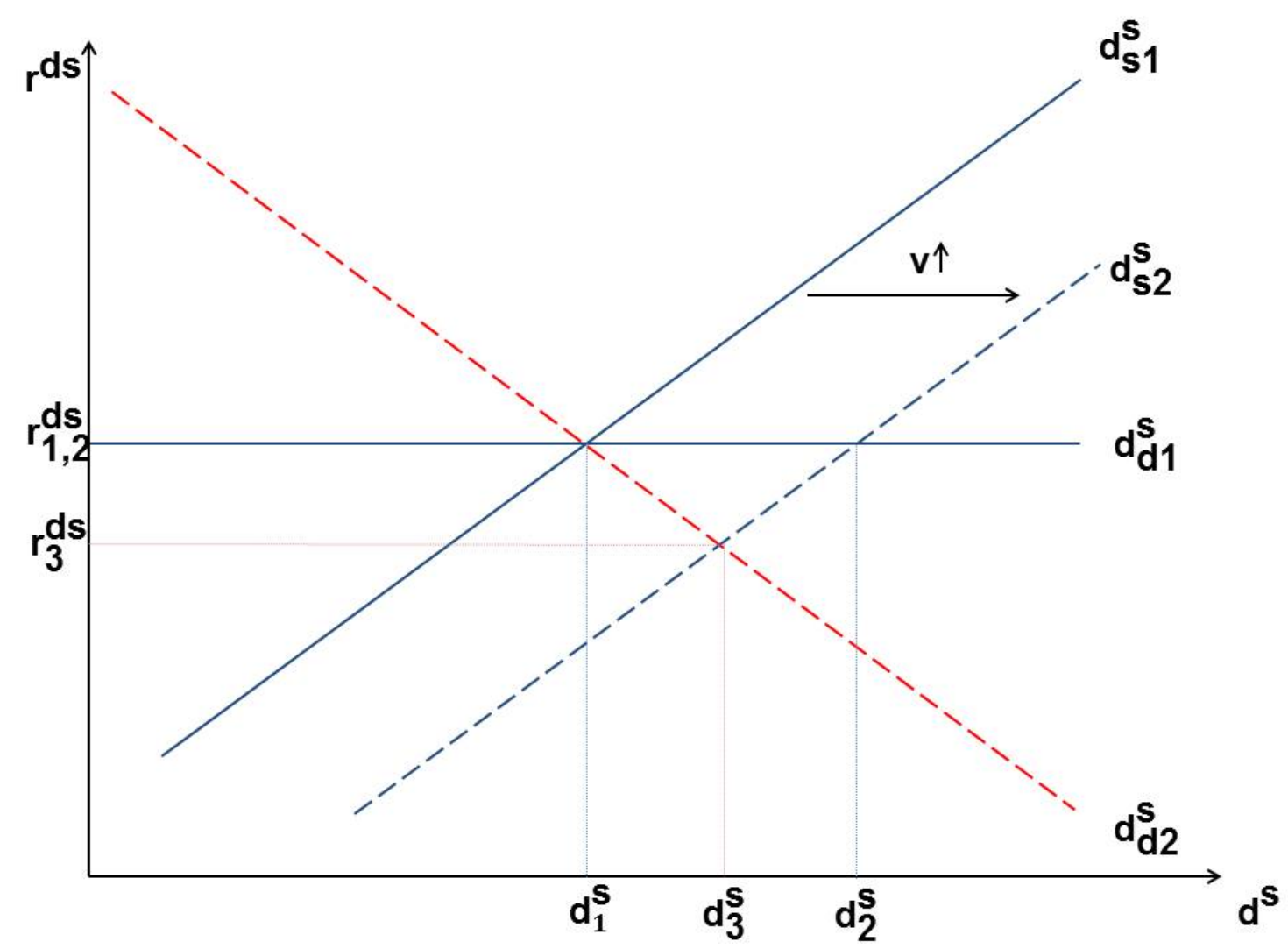


profits of commercial banks.

Turning to the market for shadow bank deposits (Figure 3), we see that a relative decrease in commercial bank intermediation due to tighter regulation is compensated by an increase in shadow bank intermediation, as the total demand for bank loans, $b$, is determined independent from the deposit market movements and not affected by regulatory changes in the commercial banking sector. ${ }^{11}$ Falling rates on commercial bank deposits increase the deposit rate spread $r^{d s}-r^{d c}$, and, according to equation 13 , raise savers supply of deposits, $d^{s}$, resulting in a shift of the deposit supply curve $d_{s 1}^{s}$ to the right in Figure $3\left(d_{s 2}^{s}\right)$. As a consequence, shadow bank deposits, and ultimately lending, increase whenever capital requirements for commercial banks are raised.

We now consider the impact of introducing the incentive constraint friction in the model on the markets for commercial and shadow bank deposits. As stated in Proposition 5, whenever condition 41 is violated, as in the cases we evaluate, the spread on shadow bank intermediation, $r^{b}-r^{d s}$ turns out to be positive. Therefore, shadow banks are no longer characterized by a horizontal, but by a downwardsloping demand curve $d_{d 2}^{s}$ when the incentive constraint friction is introduced. By introducing a positive spread between loan and deposit rates, shadow banks are, as their commercial counterparts, willing to accept more deposits whenever the rate they have to pay on deposits $r^{d s}$ decreases. On the shadow bank deposit market, as depicted in Figure 3, the same shift of deposit supply due to tighter commercial bank regulation as before still results in an increase in shadow bank deposits, even though the level of deposits is relatively lower as induced by a similar shift in the benchmark model, given that the original equilibrium was the same. Furthermore, and as indicated by Proposition 5, the rate on shadow bank deposits $r^{d s}$ is now lower than $r^{b}$; both increasing shadow bank deposits and decreasing deposit rates are again indicated by simulations in Figure 1.

The fall in shadow bank deposit rates once the incentive constraint friction is introduced, ceteris paribus, reduces the spread between shadow and commercial bank deposit rates, $r^{d s}-r^{d c}$ compared to the benchmark case. Therefore, commercial bank deposits become relatively more attractive in the financial friction case, such that commercial bank deposit supply by savers shifts to the right in Figure 2. Increasing capital requirements still induce the same shift of deposit demand by commercial

\footnotetext{
${ }^{11}$ In the full model presented in section 3 of the paper, loan demand will be determined by the real side of the economy, namely by production decisions of entrepreneurs.
} 
banks as in the benchmark case $\left(d_{d 2}^{c}\right)$. However, the now contemporaneously induced shift in commercial bank supply of savers $\left(d_{s 2}^{c}\right)$, driven by developments in the shadow bank deposit market (Figure 3), ultimately leads to a new equilibrium in the commercial bank deposit market where deposits still fall due to an increase in capital regulation, but to a lower extent than in the benchmark case. Furthermore, commercial bank deposit rates fall by more whenever capital requirements are raised in the financial friction model compared to the benchmark. Again, simulations in Figure 1 highlight these developments.

Overall, increasing capital requirements for commercial banks provide some scope for leakage of financial intermediation towards shadow banks in the two-period model we derived, even though the magnitude of lending leakage is somewhat reduced when we pose restrictions on shadow banks, i.e. introduce a moral hazard problem between shadow banks and savers, as interest rate adjustments cushion some of the quantity effects relative to the benchmark case. In our setup, relative changes on deposit markets due to regulation are transmitted, via balance sheets of intermediaries, to the credit markets, which we assume to be homogeneous in the setup.

\subsection{Loan Market Equilibrium: The Borrowing Constraint Friction}

In section 4.1, we discussed the effects of changes in capital requirements in the benchmark case without financial frictions and evaluated how introducing an incentive constraint in the spirit of Gertler and Karadi (2011) affects equilibrium values. For the sake of brevity, we do not again discuss the model mechanism of how changes in capital requirements affect deposit markets, as the key mechanism is not affected by the introduction of heterogeneity in the loan market.

In the following, we provide evidence on how changes in the second macroprudential tool that we introduced in the previous section, i.e. regulatory requirements on the level of loan-to-value (LTV) ratios for commercial banks, affect model variables in equilibrium. In Figure 4, we show simulation results for changes in the LTV ratio over a grid of 50 to 100 percent. As we linked the level of the LTV ratio to the probability of being in the high-valued collateral state, we know that an increase in the LTV ratio indicates an increase in the probability of borrowers to have high collateral value at hand in the second period. We use the same calibration as in Table 1 in the previous section, and assume the probability $p^{b}$ of borrowers ending up with a low value of collateral $k^{-}$in period two to be equal to the probability $p$ of savers 
being confronted with a low outcome for period-two consumption, $C^{-}$. In this sense, we can assume that both events are related: whenever borrower collateral turns out to be of low value, shadow bank loans will surely not be backed by collateral, and in the model, they consequently default. In this case, savers cannot reclaim their investments and therefore only receive returns on deposits placed with commercial banks, which ultimately reduces their consumption possibilities in period two.

As described by equations 60 and 61, an increase in the LTV ratio increases lending of commercial banks and reduces shadow bank lending. An increase in the commercial bank LTV ratio allows borrowers to draw more extensively on funding provided by commercial banks as constraint 47 is relaxed. As shadow banks charge higher interest due to the collateral risk they face, increasing the LTV ratio raises borrower demand for commercial bank credit and crowds out shadow bank lending. Ceteris paribus, an increase in demand for commercial bank loans raises the rate charged on commercial bank lending, and the intermediation spread for commercial banks, $r^{b c}-r^{d c}$, widens. By implication, demand for shadow bank loans decreases, and both the volume of shadow bank lending, $b^{s}$, and the spread earned by shadow banks on intermediation, $r^{b s}-r^{d s}$, decrease.

At the same time, credit supply is affected by a changing degree of regulation. Raising the LTV ratio for commercial banks also increases the amount of lending commercial banks can provide, and they will do so if the spread they earn on intermediation is positive. This dampens the positive effect of increasing demand for commercial bank credit on commercial bank loan rates. Contemporaneously, shadow bankers know that borrowers will prefer commercial bank lending due to the lower rate charged, and also anticipate that higher levels of LTVs reduce the share of borrowers' collateral they can claim in case of default, which is given by $\left(1-m^{c}\right) k$ according to constraint 49. Consequently, shadow bankers reduce their credit supply, which mitigates the increase in the shadow bank loan rate, ceteris paribus.

In reality, whether the spread between the rates charged on the two loan markets, $r^{b s}-r^{b c}$, should increase or not whenever commercial bank regulation is changed, is not clear a priori and crucially depends on the function of shadow banks and the type of borrowers attracted. For instance, if shadow banks are perfect substitutes for commercial bank lending, indicating that business models and customer bases are similar, one would expect the spread between rates charged on shadow bank and commercial bank loans to decrease. Lowering commercial bank regulation by raising 
Figure 4: Changes in Commercial Bank LTV Ratio
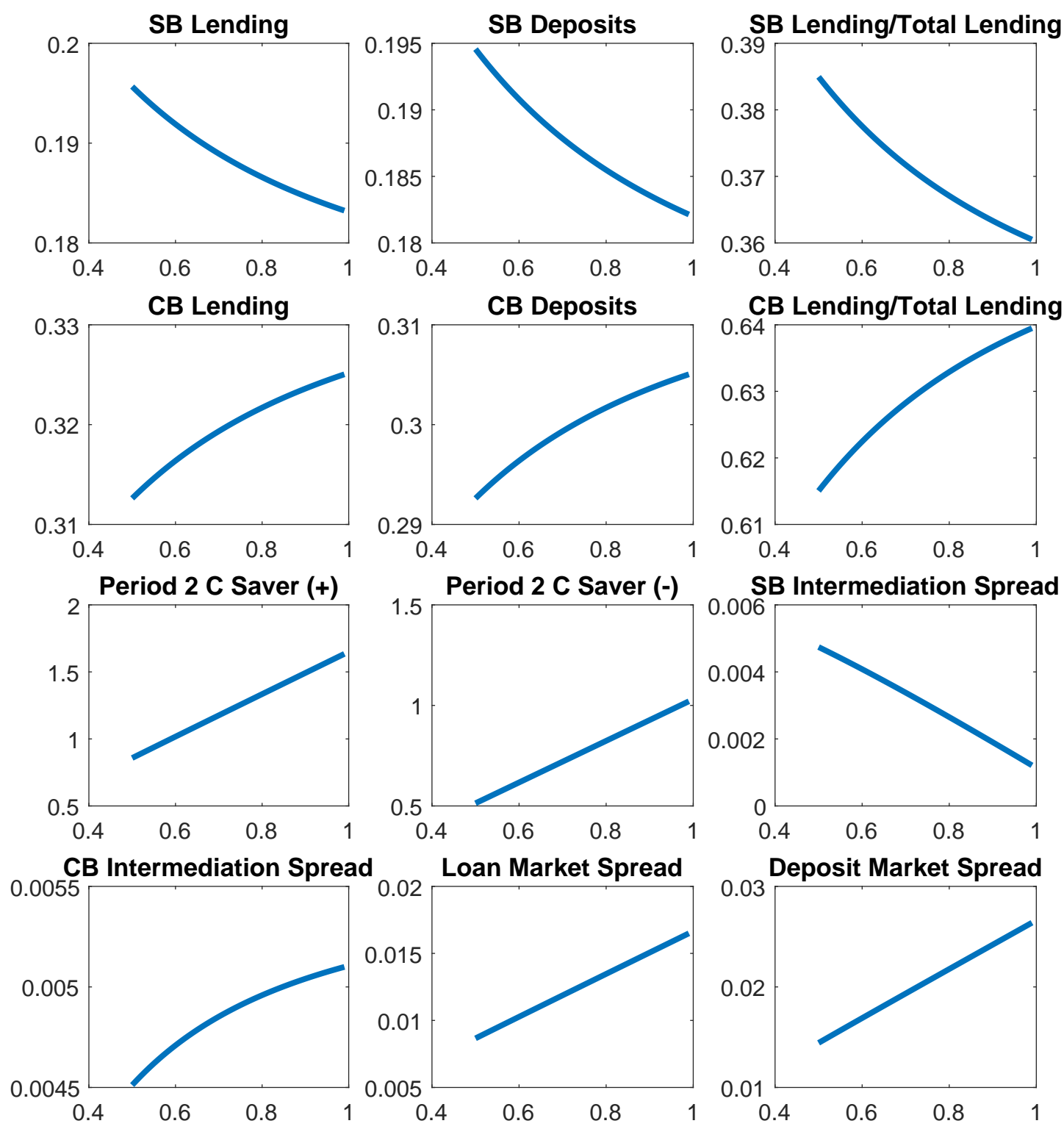
LTV ratios should result in a decrease the rate charged on shadow bank lending, as customers prefer loans from regulated and safe banks, at least in relative terms. However, whenever the asset structure of commercial banks' and shadow banks' balance sheets is differently affected by changes in regulation, the development of loan rates might change. For instance, if shadow banks are primarily engaged in subprime lending, lowering regulatory standards for commercial banks could attract borrowers who were not able to receive funding from commercial banks under previously tighter regulatory standards and turned to shadow banks before. Due to such crowding-in of borrowers to the commercial banking sector, the risk profile of borrowers in the pool of shadow bank borrowers could deteriorate. As relatively solvent borrowers are, under the now looser regulation for commercial banks, able to draw on funding from these institutions, the average quality of borrowers in the pool of shadow bank borrowers deteriorates. As a consequence, shadow banks would be oblidged to charge higher rates on average to compensate for the increasing level of risk, and the spread between shadow bank and commercial bank loan rates would widen.

Thus, the development of the spread between the rates charged on the two loan markets, $r^{b s}-r^{b c}$, depends on both borrower and banking conditions, or, turning to our model, on the steepness of the supply and demand curves on both deposit markets, as well as on the parameterization. With the chosen specification, the model described in this section appears to be a representation of the second case, as the loan market spread increases in response to higher LTV ratios. ${ }^{12}$ We furthermore see that developments on the loan market are transmitted towards deposit markets, as the deposit rate spread $r^{d s}-r^{d c}$ rises: a higher share of lending conducted by commercial banks in response to lower regulatory burden increases the supply of deposits by commercial banks, as they require - with fixed bank capital in the short run - external funds to engage in intermediation. This depicts a rightward shift of the deposit supply curve in Figure 2, and a consequent fall in the commercial bank deposit rate. Conversely, shadow bankers reduce their demand for external funding, as they are less engaged in intermediation whenever LTV ratios for commercial banks are raised. Consequently, the shadow bank deposit supply curve in Figure 3 shifts to the left, and the shadow bank deposit rate increases.

\footnotetext{
${ }^{12}$ As we rely on a shortcut in our DSGE model where we do not explicitly introduce heterogeneous loan markets, the conditions of the model extension presented in this section are not directly translateable to the DSGE model introduced in the paper.
} 


\section{References}

Gerali, A., Neri, S., Sessa, L., and Signoretti, F. M. (2010). Credit and Banking in a DSGE Model for the Euro Area. Journal of Money, Credit and Banking, 42(1):107-141.

Gertler, M. and Karadi, P. (2011). A Model of Unconventional Monetary Policy. Journal of Monetary Economics, 58(1):17-34.

Iacoviello, M. (2005). House Prices, Borrowing Constraints, and Monetary Policy in the Business Cycle. American Economic Review, 95(3):739-764. 